\title{
5 Focalización
}

En este capítulo analizaremos el desarrollo de los valores pragmáticos asociados a los focalizadores precisamente, justo, exactamente, cabalmente, etc. En primer lugar, daremos una introducción teórica al concepto de focalización; definiremos el concepto de foco, la terminología empleada, así como las propiedades sintácticas y semánticas de los adverbios focalizadores. De acuerdo con el estado de la cuestión sobre los diversos valores pragmáticos de los focalizadores precisamente, justo, exactamente, cabalmente, etc., en el español actual, estableceremos una categorización para estructurar el análisis diacrónico de los datos del corpus según las diversas subfunciones pragmáticas y las diversas construcciones sintácticas. En las conclusiones resumiremos la formación de este paradigma pragmático y analizaremos los cambios semánticos y sintácticos y su interpretación teórica en términos de gramaticalización, pragmaticalización o subjetivización.

\subsection{Bases teóricas}

En una concepción amplia del término focalización, se trata de un procedimiento mediante el que se dota a un constituyente de realce informativo (Llopis Cardona 2014, 57). La definición común es la de 'realzar un segmento lingüístico con fines informativos' (DLE 2014, s.v. focalizar). Esto se observa en diversos niveles lingüísticos, o sea, hay varios procedimientos o mecanismos para resaltar un segmento en el interior de un mensaje y para poner de relieve la información que se desea resaltar. Es más, los mecanismos suelen combinarse entre sí (NGLE 2009, 2985; Espinosa Elorza 2014, 988-989; Llopis Cardona 2014, 57):

a) Prosodia: prominencia fónica de un segmento.

b) Sintaxis: desplazamiento del orden habitual de las palabras.

c) Léxico: partículas focales o adverbios de foco.

Los elementos léxicos de focalización son signos (focalizadores) que tienen por función destacar la relevancia de otros elementos de la oración (Cifuentes Honrubia 2002, 26-27). Nos centraremos en el presente capítulo en elementos léxicos -adverbios de foco como precisamente, justo, etc.- pero en algunos ejemplos también observaremos estructuras sintácticas de focalización. Por ejemplo, un mecanismo sintáctico típico para destacar una parte del mensaje es la anteposición del elemento resaltado:

Mucho se ha escrito y dicho sobre el papel de la prensa en la Transición.

Y de eso quería yo hablar. (NGLE 2009, 2987-2989) [negritas nuestras]

D Open Access. () 2020 Katharina Gerhalter, published by De Gruyter. (c) BY under the Creative Commons Attribution 4.0 International License. 
Otro procedimiento frecuente para focalizar una parte específica de la oración consiste en las oraciones escindidas en las cuales se altera el orden no marcado y habitual de la oración mediante una construcción con cópula:

La que votó por Pedro fue Luz.

Los que no entregaron la tarea fueron Jaime y Tania. (Gutiérrez Bravo 2008, 377) [negritas nuestras]

En cuanto a la entonación marcada, esta naturalmente no se representa en la lengua escrita. Dado que los textos recogidos en el CDH son de naturaleza propiamente escrita, no analizaremos la focalización prosódica. Mencionemos brevemente que los segmentos sobre los que inciden los adverbios precisamente, justo, etc., podrían aparecer marcados, además, por prominencia fónica en la lengua hablada. Aparte, en algunos ejemplos, el empleo de comas indica un uso destacado del adverbio de foco, que se separa prosódicamente del resto de la oración para aumentar el énfasis.

Conviene diferenciar esta acepción general de focalización en un sentido amplio - entendida simplemente como realce informativo- del concepto teórico de focalización en un sentido estricto, de acuerdo con la terminología de la estructura informativa.

\subsubsection{La definición de foco en la estructura informativa}

La estructuración informativa de la oración permite valorar la aportación de cada segmento al discurso: ¿qué parte del mensaje ya es conocida y qué parte es nueva? La parte que conlleva información conocida suele denominarse tema y la parte que conlleva información nueva y que posiblemente posee una marca léxica, sintáctica o entonacional, rema (NGLE 2009, 2963; Ferrari/Giammatteo/ Albano 2011, 31-32; López Carretero 2016). En esta misma línea, la definición tradicional de foco se basa en su oposición a la presuposición: ${ }^{1}$ el foco corresponde a la parte nueva, no presupuesta de la oración, o sea, el rema (Cifuentes Honrubia 2002, 26; Ferrari/Giammatteo/Albano 2011, 32; Espinosa Elorza 2014, 988). Por lo

1 El término presuposición es ambiguo. En el análisis de la estructura informativa hace referencia a una información conocida, la que no es foco: «Los constituyentes que no introducen referentes nuevos en el discurso, sino que reutilizan referentes accesibles en el contexto son presupuestos» (López Carretero 2016, 577). Es decir, una parte explícita de la oración es foco y la otra parte explícita es presuposición. Sin embargo, en el ámbito de la pragmática, las implicaturas y presuposiciones hacen referencia a conclusiones inferenciales que surgen del contexto del enunciado (Blackwell 2016, 632): la presuposición es un tipo de información adicional implícita 
general, el foco suele posicionarse al final de la oración y en la anotación lingüística se marca entre corchetes:

¿Quién dará la conferencia por la tarde? -Por la tarde, la conferencia la dará [la doctora Pujol].

¿Cuándo dará la conferencia la doctora Pujol? - La doctora Pujol dará su conferencia [por la tarde]. (López Carretero 2016, 575-576)

En otras palabras, los constituyentes focalizados son los que introducen un nuevo referente en el discurso presente, mientras que el referente de los constituyentes presupuestos ya está contenido en el contexto (López Carretero 2016, 575). Según esta definición, las partículas de foco o los adverbios de foco marcarían la información nueva (Cifuentes Honrubia 2002, 31) y se asocian con el foco de la oración:

El doctor Recante trajo sólo [una camisa]. (López Carretero 2016, 582) [marcas nuestras]

La concepción más actual y abarcadora del foco es la de Rooth (1985; 1996): el foco - que se opone al trasfondo- indica, evoca y conlleva la presencia de alternativas que son relevantes para la interpretación de expresiones lingüísticas. Generalmente, el foco se marca por prominencia prosódica (Rooth 1996, 271). En el caso de adverbios de foco como only 'solo', also 'también' o even 'incluso', la interpretación de su alcance depende del foco de la oración (Rooth 1996, 272). Es decir, el alcance de estos adverbios de foco coincide con el foco de la estructura informativa de la oración.

Asimismo, König $(1991,32)$ reconoce dos propiedades principales de los focalizadores -focus particles, en su terminología-: expresan carga informativa (highlighting 'realce, énfasis') y establecen una relación entre la expresión focalizada y un set de alternativas. Consiguientemente, los focus particles llaman la atención sobre el hecho de que fue este el elemento elegido de una serie de alternativas, y ningún otro. Asimismo, Briz Gómez/Pons Bordería/Portolés Lázaro (2008) definen la focalización como el procedimiento de destacar un elemento expreso, el foco, frente a una alternativa expresa o sobreentendida.

Dichas dos nociones de foco se corresponden con la distinción entre el foco informativo y el foco contrastivo: el foco informativo diferencia información nueva o remática de información conocida o temática, mientras que el foco contrastivo realza una entidad específica entre una serie de alternativas (Gutiérrez Bravo 2008, 376-377; Espinosa Elorza 2014, 988). Según Espinosa Elorza (2014, 988), el

que, según la definición de Grice, consiste en proposiciones cuya veracidad se da por supuesta al utilizar una expresión lingüística (Blackwell 2016, 644). La presuposición pragmática no se corresponde con una parte explícita de la oración, sino que se trata de una información implícita. 
foco contrastivo es el que interesa para los adverbios de foco. Asimismo, la NGLE (2009, 2990) indica que los adverbios de foco resaltan y destacan un elemento entre un conjunto, por lo cual su interpretación es «contrastiva» o «exhaustiva». Son exhaustivos porque excluyen posibles alternativas. Estas alternativas aparecen o bien explícitamente en el discurso previo o bien se sobreentienden en el contexto extralingüístico (NGLE 2009, 2986).

De todas formas, tanto el foco contrastivo como el foco informativo implican alternativas al valor focalizado; o sea, excluir alternativas no es una propiedad exclusiva del foco contrastivo. También el foco informativo, que especifica una variable antes desconocida, presupone alternativas, porque si no hubiera alternativas al valor focalizado, no sería necesario especificar la variable. La existencia de alternativas hace la comunicación relevante (Heidinger 2018, 50). Consiguientemente, según parte de la bibliografía actual sobre el tema, la presencia de alternativas se considera definitoria para el foco tanto informativo como contrastivo; así, por ejemplo, en la «semántica de alternativas» de Rooth (1985). La diferenciación entre ambos tipos de foco radica en si las alternativas han sido mencionadas anteriormente o no. Así, las alternativas del foco contrastivo forman un conjunto cerrado (por ejemplo, se selecciona una variante de un conjunto dado), mientras que el foco informativo implica un conjunto abierto de alternativas (Heidinger 2018, 51).

Consiguientemente, el foco conlleva siempre una serie de posibles alternativas implícitas. En los ejemplos a continuación, las alternativas implícitas son otras personas posiblemente «sospechosas»:

La que votó por Pedro fue [Luz].

Los que no entregaron la tarea fueron [Jaime y Tania]. (Gutiérrez Bravo 2008, 377) [corchetes nuestros]

El foco especifica que esa fue la persona que efectuó dicha acción, y no otra (Heidinger 2018, 49). El elemento focalizado y las alternativas posibles forman un conjunto de unidades que pueden aparecer como respuesta a una misma pregunta (Rooth 1996, 271-272; Heidinger 2018, 50-51): ¿Quién votó por Pedro? o ¿Quiénes no entregaron la tarea? Así, el foco suele ser aquella parte de una respuesta a una pregunta que aporta la información nueva y requerida seleccionando un elemento entre varias alternativas: ¿Qué se compró María? -María se compró [una calculadora] (Gutiérrez Bravo 2008, 381).

Ahora bien, los adverbios de foco precisamente, justo, exactamente, etc., no señalan necesariamente una información nueva y no presupuesta, ya que la información destacada por estos adverbios frecuentemente coincide con alguna información anterior, por lo cual ya es conocida. Aunque tengan una interpretación contrastiva (implican alternativas), creemos que el alcance de estos adver- 
bios no siempre coincide con el foco de la oración. Es decir, estos adverbios no se asocian necesariamente con la estructura foco/presuposición de la oración. Como observa también Hummel $(2012,159)$, focalizadores como justo otorgan un énfasis especial a un elemento del discurso, pero no necesariamente lo convierten en rema.

Es decir, el segmento focalizado por el adverbio no se corresponde automáticamente con el foco de la oración. En ejemplos como el citado a continuación, solo una parte del segmento (marcado en cursivas) sobre el que recae el alcance del adverbio de foco sería también el foco de la oración: ${ }^{2}$

¿Cuántas manzanas comió Juan? -Juan comió exactamente [tres] manzanas. ${ }^{3}$

En otros casos, el adverbio enfatiza solo una parte dentro del foco de la oración:

¿Qué hizo Juan ayer? -Ayer, Juan [comió exactamente tres manzanas].

Es más, el adverbio de foco puede enfatizar una información que forma parte de la presuposición y no del foco:

¿Qué pasó ayer? -Justamente ayer [se me rompió el coche].

Nos basamos, por lo tanto, en la definición de König (1991): los adverbios de foco indican la existencia de alternativas al elemento destacado y conllevan énfasis, ya que resaltan un segmento específico de la oración. Consiguientemente, usaremos el término «focalización» en un sentido más general y amplio: los adverbios de focalización destacan y llaman la atención sobre cualquier tipo de información, pero esta no necesariamente coincide con el foco de la oración. En realidad, aportan énfasis y para evitar ambigüedades, habría que preguntarse si no se denominarían mejor enfatizadores.

\subsubsection{Clasificación y denominación de focalizadores}

En cuanto a la terminología para los elementos léxicos de focalización, se emplean principalmente partículas de foco (König 1991; Cifuentes Honrubia 2002; López

2 Agradezco a Steffen Heidinger su ayuda y sus aclaraciones en este aspecto teórico.

3 Consideramos que el adverbio exactamente modifica todo el sintagma, tres manzanas, no solo el numeral. Por ejemplo, al posponerlo, se coloca al final del sintagma y no después del numeral: Juan comió tres manzanas exactamente; `Juan comió tres exactamente manzanas. Sobre la posposición del focalizador, véase apartado 5.4.4. 
Carretero 2016) o partículas focales (Briz Gómez/Pons Bordería/Portolés Lázaro 2008), así como adverbios de foco (Kovacci 1999; NGLE 2009, §40.5-40.9; García Pérez 2013a; Espinosa Elorza 2014). Elementos como los adverbios ingleses even, only, also o too presentan un comportamiento sintáctico particular, por lo cual König $(1991,10)$ prefiere reemplazar la tradicional denominación de adverbios por la de focus particles. Sin embargo, en nuestro caso, los focalizadores precisamente, justamente, etc., siguen funcionando plenamente como adverbios, por lo cual los llamaremos adverbios de foco o simplemente focalizadores.

Aparte, dado que no todos los focalizadores son adverbios, conviene la denominación propiamente pragmática de operadores: operadores de focalización (Fuentes Rodríguez 2016) operadores de foco (Ferrari/Giammatteo/Albano 2011) $\mathrm{u}$ operadores focales (Gutiérrez-González 2011). Nada más lejos, los adjetivos justo y preciso en ocasiones también funcionan pragmáticamente como operadores informativos (Fuentes Rodríguez 2009), aunque no son tan frecuentes como sus adverbios correspondientes. Tradicionalmente los adjetivos no se han relacionado con el fenómeno de la focalización, a pesar de que los adjetivos antepuestos al sustantivo se han descrito repetidas veces como «enfáticos» (Fuentes Rodríguez 2013a).

Por último, De Cesare (2015) usa el término focusing modifiers ('modificadores focalizantes') para evitar la adscripción a categorías como adverbio, adverbiales o partículas. Esta denominación nos parece acertada, ya que los focalizadores que nos ocupan en este capítulo - sean adjetivos o adverbios- modifican un constituyente de la oración, es decir, tienen alcance semántico y sintáctico. La función de modificación o atribución (Hummel 2012), que es la función base de los adjetivos y adverbios de exactitud, se extiende a la focalización.

La clase de los focalizadores no es una clase cerrada, sino que muestra la organización prototípica de un paradigma: aparte de los focalizadores centrales que cumplen ciertas características en mayor medida, hay otros focalizadores marginales y periféricos (De Cesare 2015, 75). Consiguientemente, el inventario de los adverbios de foco varía según los autores consultados. Es un inventario bastante amplio y se suele categorizar según la interpretación semántico-pragmática que indica el focalizador. Es decir, el macroparadigma de los focalizadores se subdivide en varios sub- o microparadigmas, siendo estas categorizaciones de lo más diverso:

i. Kovacci (1999, 772-778) distingue entre adverbios focalizadores exclusivos (solamente, solo, únicamente, exclusivamente, puramente, meramente, simplemente, sencillamente), particularizadores (particularmente, especialmente, principalmente) e identificativos (exactamente, justamente, justo, precisamente). 
ii. La clasificación de la $\operatorname{NGLE}(2009,2992)$ es más detallada: adverbios de foco de inclusión (también, tampoco, incluso, inclusive, ni siquiera, hasta, todavía, aun, aún), de exclusión (solo, tan solo, solamente, únicamente, exclusivamente, no más, nada más), de particularización, especificación o precisión (particularmente, concretamente, en concreto, sobre todo, en particular, en especial, justamente, precisamente, mismamente), de aproximación (casi, prácticamente, apenas) y escalares (al menos, como mucho, por lo menos). Esta clasificación es seguida por García Pérez en su investigación sobre los adverbios focalizadores de exclusión, inclusión y aproximación (García Pérez 2013a) y sobre los adverbios de foco particularizadores (García Pérez 2013b).

iii. A su vez, Espinosa Elorza (2010; 2014, 990) establece dos grupos principales de adverbios de foco: los no restrictivos (de inclusión, de suma, de adición) y los restrictivos (de excepción, de exclusividad, de particularización, de aproximación y de exactitud). Este último grupo limita la validez del enunciado al elemento focalizado y excluye las alternativas. A su vez, todos los adverbios de foco se integran en el grupo de los adverbios adjuntos (Espinosa Elorza 2010).

Los focalizadores que analizamos cuentan con correlatos en otros idiomas. En su lista de focus particles, König $(1991,15)$ incluye también exactly 'exactamente’ y just (en el sentido de 'solo', no existente en el español justo). El inglés precisely 'precisamente, exactamente' es solo un elemento marginal que cumple algunas de las características de los focus particles. Además, König (1991) incluye focalizadores del alemán como genau 'exacto' y ausgerechnet 'precisamente' (con valor de coincidencia desafortunada). A esta lista, De Cesare $(2015,65)$ añade el francés justement y précisément y el italiano esattamente y precisamente.

Según De Cesare $(2015,56)$, los adverbios de exactitud son focalizadores más bien marginales o periféricos, es decir, menos prototípicos, ya que cumplen solo parcialmente ciertas características semánticas y sintácticas. Focalizadores prototípicos y centrales son, por ejemplo, even, also, only (inglés) o aussi, seulement, même (francés). En este sentido, serían focalizadores centrales o prototípicos en español solo, incluso y también. Por lo tanto, dentro del macroparadigma de los focalizadores, el microparadigma de los adverbiales de exactitud tiene una posición periférica y marginal. En el presente capítulo, comprobaremos en qué rasgos específicos se muestra este estatus no prototípico.

\subsubsection{Propiedades sintácticas y semánticas de adverbios de foco}

En general, los adverbios de foco no se consideran propiamente marcadores del discurso. Se caracterizan por tener un significado de procesamiento, pero, al 
contrario de los marcadores discursivos, no cuentan con independencia sintáctica (Portolés Lázaro 2016). En el caso de incluso, solo, justo, cierto, puro, mero, mismo y único, Hummel (2012, 131-132) observa que suelen ejercer su función discursiva desde una posición intrasintagmática, mientras que los marcadores discursivos son esencialmente extraoracionales. Esta observación es extrapolable a los adverbios en -mente que nos atañen. Concretamente, los adverbios de foco tienen en su ámbito sintagmas oracionales de distintos tipos y de extensión variada (Kovacci 1999, 772-778), como hemos mostrado también en el análisis sintáctico comparativo (véase apartado 4.4).

Si ampliamos esta observación a los adjetivos de focalización, estos obviamente también conservan su función sintáctica en la oración: como adjetivos atributivos modifican algún sustantivo y no desarrollan posiciones o funciones extraoracionales.

Según De Cesare (2015, 70-73), los adverbios de foco (modificadores focalizantes, en su terminología) modifican siempre un constituyente de la oración, pero nunca toda la oración. En cambio, los adverbios oracionales (adverbios disjuntos) y los marcadores discursivos operan a nivel oracional. Hay casos ambiguos en los que un adverbio puede interpretarse como adverbio de foco (alcance sobre una parte de la oración) o como discourse connective (es decir: marcador discursivo o conector con alcance sobre toda la oración):

[...] mais surtout les pays industrialisés ont modifié profondément leur attitude. (De Cesare 2015, 70-73)

a) 'mainly' (focusing modifier)

b) 'most of all' (discourse connective)

En este ejemplo, surtout 'sobre todo' se interpreta como adverbio de foco si focaliza el constituyente les pays industrialisés ‘los países industrializados’ e implica la alternativa de otros países que no han modificado (tanto) su actitud. En cambio, el marcador discursivo surtout situaría en el nivel alto de la escala argumentativa toda la proposición expresada por la oración, lo cual correspondería en español a marcadores como además o es más.

Una propiedad central de los adverbios de foco es su cross-categoriality (König 1991, 96; De Cesare 2015, 71-73), es decir, que pueden combinarse con una amplia gama de elementos oracionales: con todo tipo de sintagmas (nominales, preposicionales, verbales, etc.) y también con algunas categorías léxicas, o sea, lexemas simples (sustantivos, adjetivos, adverbios y verbos) (Kovacci 1999, 772). La propiedad sintáctica más destacada de los adverbios de foco es, por lo tanto, su flexibilidad posicional. Dependiendo de su posición en la oración y de su alcance, la contribución semántica de los adverbios de foco varía (De Cesare 2015, 70). 
Esta flexibilidad sintáctica de los adverbios focalizadores se correlaciona con la naturaleza del propio foco, que igualmente puede ser de menor o mayor orden sintáctico. El foco es de extensión reducida cuando está constituido por una sola palabra, como en el ejemplo La que votó por Pedro fue [Luz]. Es de extensión amplia cuando corresponde a un sintagma (¿Qué hizo Luz? - [Votó por Pedro]) o a una oración completa. En este último caso, toda la oración constituye el foco y responde a una pregunta general de tipo ¿qué pasó? (Heidinger 2018, 52). Consiguientemente, el alcance de adverbios focalizadores como solo, incluso, etc., varía en función de la extensión del foco.

Dado que el alcance de las partículas o adverbios de foco es variable, son varios los constituyentes con los que se pueden asociar en una misma oración, como ilustra el siguiente ejemplo:

Juan solo compró una camisa de cuadros. (López Carretero 2016, 581)

Según la unidad focalizada por solo, hay varias interpretaciones posibles y el foco puede recaer sobre diversos elementos de la oración: de cuadros (y no de rayas), una camisa (y no una chaqueta), una (y no dos), la compró (no la robó) (López Carretero 2016, 581). Tal y como observan Medina Gómez/Alarcón Neve (2017, 290), los adverbios de foco solo y solamente 4 pueden focalizar cualquier elemento, por lo cual su posición sintáctica es libre:

Solo [María] escucha discos de música clásica.

María solo [escucha discos de música clásica].

María escucha solo [discos de música clásica]. (Medina Gómez/Alarcón Neve 2017, 290) [corchetes nuestros]

Como se apuntó anteriormente, el procedimiento general de todos los adverbios de foco consiste en resaltar y destacar un elemento entre otros elementos posibles (NGLE 2009, 2990), es decir: se asocian con una serie de alternativas (König 1991; Cifuentes Honrubia 2002, 28; De Cesare 2015, 61-64). En este sentido, un constituyente focalizado abre un conjunto de alternativas y lo resuelve simultáneamente (López Carretero 2016, 581). En el ejemplo citado arriba, las alternativas implícitas según la interpretación del foco serían, por ejemplo: solo una camisa (y no dos

\footnotetext{
4 Entre los adverbios de foco, solo/solamente y justo/justamente parecen ser los únicos en presentarse como pareja léxica formada por un adverbio en -mente y un adverbio corto. En el caso de solo/solamente, la preferencia por la forma corta para la focalización parece ser clara: en la bibliografía suelen aparecer citados y analizados ejemplos con solo, y no con solamente, y la frecuencia de solo es mayor que la de solamente en el corpus analizado por Medina Gómez/Alarcón Neve (2017, 292). En cambio, justo y justamente parecen mantenerse a la par (véase apartado 4.4).
} 
o tres, etc.), o solo una camisa de cuadros (y no de rayas o lisa o estampada, etc.). También en este otro ejemplo, las alternativas se abren sola y específicamente para el elemento focalizado:

Solo María escucha discos de música clásica. (y nadie más)

María solo escucha discos de música clásica. (y no hace nada más)

María escucha solo discos de música clásica. (y ningún otro tipo de discos) (Medina Gómez/ Alarcón Neve 2017, 290)

La operación semántica de las partículas de foco consiste en ordenar en una escala los valores alternativos y asignar al foco una posición baja (restricción) o alta (inclusión) en dicha escala (De Cesare 2015, 75). Las partículas de foco introducen una valoración del foco y de sus alternativas en alguna escala de valores relevantes en una situación dada (König 1991, 43). Por ejemplo, solo (adverbio focalizador de exclusión) excluye las alternativas implícitas y sitúa al elemento focalizado en una posición baja: Juan debería haber comprado más que una sola camisa y María debería escuchar también otro tipo de música. En cambio, la interpretación del foco cambiaría con incluso (adverbio de foco de inclusión) o al menos (focalizador escalar).

La flexibilidad sintáctica también es posible gracias a que los adverbios de foco inciden sobre múltiples expresiones tanto de forma contigua como a distancia, como se ve claramente en esta oración:

El doctor solo recibe [los martes]. (NGLE 2009, 2990) [corchetes nuestras]

En este ejemplo, la asignación más probable del foco es el constituyente los martes (y no los lunes, miércoles, etc.) (Espinosa Elorza 2014, 989). Esta oración sería la respuesta natural a la pregunta ¿Cuándo recibe el doctor? Consiguientemente, los adverbios focalizadores no se limitan a las posiciones adyacentes a su foco (König 1991, 18). El contexto y/o la entonación suelen desambiguar las diferentes interpretaciones posibles del alcance de los focalizadores (Ferrari/ Giammatteo/Albano 2011, 34).

Los adverbios $u$ operadores de foco se sitúan, pues, en una interfaz entre sintaxis y pragmática. Por eso, Ferrari/Giammatteo/Albano (2011, 31) consideran que hay que estudiarlos desde una perspectiva que vincule el contenido proposicional que destacan con los valores ilocutivos expresados o implicados por los hablantes. Por lo tanto, «la focalización posee una vertiente metalingüística» (NGLE 2009, 2985). Podríamos definir esta vertiente metalingüística como el procedimiento de indicar al oyente en qué parte del mensaje se tiene que fijar y cómo interpretarlo en relación con la situación comunicativa para obtener las 
inferencias pragmáticas intencionadas. Asimismo, Cifuentes Honrubia (2002, 27) menciona que los focalizadores generan presuposiciones. ${ }^{5}$

\subsubsection{Estado de la cuestión: precisamente, justamente, justo, etc., como focalizadores}

Al señalar un segmento dentro del enunciado como el más relevante, precisamente, justamente, justo y exactamente focalizan la singularidad del referente y excluyen otras posibilidades o alternativas implícitas (López Samaniego 2007). Enfatizan la entidad denotada por su foco y llaman la atención sobre ella, la destacan o resaltan (NGLE 2009, 3016). Por lo tanto, comparten con los demás adverbios de foco la propiedad de implicar alternativas y excluirlas simultáneamente.

Según la clasificación de la NGLE (2009, 2992), justamente y precisamente son «adverbios de foco de precisión». Fuentes Rodríguez (2009) clasifica justamente, precisamente y exactamente como «operadores informativos». Exactamente y justamente señalan que la información ofrecida es precisa, exacta, adecuada. Ambos ponen de relieve la precisión o exactitud de la información proporcionada, sobre todo, en referencia a cantidades, al tiempo, a localizaciones o a cualidades (Briz Gómez/Pons Bordería/Portolés Lázaro 2008, s.v. justamente; Fuentes Rodríguez 2009, s.v. justo, justamente, exactamente). En cambio, precisamente resalta la información como relevante y adopta frecuentemente cierto valor de coincidencia o casualidad: destaca una «curiosidad casual u oportuna» (Santos Río 2003, s.v. precisamente). Según Fuentes Rodríguez (2009), precisamente es el «mecanismo de focalización informativa por excelencia».

El análisis más detallado de los diversos valores pragmáticos de precisamente y justamente en el español actual ${ }^{6}$ es el de López Samaniego (2007), que reconoce el valor de coincidencia como el valor base de precisamente y justamente. Según esta autora, la función más frecuente de precisamente $\mathrm{y}$, en menor medida, justamente consiste en focalizar una información sobre la que el hablante pretende llamar la atención, ya que la considera una coincidencia curiosa, sorprendente, inesperada, oportuna o inoportuna, y en todo caso significativa para la interpretación del discurso (López Samaniego 2007, 62). Ambos adverbios presentan un alto grado de fijación como elementos discursivos («partículas discursivas», en

5 Aquí entendida como presuposición pragmática: información adicional inferida del contexto, proposición cuya veracidad se da por supuesta al utilizar una expresión lingüística. De aquí en adelante, presuposición aparecerá en este sentido.

6 La autora basa su análisis en ejemplos recopilados del año 2006 y del CREA (1984-2004); sus observaciones son, por lo tanto, pertinentes para el español más actual y reciente. 
la terminología de la autora), ya que los usos más frecuentes en el español actual son los que transmiten una información relativa a la interpretación del discurso. Por el contrario, el uso como adverbios de manera es «poco frecuente» (López Samaniego 2007, 47), como comprobamos también en nuestro corpus (véase apartado 4.4).

Consideramos que hay dos contextos o usos principales, es decir, la información focalizada por estos adverbios (y en ocasiones, adjetivos) puede ser de dos tipos. Esta es la división, adaptada principalmente de López Samaniego (2007), que seguimos en el análisis del presente capítulo:

a) Por un lado, la focalización de datos temporales o espaciales. En este contexto puede haber focalización de exactitud rigurosa o focalización de coincidencias en el tiempo o espacio.

b) Por otro lado, la focalización enfática puede afectar a cualquier información que no sea espaciotemporal, como, por ejemplo: personas, cosas, sucesos, argumentos, etc. También en este contexto hay tanto énfasis en la exactitud de la información focalizada, como focalización de coincidencias.

En el primer caso, los adverbios de focalización de exactitud enfatizan la exactitud minuciosa y rigurosa en un dato temporal o espacial:

(1) Dormí cuatro horas y me desperté exactamente a las cuatro de la mañana cuando ya era completamente de día. (Arturo Barea, La forja de un rebelde, 1951)

Como observa König (1991, 125-126), las partículas focales de exclusión como las del inglés exactly, precisely y del alemán ausgerechnet, genau, gerade operan sobre escalas y excluyen valores en ambos lados de la escala. Es decir, en una escala, los adverbios de exactitud acotan tanto inferiormente como superiormente un valor focalizado (esto es, implican 'ni más ni menos'): exactamente a las cuatro de la mañana ('ni antes ni después'). Por el contrario, los adverbios restrictivos como solo excluyen del valor indicado exclusivamente los valores superiores (Kaul de Marlangeon 2002, 120).

Por su semántica escalar, los adverbios de foco se relacionan con la cuantificación. Así, Kaul de Marlangeon (2002) incluye exactamente, precisamente y justamente dentro de los adverbios de cuantificación, que generalmente operan sobre una escala o un continuo de propiedades. Asimismo, Hummel (2012, 133) opina que la función enfática de justo, solo, incluso, etc., los acerca al grupo de los cuantificadores.

Según Kaul de Marlangeon (2002, 151), la precisión es un modo sutil de cuantificación y en el caso concreto de los adverbios de exactitud, hay énfasis, precisión y focalización de la propiedad en cuestión. El adverbio de exactitud 
explicita la cantidad o la medida de la extensión ocasional de la propiedad expresada por el núcleo modificado (sustantivo, adjetivo, sintagma, etc.) (Kaul de Marlangeon 2002, 143). Por ejemplo, exactamente acota la extensión referencial de a las cuatro de la mañana y la limita o reduce estrictamente al valor indicado.

En esto, la focalización de exactitud se opone a la focalización de aproximación, ya que los adverbios de aproximación como casi o aproximadamente aumentan la extensión referencial del dato: aproximadamente a las cuatro de la mañana indica tanto la posibilidad de un valor (ligeramente) inferior como de un valor (ligeramente) superior, es decir, permite incluir diversas alternativas (las cuatro menos cinco, las cuatro y diez...) dejando abierta la escala de alternativas. En cambio, los adverbios focalizadores de exactitud expresan explícitamente que el valor focalizado se aplica literal y exactamente al referente extralingüístico. 0 sea, indican un solo punto exacto de la escala gradual y las demás alternativas de la escala quedan excluidas.

Además de una exactitud temporal rigurosa, el hablante puede insinuar una coincidencia desafortunada o inoportuna al llamar la atención sobre el momento en el que ocurre un hecho:

(2) Aquel día lloró de rabia y de impotencia como jamás antes lo había hecho. Precisamente ahora, que quería ayudar a alguien muy especial para él, su poder lo abandonaba. (Federico Henríquez Gratereaux, Empollar huevos históricos, 2001)

En este ejemplo, precisamente no se opone a la aproximación, ya que no indica exactitud rigurosa del dato, sino que guía la interpretación pragmática del enunciado. Insinúa una coincidencia temporal (desafortunada) entre el hecho de querer ayudar y el hecho de quedarse sin poder.

En la focalización que no hace referencia a datos espaciales o temporales, los adverbios de focalización enfática insisten, por ejemplo, en que la aparición de una determinada persona es significativa o sorprendente:

(3) Entonces Danielito Gómez Ferrando, un pendejo [...], un delicado que no pisa un restorán después que ha visto allá a alguien que usa escarbadientes, ése, justamente ése, me contestó: «Pero, señor, nosotros estamos con el Abstracto.» (Mario Benedetti, La tregua, 1960)

(4) Los goles fueron marcados por Germán Castillo, Tilger y Silvera. Precisamente Silvera, que estaba en duda, fue la figura del partido. (Buenos Aires: clarin.com, 2001-02-19. CORPES XXI)

Tanto en estos ejemplos como en los que siguen en el presente capítulo, marcamos en cursivas el constituyente sintáctico sobre el que recae el alcance del adverbio (y que solo ocasionalmente coincide con el foco de la oración). De acuerdo con 
la propiedad general de los adverbios de foco, el alcance de precisamente, justamente, justo y exactamente es variable: en los ejemplos citados, a las cuatro de la mañana es un sintagma preposicional, ahora es un adverbio y ése es un pronombre demostrativo. Asimismo, estos constituyentes pueden tomar funciones diversas en la oración, tales como complemento circunstancial de tiempo (a las cuatro de la mañana) o sujeto (ése). Respecto a las funciones en la oración, Santos Río (2003, s.v. precisamente, exactamente, justamente) menciona que se anteponen principalmente a circunstanciales de lugar, tiempo, modo, causa, fin, cantidad, etc.

Para König (1991, 125-126), las partículas de foco como las del inglés exactly, precisely y del alemán ausgerechnet, genau, gerade funcionan como emphatic assertion of identity ('aserción enfática de identidad'). Además de operar en una escala, suponen una aserción enfática de la identidad entre un argumento en la proposición y un argumento en una proposición distinta. Esta identificación puede ser lograda por exclusión de alternativas (König 1991, 127). Opinamos que la denominación de focalización enfática de identidad es más abarcadora y permite incluir, además de la focalización de exactitud en un dato rigurosamente preciso, la focalización de cualquier información coincidente, sorprendente y significativa. Así, por ejemplo, se enfatiza la coincidencia entre dos proposiciones distintas en el ejemplo (2): querer ayudar y quedarse sin poder. Se enfatiza la identidad temporal de ambas.

En la misma línea de la idea de la enfatización de identidad, la denominación como «adverbios focalizadores identificativos» (Kovacci 1999, 777s.) para exactamente, justamente, justo y precisamente indica que identifican de manera enfática cualquier tipo de información relevante. A modo de matización o especificación de la denominación «identidad» propuesta por König, López Samaniego $(2007,66)$ opta por hablar de «focalización de coincidencia entre entidades iguales o semejantes»: precisamente o justamente realzan la semejanza entre dos entidades discursivas; la coincidencia afecta a dos elementos informativos que aparecen en contextos proposicionales diferentes.

Adoptamos la denominación «focalización de coincidencia» de López Samaniego (2007), aunque, estrictamente hablando, el adverbio no focaliza una coincidencia («precisamente esta coincidencia»). El adverbio focaliza cualquier información coincidente, es decir, la identidad entre dos proposiciones, $\mathrm{y}$ la interpretación global que se obtiene como inferencia de todo el contexto es una coincidencia. La coincidencia es el efecto pragmático (o uno de ellos) que surge de la focalización enfática de un segmento discursivo, pero, estrictamente hablando, la coincidencia no es el segmento focalizado. ${ }^{7}$

7 Agradezco esta matización a Catalina Fuentes Rodríguez. 


\subsubsection{Hipótesis y objetivos de este capítulo}

Según De Cesare (2015, 70-73), los adverbios de foco generalmente no modifican a oraciones, ya que este es el alcance de los adverbios oracionales, esto es, de los adverbios disjuntos. Sin embargo, ese no parece ser el caso de los adverbios que analizamos en este capítulo: según el DPDE (Briz Gómez/Pons Bordería/Portolés Lázaro 2008), precisamente y justamente pueden aparecer en un sintagma, pero también en una oración. Asimismo, según Fuentes Rodríguez (2009), justamente se combina con oraciones subordinadas o sintagmas (nominales o verbales), mientras que precisamente también puede afectar a toda la oración (Fuentes Rodríguez 1995-1996, 782).

En todo caso, precisamente no funciona como adverbio oracional cuando su alcance es la oración completa, sino que sigue siendo un adverbio de foco: focaliza toda la oración en su conjunto. ${ }^{8}$ Creemos que esto se correlaciona con el hecho de que también el foco - entendido estrictamente como foco en la estructura informativa - puede ser extenso y recaer sobre toda la oración; es decir: oraciones enteras pueden formar el foco. Por tanto, la observación de que precisamente, justamente, etc., no son adverbios focalizadores prototípicos (De Cesare 2015) quizás alude al hecho de que su alcance también puede recaer sobre una oración completa. Comprobaremos si, además de precisamente, eso es posible para todos los adverbios del paradigma.

Por otra parte, el elemento sobre el que recae el alcance de los focalizadores prototípicos como solo y solamente siempre es el foco de la oración (Medina Gómez/Alarcón Neve 2017). En cambio, este no es el caso de precisamente, justo, exactamente, etc. Son focalizadores cuyo alcance no se asocia automáticamente con el foco de la oración y es por eso por lo que no se pueden considerar adverbios de foco prototípicos.

Para analizar desde un punto de vista onomasiológico el grupo de los adverbios en cuestión, comprobaremos en qué contextos son intercambiables. Todos ellos podrían emplearse, por ejemplo, en me desperté exactamente/precisamente/

8 De hecho, precisamente (y exactamente, etc.) no encajan en ninguna categoría de los adverbios oracionales o disjuntos: adverbios evaluativos (felizmente, naturalmente), de punto de vista (técnicamente), de modalidad (seguramente, obviamente), o de enunciación (sinceramente, literalmente) (Iglesias Bango 2004; Torner Castels 2016, 387). Sí hay cierto solapamiento con los adverbios de enunciación en el caso del marcador de reformulación más precisamente/más exactamente (véase capítulo 7). Además, Santos Río (2003) menciona el uso de justamente como «adverbio oracional de evaluación factual descriptiva»: con el significado 'merecidamente, justificadamente': Justamente, le negaron el primer premio. Este uso atañe el primer significado de justamente (el de justicia), y no el valor semántico de exactitud. Este sí es un adverbio oracional, que corresponde a la oración atributiva es justo que (Iglesias Bango 2004, 1637-1639). 
justo/justamente/cabalmente a las cuatro de la mañana. Consiguientemente, analizaremos en las siguientes secciones en qué contextos son sinónimos y en cuáles su comportamiento sintáctico y/o pragmático difiere. Es decir, nos interesa analizar si hay una diferenciación o especialización interna en este paradigma pragmático.

Los apuntes sobre la diacronía de los diversos valores pragmáticos y discursivos de estos adverbios de foco en la bibliografía consultada son escasos. Para el análisis histórico, partimos de la hipótesis de que los adverbios de exactitud, de acuerdo con su significado conceptual base, primero focalizan la exactitud rigurosa y minuciosa de una información dada. De este uso surgiría, posteriormente, el valor de coincidencia significativa: la información no solo es exacta, sino que es importante y significativa por coincidir con otra información.

Aunque en la actualidad cabalmente no suele usarse como adverbio de foco, sí lo menciona Santos Río (2003) como «adverbio de coincidencia»:

Necesito un paraguas -Cabalmente, hay aquí dos de sobra. (Santos Río 2003, s.v. cabalmente)

Además, los ejemplos de cabalmente en el DHLE (1933-1936) indican que se usaba, al menos en el siglo XIX, como adverbio de foco con un valor que actualmente tienen precisamente y justamente. Así, cabalmente encajaría en los valores de coincidencia descritos por López Samaniego (2007) para justamente y precisamente. Nuestra hipótesis para el análisis histórico consiste en que se empleaba como adverbio de foco y se integraba en este paradigma, pero cayó en desuso. Consiguientemente, otro objetivo de este capítulo consiste en analizar qué usos compartía cabalmente con los demás adverbios del paradigma.

La focalización también se da a veces con los adjetivos preciso, justo y exacto, aunque son menos frecuentes que los adverbios. Solamente encontramos mencionado este uso en dos diccionarios:

«Crítica, justo, mismísimo, mismo. Subraya coincidencia: En aquel preciso momento dieron las doce en el reloj de la torre.» (Moliner 1998, s.v. preciso)

A su vez, Fuentes Rodríguez (2009, s.v. preciso, justo) incluye una entrada de preciso (adjetivo) y justo (adjetivo) - pero no de exacto- como operadores informativos de enfatización: focalizan el sustantivo al que acompañan (frecuentemente: instante, momento) e indican precisión en el decir. Como operadores, su posición es antepuesta al sustantivo.

El objetivo global del presente capítulo consiste en analizar el desarrollo diacrónico de los diversos valores de focalización, basándonos en los aspectos pragmáticos que surgen en diversas construcciones o posiciones sintácticas. 
Postulamos la hipótesis de que la pragmaticalización o gramaticalización está más avanzada en precisamente que en los demás, ya que es el adverbio que experimenta un mayor incremento de frecuencia (véase apartado 4.1.2). Al parecer, es el elemento central del microparadigma de los focalizadores que nos atañe. Desde un punto de vista cronológico, nos interesa comprobar si precisamente fue el primero de este grupo en adquirir las diversas funciones como adverbio de foco.

Las búsquedas específicas, que complementan los ejemplos detectados en nuestra muestra base, se llevaron a cabo en todas las secciones del CDH (nuclear y extensiones) con el fin de profundizar el análisis de determinadas funciones y rastrear las primeras documentaciones de ciertas construcciones relevantes para el desarrollo de los usos de focalización. Al tratarse de adverbios que pueden tomar diversas posiciones y funciones en la oración, son varios los patrones de búsqueda que pueden dar resultados pertinentes. Sin embargo, en casi todas las búsquedas es necesaria una criba manual para excluir los adverbios de modo correspondientes que coinciden en los mismos patrones. En los casos en los que un determinado patrón de búsqueda coincide (casi) plenamente con un determinado valor pragmático de focalización y, consecuentemente, el número de resultados se pueden considerar representativo, comparamos la frecuencia de cada adverbio en la misma construcción para detectar cuál predomina.

\subsection{Focalización enfática de informaciones temporales y espaciales}

El uso de los adverbios y adjetivos de exactitud en relación con circunstancias de tiempo y, con frecuencia algo menor, de lugar, es un dominio semántico que aparece desde el siglo XVI en todos los lexemas analizados: indican que una determinada fecha es precisa, o un determinado período de tiempo es exacto o una determinada localización es exacta, precisa (véase apartado 4.2.2.1). La medición exacta y precisa de datos cuantificables también aparece en los adverbios modales: contar exactamente, medir precisamente, etc. En este sentido, el valor de focalización enfática surge dentro de una variante contextual especialmente frecuente de los adjetivos y adverbios de exactitud, en la que su valor semántico inicialmente es conceptual ('exacto, no aproximado').

En los siguientes apartados analizaremos cuáles de los adverbios de foco pasan de focalizadores de exactitud a focalizadores de coincidencia significativa en el dominio de indicaciones temporales o espaciales y cómo se produce esta evolución. Asimismo, analizaremos si esta evolución también se observa en los adjetivos de exactitud. 


\subsubsection{Adverbios enfatizadores de exactitud de un dato temporal o espacial}

Actualmente, el uso de indicar exactitud en el tiempo o en una localización se atribuye a los adverbios justamente, justo y exactamente (Briz Gómez/Pons Bordería/ Portolés Lázaro 2008; Fuentes Rodríguez 2009). Asimismo, López Samaniego (2007, 48-50) atribuye este uso solo a justamente y exactamente. En cuanto a precisamente, este adverbio originariamente también se usaba como focalizador de exactitud, como observa también López Samaniego (2007, 50). Además, los ejemplos que analizamos indican que también cabalmente se usaba para la misma función.

König (1991, 33) incluye el inglés exactly dentro de las partículas de foco exclusivo (restrictivo), dado que excluye las posibles alternativas implícitas. Consideramos, pues, que justamente, justo y exactamente (originariamente también precisamente y cabalmente) son adverbios de foco de exactitud que -al fijar, por ejemplo, el número exacto de una información- excluyen las posibles alternativas: «exactamente X, ni más ni menos». Asimismo, López Samaniego $(2007,49)$ opina que justamente como focalizador de exactitud excluye otras alternativas implícitas que son menos exactas. El elemento destacado por el adverbio de foco y sus alternativas se ordenan en una escala de mayor a menor correspondencia exacta con la realidad (López Samaniego 2007, 55).

El primero de los adverbios en indicar exactitud en un dato temporal es cabalmente, ya en el siglo XIII (atestiguación ya citada en el capítulo 3 [véase ejemplo 91 en el apartado 3.2.2]):

(5) E si alguno bien lo quisiere contar en siet sedmanas de años á VII VII años en la sedmana, como á en la sedmana siet días, fallará ý XLIX años cabalmientre, e el que viene adelant es el Lo año, e aquell año mandó Dios que fuesse el jubileo. (Alfonso X, General Estoria. Primera parte, 1275 [s. XIII c1270])

En este ejemplo, el alcance del cabalmente es el sintagma nominal XLIX años. El adverbio indica que el número no es aproximado: 'exactamente 49 años, ni más ni menos'. Es decir, el numeral 49 se corresponde mejor con la realidad que los números alternativos en la escala (...47, 48, 50, 51...).

En la segunda mitad del siglo XVI, precisamente, justamente y justo aparecen como focalizadores de exactitud en contextos temporales. Este uso se documenta, pues, casi simultáneamente con la primera documentación de estos mismos adverbios como adverbios de modo. Como muestra este ejemplo, precisamente llama la atención sobre la exactitud rigurosa de un dato:

(6) [este presente año de 1545 entró el sol ...] En Libra, a 13 de setiembre 4 horas 4 minutos. En Scorpio, a 13 de octubre 7 horas 31 minutos. En Sagitario, a 12 de noviembre precisamente 
al mediodía. En Capricornio, a 11 de deziembre 8 horas 16 minutos. En Aquario, a 9 de henero 11 horas 1 minuto. (Martín Cortés Albacar, Breve compendio de la esfera y de la arte de navegar, 1551)

El adverbio enfatiza que la indicación del tiempo es claramente precisa y exacta. En este sentido, las alternativas que implícitamente excluye el adverbio de foco son datos más aproximados: algunos minutos antes o después de la hora indicada (las 12:00 del mediodía). El mismo uso se observa en justo y justamente:

(7) el infelice y triste casamiento en forma y acto público se hizo.

Hoy hace justo un mes, joh suerte dura, qué cerca está del bien la desventura! (Alonso de Ercilla, La Araucana, segunda parte, 1578)

(8) Este relox es más difficultoso que los passados, por estar medido el espaçio de la rueda que buelve la agua, que ello sea justamente una hora; que aquí es la difficultad, que en lo demás breve materia es el modo d'ello. (Anónimo, Los veintiún libros de los ingenios y máquinas de Juanelo Turriano, 1605)

También en estos ejemplos, los adverbios subrayan que el dato es rigurosamente preciso y exacto, no aproximado: exactamente un mes, exactamente una hora. Durante los siglos XVI y XVII, justo y justamente cuentan también con variantes como la locución al justo (es al justo medianoche, véase apartado 3.1.7.2) y el adverbio flexionado (justos treynta días después de la muerte de los Caravajales, véase apartado 3.1.7.1), aunque el uso de estas variantes se marginaliza.

Por último, el primer ejemplo donde exactamente focaliza un dato temporal exacto es del siglo XIX. Por lo tanto, es - con bastante distancia- el último adverbio del grupo en aparecer en este contexto:

(9) El día en que cumplía exactamente un mes de su salida de Sevilla hallose más triste que de costumbre, y pensó para distraerse en rogar a Elvira le permitiese estar con ella aquel día. (Gertrudis Gómez de Avellaneda, Dos mujeres, 1842-1843)

Creemos que, en los ejemplos citados, los adverbios insisten en que un número que a primera vista podría parecer redondeado es, de hecho, rigurosamente exacto. Por ejemplo, en (6), los demás signos del zodíaco aparecen todos determinados exactamente al minuto (7 horas y 31 minutos, 11 horas 1 minuto, etc.) y sagitario aparece precisamente al mediodía, es decir, 'a las doce en punto, ni un minuto antes ni después', es decir, literalmente a las 12 horas y 0 minutos. 
Por lo general, los hablantes no determinan la hora al minuto exacto, sino que redondean porque detallar la hora minuciosamente suele ser redundante. Así, al mediodía normalmente indica una hora más bien aproximada, con un margen de varios minutos o hasta horas. El DLE (2014, s.v. mediodía) incluso define mediodía como "período de extensión imprecisa alrededor de las doce de la mañana». Por defecto, un mes y una hora no se suelen usar en un sentido estrictamente matemático, sino aproximado. Es decir, en la lengua común, una hora raras veces designa y se refiere a 60:00 minutos literalmente. Los hablantes - probablemente de acuerdo con la máxima conversacional de cantidad y de manera - tienden a usar datos temporales redondeados y, por lo tanto, aproximados (al mediodía, una hora, una hora y media, etc.). En la mayoría de las situaciones cotidianas es irrelevante concretar hasta el minuto o segundo estas informaciones: sería una cantidad de información innecesaria.

La convención social de usar números y datos redondeados forma parte del conocimiento extralingüístico compartido. Ahora bien, cuando un acontecimiento sucede a las 12:00 horas en punto, el hablante probablemente quiere dejar claro que se refiere al mediodía en un sentido estricto y literal, no aproximado, y lo hace con un adverbio de exactitud (exactamente al mediodía) o con la locución en punto. Asimismo, cuando una hora realmente se refiere a un período exacto de 60 minutos, el hablante puede sentir la necesidad de explicitarlo y dejarlo claro mediante un adverbio focalizador de exactitud. Consiguientemente, los adverbios precisamente, justamente, exactamente, etc., indican que un espacio de tiempo (un mes, dos años) designa literal y exactamente lo que expresa, o una hora (al mediodía) es exacta y no aproximada. Se añade esta indicación cuando la información se desvía de una interpretación por defecto aproximada. Este es un uso típico cuando los focalizadores de exactitud aparecen con números redondos, pero no redondeados.

A nuestro modo de ver, el hecho de que las expresiones lingüísticas y las categorías lingüísticamente codificadas suelen ser aproximativas a la realidad (el fenómeno denominado fuzziness), explica por qué la focalización de aproximación (casi, apenas, aproximadamente, etc.) es más productiva y está mejor documentada en todas las épocas (véase apartado 1.2.1). Los ejemplos que acabamos de citar muestran que los focalizadores de exactitud se usan especialmente en los casos en los que - al contrario de lo esperado y de lo normal- no hay fuzziness. Es decir, en el lenguaje cotidiano, constituyen la excepción, no la regla.

Los focalizadores enfáticos de exactitud se oponen, por lo tanto, a los de aproximación: aproximadamente, como, prácticamente, casi, etc., son hedges, esto es, se emplean para la estrategia discursiva de atenuación por hedging, que consiste en mitigar la fuerza o la verdad de un enunciado y así reducir el riesgo 
que corre el hablante al comprometerse, por ejemplo, con una aserción fuerte (Kaltenböck/Mihatsch/Schneider 2010, 1). En concreto, la combinación de marcadores de imprecisión como aproximadamente con medidas o números indica fuzziness en el propio contenido proposicional y, por lo tanto, estas expresiones suelen categorizarse también como rounders o bushes (Kaltenböck/Mihatsch/ Schneider 2010, 5-6).

En este sentido, deducimos que los focalizadores de exactitud hacen justo lo contrario: enfatizan la fuerza, la exactitud de la información y, con ello, intensifican la verdad del contenido proposicional. Así, el hablante se presenta como informante creíble, subrayando el rigor con el que se expresa (López Samaniego 2007, 49). Según Kaul de Marlangeon (2002, 142), los adverbios de exactitud ponen en evidencia la máxima cooperativa de calidad: enfatizan que lo dicho es verdadero y queda exento de dudas para el interlocutor. Asimismo, König (1991, 126-127) observa el empleo del inglés exactly 'exactamente, ni un poco menos ni un poco más' como estrategia del hablante para asegurarse de que los demás no piensen que esté diciendo algo ligeramente divergente de la verdad.

Veamos ejemplos en los que el numeral no es redondeado. Aparte de focalizar un dato que pudiera parecer redondeado e impreciso, los adverbios de exactitud aparecen también con un dato que parece casi exagerada y excesivamente preciso:

(10) Porque sí, pequeña mía, hoy es el aniversario de nuestro primer encuentro, que sucedió exactamente a las veintitrés y diez (las once y diez minutos) de esta noche. (Darío Fernández Flórez, Lola, espejo oscuro, 1950)

(11) Eso fue, lo recuerdo muy bien, una tarde de mayo. El domingo veinticuatro de mayo de 1998, exactamente a las cinco de la tarde. Lo sé porque era mi cumpleaños [...]. (Enrique Jaramillo Levi, Luminoso tiempo gris, 2002)

En ambos ejemplos, exactamente llama la atención sobre el hecho de que el hablante se toma la molestia de indicar un dato rigurosamente preciso, casi exageradamente exacto, porque de alguna manera es importante para él. En el primer ejemplo, el hablante recuerda la hora exacta del primer encuentro y en lugar de decir simplemente un dato aproximado como sobre las once -lo que sería lo normal en cualquier otra situación cotidiana, según lo expuesto más arriba- especifica que fue exactamente a las once y diez minutos. Enfatiza la exactitud de la hora para dejar claro que este acontecimiento importante se le quedó grabado. En el segundo ejemplo, el hablante también es capaz de recordar exactamente la fecha y hora de un acontecimiento, ya que lo vincula igualmente con un recuerdo significativo: su cumpleaños. Consiguientemente, cuando los 
adverbios de focalización de exactitud inciden sobre un dato (excesivamente) concreto y detallado, este énfasis puede conllevar una interpretación subjetivamente significativa.

Cabalmente, a pesar de su documentación temprana en el siglo XIII, no vuelve a aparecer en el CDH nuclear como adverbio de foco hasta el siglo XVIII, ya que los ejemplos de los siglos XVI y XVII solo documentan su uso como adverbio de modo. En el siguiente ejemplo, el énfasis en el número concreto de días parece aportar una valoración de este período de tiempo como apresurado. La cantidad se valora subjetivamente como poca:

(12) En este tiempo, llegó de Madrid mi hijo Bernardo que lo había enviado a llamar para embarcarlo en compañía de su cuñado, que llegó cabalmente cuatro días antes de la partenza o salida de dicha Flota, que tasadamente hubo lugar de hacerle un vestido de color para saltar en tierra en la Veracruz. (Raimundo de Lantery, Memorias, 1705)

La focalización de exactitud en complementos circunstanciales de lugar es más tardía y menos frecuente en todos los adverbios. Consiste en la misma estrategia que la focalización de exactitud de un dato temporal: la localización indicada es rigurosamente exacta y esta exactitud de alguna manera es importante o significativa:

(13) El río Hueso ó Yare se encuentra á los $13^{\circ}$ y algunos minutos al Norte precisamente. Es decir, que según López de Velasco, Honduras llegaba hasta dos grados más al Sur del Cabo de Gracias á Dios. (Antonio A. Ramírez F. Fontecha, El arbitraje entre Honduras y Guatemala, 1908)

(14) ¿Qué otro recurso, contra esa recurrencia, que ponerse el sombrero y salir a andar, exactamente a la misma hora y exactamente por las mismas calles? (Eduardo Mallea, Todo verdor perecerá, 1941)

(15) El Almirante sintió gran satisfacción por haber ido a parar exactamente donde se proponía. (Salvador de Madariaga, Vida del muy magnífico señor don Cristóbal Colón, 1940-1947)

(16) - Mirá. A los Secretarios nos está prohibido eso de andar buscando nombres para la gente, pero tú me ganaste el corazón justo desde que entraste. La asentada de la partida, sin embargo, te va a costar unos riales. (Víctor Cáceres Lara, «Humus», Cuentos completos, 1952)

En resumen, los adverbios focalizadores de exactitud conservan plenamente su significado conceptual base, 'exacto, no aproximado'. No hay realmente un significado procedimental, sino simplemente énfasis: se llama la atención sobre el dato para indicar que es exacto. Este énfasis es relevante vista la presuposición de fuzziness. Sintácticamente, el énfasis se consigue con la anteposición. Además, la propiedad de excluir alternativas implícitas - que definimos como 
central para los adverbios de foco- viene inherente al concepto semántico de exactitud, ya que esta implica que las alternativas aproximadas quedan excluidas. Dicho de otro modo: la exactitud es un concepto inherentemente gradual y cuantificable.

A pesar de ser el último de los adverbios en adoptar este contexto de uso, exactamente se convierte en el focalizador de exactitud de tiempo o lugar más frecuente en el siglo XX. En cambio, justamente, justo y, sobre todo, precisamente dejan de usarse como meros focalizadores de exactitud, ya que desarrollan otros valores pragmáticos en este mismo contexto, como mostraremos en el siguiente apartado. La última ocurrencia en nuestra muestra base de precisamente como mero adverbio de exactitud es la que acabamos de citar (véase ejemplo 13, del año 1908). En todo caso, precisamente parece mantener marginalmente el valor original como focalizador de exactitud, sin valoración subjetiva, en el español de América:

(17) Aquel nublado y frío día del 15 de abril de 1947, Jackie Robinson fue el primer pelotero negro en el deporte de los blancos. Hoy, hace precisamente 60 años. (Moisés Ramírez Segundo, «Legado sin igual». El Universal.com.mx, México D. F., 15/04/2007, CORPES XXI)

\subsubsection{Adverbios enfatizadores de coincidencia significativa en el tiempo o espacio}

En el apartado anterior, hemos mencionado que el énfasis en un número en ocasiones conlleva alguna valoración subjetiva, es decir, deja entrever la perspectiva del hablante frente al dato mencionado (por ejemplo, sucedió exactamente a las veintitrés y diez o llegó cabalmente cuatro días antes de la partenza). Esta subjetividad abre un abanico de posibles valores, entre ellos, permite interpretar el dato como coincidente. El efecto de coincidencia significativa supone un paso más allá de la focalización de exactitud. La información temporal o espacial enfatizada no solo es rigurosamente exacta, sino que el hablante llama la atención sobre ella por alguna razón más: es curiosa, inesperada o especialmente oportuna. El análisis diacrónico de esta función se complica por el hecho de que este uso surge como inferencia pragmática en el mismo contexto que la focalización de exactitud. Al tratarse de una inferencia pragmática contextual, depende del oyente y de su interpretación del contexto amplio si capta que el hablante quiere insinuar «algo más» que exactitud o no.

Tal y como nota López Samaniego (2007, 61-63), una de las definiciones de coincidencia es la de 'concurrencia en el tiempo o en el espacio de dos o más sucesos'; así que, cuando los adverbios de foco destacan una coincidencia de este tipo, relacionan dos sucesos por diversos motivos: un suceso explica a otro (hay 
una relación casual, incluso intencionada), o - por el contrario- es totalmente casual o fortuito. En cualquier caso, el oyente (o lector) tiene que decidir cuál es la inferencia contextual más accesible.

La focalización que infiere una coincidencia se desarrolla primero en el adverbio precisamente; aparece esporádicamente en el siglo XVII y se difunde en el XVIII. El siguiente ejemplo es el primero en la muestra base donde se detecta este valor de coincidencia significativa entre dos hechos:

(18) Un gran señor fué a visitar la cárcel de su corte, porque le dijeron servía de heredad y bolsa a los que la tenían a su cargo, que de los delitos hacían mercancía, [...] halló que los habían preso por los delitos que habían cometido, y que los tenían presos por los que su codicia cometía con ellos. Supo que a los unos contaban lo que habían hurtado y podido hurtar y a otros lo que tenían y podían tener y que duraba la causa todo el tiempo que duraba el caudal y que, precisamente el día del último maravedí era el día del castigo y que los prendían por el mal que habían hecho y los justiciaban porque ya no tenían. (Francisco de Quevedo y Villegas, La Fortuna con seso y la Hora de todos. Fantasía moral, 1635-1645)

El hablante no destaca el complemento circunstancial de tiempo como rigurosamente exacto (nótese la ausencia de un numeral), sino que al focalizarlo obliga al oyente a buscar una interpretación que va «más allá». La coincidencia significativa surge como inferencia de todo el contexto: los encargados de la cárcel se aprovechaban el máximo tiempo posible de los presos para sacarles dinero. El día en el que se acaba el dinero, finalmente los castigan. Hay, por lo tanto, una coincidencia temporal entre dos sucesos, es decir, entre dos proposiciones (el castigo y el fin del dinero). El hablante, al destacar que ambas cosas ocurren exactamente el mismo día, pretende insinuar que hay una relación significativa entre ellos: la coincidencia temporal no es casual, sino intencionada.

Las alternativas implícitas serían todos los demás días en los que los encargados de la cárcel podrían haber aplicado el castigo sin levantar la sospecha de enriquecerse a costa de los presos. Se trata claramente de una inferencia, es decir, el oyente reinterpreta el enunciado y obtiene informaciones no codificadas explícitamente gracias al contexto amplio (Company Company 2016, 524). Lo único que codifica explícitamente el hablante es la exactitud y la coincidencia temporal, es decir, la identidad temporal entre dos proposiciones. La relación causal solo se infiere del contexto y del énfasis.

En el siguiente ejemplo, precisamente focaliza una coincidencia significativa en el espacio:

(19) De esta virtud me ha hecho dudar, y aun inclinado a sospechar la contraria, un sucesso acaecido en Francia el año de 1718. El día de Viernes Santo cayó una furiosíssima tem- 
pestad en parte de la costa de Bretaña. Veinte y quatro iglesias fueron heridas de rayos. Lo que es mui de notar, y lo que hace a nuestro intento, es que los rayos cayeron precisamente en aquellas iglesias donde se pulsaron las campanas, sin tocar en alguna de otras muchas donde se observó el rito de no tocarlas el día de Viernes Santo. El vulgo, cuya religión es summamente resvaladiza a la superstición, creyó que huviesse sido una insigne profanación violar aquel rito [...]. (Benito Jerónimo Feijoo, Theatro Crítico Universal o discursos varios en todo género de materias, para desengaño de errores comunes $V, 1733)$

Los rayos cayeron solamente en aquellas iglesias que no respetaban la tradición. Por tanto, hay una coincidencia significativa y se infiere una correlación causal: las iglesias afectadas por los rayos son las mismas iglesias que tocaban las campanas. Hay, pues, focalización de identidad. El adverbio de foco excluye alternativas menos significativas: los rayos podrían haber caído en cualquier iglesia, pero únicamente afectaron a las que rompieron la tradición. Todas las demás iglesias son alternativas igualmente posibles y presentes en el contexto extralingüístico, pero menos significativas. En este sentido, el hablante focaliza una coincidencia - también la advierte en su discurso: lo que es mui de notar- para insinuar un castigo celestial y establecer una relación causal entre dos hechos. Señala, por lo tanto, su interpretación subjetiva de dos sucesos, que desde una observación objetiva no tienen por qué estar relacionados.

En estos ejemplos, precisamente adquiere un significado procedimental, que se añade al significado conceptual de exactitud. Es decir, el adverbio inicialmente codifica exactitud y expresa énfasis en esta exactitud rigurosa ('ni más ni menos') cuando se antepone a un dato temporal o espacial. La interpretación adicional de una coincidencia significativa viene dada por todo el contexto y toda la situación comunicativa. Surge como inferencia pragmática no codificada explícitamente. Tal y como observa López Samaniego (2007, 55-56), las alternativas implícitas no necesariamente se ordenan en una escala de más a menos exacto, sino que todas las alternativas están a un mismo nivel de fuerza informativa: las alternativas son siempre elementos no coincidentes, como, por ejemplo, otras iglesias.

En el siglo XVIII, también aparece cabalmente como adverbio de foco de coincidencias temporales. En este ejemplo, el efecto de énfasis es reforzado por la pregunta retórica anterior y la exclamación:

(20) D. Mariano: ¿Conque, según dices, esta noche ya tendremos una banca en forma? 
Dạ. Mónica: Mucho.

D. Mariano: Me pones en un aprieto.

Si salgo de casa, el tío

rabiará. Será un infierno.

Pero ¿no es fuerte rigor?

¡Hoy cabalmente que tengo

cien doblones! ¡Y saber

que allá os estáis divirtiendo!

Da . Mónica: ¡Cómo! ¡El mejor jugador

sin cartas! Mucho respeto

te infunde ese don Cristóbal. (Tomás de Iriarte, El señorito mimado, 1787)

El personaje D. Mariano se lamenta de una coincidencia casual (o sea, no intencionada) y desafortunada para él: precisamente el día que tiene dinero para jugar no le dejan salir. En este ejemplo, las alternativas menos significativas que quedan excluidas son todos los demás días en los que D. Mariano sí puede ir a jugar.

En el siguiente ejemplo, precisamente focaliza un dato temporal considerado inoportuno y sorprendente. No focaliza dos días como un dato exacto ('ni más ni menos que dos'), sino que la fecha del acontecimiento es sorprendente e inesperada:

(21) El Ministerio de Cultura, por su parte, manifestó su sorpresa ante la aparente ruptura de lo que se ha catalogado como «luna de miel» de este Ministerio con la Conselleria de Cultura de la Generalitat. «Nos sorprende esta reacción, precisamente dos días después de que se constituya una comisión mixta para estudiar el tema» [...]. (La Vanguardia, 14/01/1994)

En otros casos, la coincidencia significativa es solo fruto de la imaginación del hablante, pero en realidad es pura casualidad. El hablante admite que se equivocó al relacionar dos hechos curiosos y darles una interpretación significativa (una correlación causal) cuando no la había:

(22) A muy pocos días de mi introducción en algunas casas de esta corte me encontré con los tres memoriales siguientes. Como era precisamente entonces la temporada que los cristianos llaman carnaval o carnestolendas, creí que sería chasco de los que acostumbran en semejantes días en estos países, pues no pude jamás creer que se hubiesen escrito de veras semejantes peticiones. (José de Cadalso, Cartas Marruecas, 1774-1778)

El valor de coincidencia significativa en el tiempo o espacio también se da actualmente en el adverbio corto justo, como muestra el siguiente ejemplo en el que 
el hablante focaliza lo inoportuno, escandaloso y hasta ofensivo del sitio donde ocurre la blasfemia:

(23) ¡El hermano Macario hablando mal de Dios..., cometiendo sacrilegio, justo aquí, bajo el techo de la iglesia! (Augusto Roa Bastos, Hijo de hombre, 1960)

Justo intensifica aún más la valoración negativa, siempre subjetiva del hablante: es inapropiado hablar mal de Dios, pero hacerlo en la iglesia lo es todavía más. Coincide, pues, un hecho despreciable con el sitio menos adecuado. Las alternativas menos significativas serían todos los demás sitios no sagrados. También en justo son más escasos los ejemplos en los que la coincidencia -en este caso casual- es totalmente afortunada y oportuna:

(24) alguien escribe sobre la tragedia una novela y puede tener un éxito rotundo, o hace una película, en fin, si es un fotógrafo que accidentalmente tomó una foto justo en el momento, esa foto puede significar el triunfo de su vida. (Roberto Quesada, Big Banana, 2000)

Por consiguiente, la interpretación particular de la coincidencia significativa puede ser de naturaleza diversa: buscada, intencionada o puramente casual; oportuna o desfavorable. Los adverbios de foco precisamente, justamente, cabalmente y justo no codifican cuál es la interpretación y valoración concreta, solo llaman la atención sobre la coincidencia y empujan al receptor a buscar la interpretación insinuada. Por eso, hace falta un conocimiento amplio del contexto, esto es, del co-texto lingüístico (es decir, de los enunciados anteriores y/o posteriores), de la situación comunicativa y/o del conocimiento común sobre el mundo extralingüístico para interpretar correctamente las inferencias insinuadas.

Sin informaciones contextuales o conocimiento sobre la materia en cuestión, los receptores no consiguen interpretar la coincidencia insinuada, por más que el hablante indique que se trata de un hecho curioso:

(25) Y no deja de ser curioso que esta búsqueda de nuestras esencias insulares a través de la poesía, ocurra justamente un siglo después de la publicación de Rumores del Hórmigo de Juan Cristóbal Nápoles Fajardo en 1856 [...]. (Cintio Vitier, Lo cubano en la poesía, 1958)

En el caso del adverbio alemán ausgerechnet, que sería el equivalente al español precisamente, König (1991, 134-135) observa que siempre señala una disonancia o incongruencia entre la eventualidad denotada en la oración y una eventualidad dada por el contexto. El valor focalizado es el menos adecuado e apropiado entre todas las posibles variantes. Se trata, pues, de una valoración negativa, mínima, en una escala:

Willst du ausgerechnet jetzt verreisen? ('Do you want to leave now of all times?') (König 1991, 134)

¿Quieres salir de viaje precisamente ahora? [nuestra traducción] 
Este adverbio alemán siempre denota una valoración negativa: en el ejemplo citado, focaliza el momento más inoportuno o desafortunado para salir de viaje. En el caso del español precisamente, justamente y justo, se da ese mismo valor:

(26) -Es una gran mujer, don Arturo. Tal vez demasiado buena para un hombre. Y vaya una idea. ¡Venir a Madrid precisamente ahora! No sabe ni cinco palabras de español, pero si la dejan sola por la calle no se pierde, no. Ya tiene reaños esa mujer. (Arturo Barea, La forja de un rebelde, 1951)

(27) Es así de imbécil. Si voy a buscarlo, justamente hoy, con este tiempo sucio, sin que nada me impida postergar el viaje a no ser la superstición [...]. (Juan Carlos Onetti, El astillero, 1961)

De todos los momentos posibles, en ambos ejemplos se opta por el menos indicado y el menos favorable. Sin embargo, precisamente, justamente, cabalmente y justo engloban más valores como adverbios de foco y no siempre indican una coincidencia desafortunada o no deseada, sino que la coincidencia también puede ser fortuita y favorable. Además, aparecen en varios otros contextos con distintos valores pragmáticos (véanse los demás apartados de este capítulo), por lo cual son más polisémicos que el alemán ausgerechnet, que sola y únicamente se usa con el valor específico de una coincidencia desafortunada e incongruente.

La inferencia de una coincidencia significativa no es habitual en el adverbio de foco exactamente. En contextos temporales y espaciales, exactamente siempre indica exactitud rigurosa y puntual, pero no insinúa una coincidencia significativa. Presenta el dato como correcto, exacto, verdadero y objetivo; pero no añade una interpretación subjetiva. En este sentido, si reemplazamos precisamente, justamente, cabalmente y justo en los ejemplos citados por exactamente, se perdería el efecto de insinuar alguna coincidencia significativa:

El hermano Macario hablando mal de Dios..., cometiendo sacrilegio, exactamente aquí. (compárese con el ejemplo 23)

Esta búsqueda de nuestras esencias insulares a través de la poesía ocurre exactamente un siglo después de la publicación de Rumores del Hórmigo de Juan Cristóbal Nápoles Fajardo en 1856. (compárese con el ejemplo 25)

En el primer ejemplo, el hablante señalaría con precisión el punto exacto dónde ocurrió dicha blasfemia, pero no expresa su valoración subjetiva de escándalo. En el segundo ejemplo, la interpretación sería también de focalización de exactitud de un dato, tal y como analizamos en el apartado anterior: exactamente un siglo corresponde a ‘1000 años' (y no 999 o 1001). Se pierde, de nuevo, la interpretación subjetiva de alguna coincidencia significativa. Es decir, a pesar de formar un paradigma sintáctico, exactamente no aporta la misma interpretación pragmática que justamente, precisamente, etc. Esto es, no pertenece al mismo subparadigma pragmático. 
El uso como focalizador de coincidencias aparece solo esporádicamente en exactamente y no parece haber arraigado. Solo hemos encontrado un ejemplo de exactamente en el que el contexto deja claro que la focalización de exactitud conlleva además una interpretación oportuna -inesperada pero deseada-. El énfasis también se refuerza por la repetición:

(28) ALBERTO Ah, no, ¿eh? ... ¿Y cómo sabes si hoy pasa lo inesperado? ¿A lo mejor, hoy, exactamente hoy, se manda abajo, al fin, el maldito trapecista, y estalla en el piso de aserrín, en un gran estruendo de cabezas rotas? (Egon Wolff, Háblame de Laura, 1986)

En conclusión, el efecto de coincidencia significativa surge en precisamente como un paso más allá de la focalización de exactitud, ya que se da como inferencia pragmática en los mismos contextos que la focalización de exactitud: cuando el alcance de los adverbios de foco es un complemento circunstancial de tiempo o lugar. La focalización de exactitud rigurosa en el dato temporal o espacial ('exactamente $\mathrm{x}$, ni más ni menos') se convierte en la focalización de alguna coincidencia significativa: la acción ocurre exactamente en un momento significativo o exactamente en un lugar significativo. Este es el contexto puente de dicho cambio.

Por analogía, algunos de los demás adverbios de foco del paradigma también adoptan el nuevo valor de coincidencia significativa: principalmente, justamente y justo. Cabalmente también adopta el valor de coincidencia, pero desaparece en el español actual como adverbio de foco. Por último, exactamente se consolida como adverbio de foco de exactitud (pero no de coincidencia) y llena de cierto modo el hueco que dejaron precisamente, justamente y justo tras experimentar un desarrollo hacia otros valores subjetivos.

El cambio de focalización de exactitud al efecto de coincidencia significativa consiste, por lo tanto, en la convencionalización de inferencias pragmáticas. Según König (1991, 134-135) la implicatura conversacional que conlleva el alemán ausgerechnet 'precisamente' (la disonancia entre dos eventualidades) se transforma en parte de su significado convencional y se lexicaliza. Es decir, este significado está convencionalizado en alemán ausgerechnet, pero (todavía) no en inglés precisely y exactly (König 1991, 134-135). En español, el adverbio de foco precisamente, donde este valor surge a partir del siglo XVII, deja de usarse con un valor meramente focalizador de exactitud en el siglo XX. Es decir, precisamente ha generalizado y convencionalizado la inferencia de coincidencia significativa. Sin embargo, la coincidencia destacada por precisamente puede ser de índole diversa, no solo de disonancia desfavorable entre dos eventualidades, como en el caso del alemán ausgerechnet. Precisamente no se ha especializado y no codifica la disonancia desfavorable como parte de su significado léxico, sino que esta sigue siendo una de varias inferencias contextuales posibles. 
En cambio, en justamente y justo sigue habiendo ambigüedad entre una interpretación meramente de focalización de exactitud (el dato es rigurosamente exacto) y un posible efecto añadido de coincidencia significativa. Deducir correctamente la interpretación insinuada por el hablante siempre depende del conocimiento de las circunstancias por parte del oyente. Sin más informaciones sobre las circunstancias y las personas involucradas, resulta imposible interpretar cuál es el efecto pragmático intencionado de esta focalización temporal:

(29) El 27 de abril de 1939, justo el día en que Pere Figueras y sus ocho compañeros de Cornellà de Terri ingresaron en la prisión de Gerona, Rafael Sánchez Mazas acababa de ser nombrado consejero nacional de Falange Española Tradicionalista y de las JONS y vicepresidente de su junta Política [...]. (Javier Cercas, Soldados de Salamina, 2001)

¿Es casual la coincidencia o se insinúa una relación entre ambos hechos? En este mismo contexto, el adverbio de foco precisamente indicaría una coincidencia intencionada y significativa entre ambos hechos, mientras que justo y justamente son ambiguos.

\subsubsection{Aumento de alcance sintáctico de los adverbios de focalización}

Como muestran los ejemplos citados, los adverbios focalizadores se anteponen a sintagmas nominales o preposicionales y adverbios de tiempo o lugar. En el siglo XVIII, se extienden a contextos sintácticos nuevos y aumentan su alcance. Así, los adverbios en cuestión aparecen como focalizadores de oraciones temporales subordinadas:

(30) Por aqui se sube igualmente a los apartamentos del Doge que por favór, y dinero me permitieron vér justamente quando se hiva á servir la mesa... notandose una suma moderacion en la fornitura interior; y mesquindad en su mesa, que aun estava puesta con negligencia, у poco aseo... (Francisco de Miranda, Diario de viajes, 1785-1786)

En este ejemplo, hay coincidencia o simultaneidad entre el hecho referido en la oración principal (dejar a alguien observar los apartamentos) y el hecho referido en la oración subordinada (se sirve allí la mesa). Esta coincidencia es llamativa e importante para el hablante. Se trata de un favor concedido y la coincidencia temporal es, por lo tanto, intencionada y buscada. Es una coincidencia afortunada. Sin embargo, en la mayoría de los ejemplos, las coincidencias son inoportunas y suponen una desgracia imprevista. Es decir, la simultaneidad de dos hechos es casual, desafortunada e inapropiada:

(31) Así que llegue por acá el Rl diploma se acabaron los socorros, y los socorridos se marcharán a puto el postre a ver sus patrios lares, precisamente quando yo trataba de ir a 
refocilarme con ellos. Desgracia es mía que haya de vivir condenado a perpetua soledad. (Leandro Fernández de Moratín, Cartas de 1818, 1818)

(32) Al cariño de padre, al aguijón del remordimiento vinieron a mezclarse entonces los temores del caballero que temblaba por la suerte y el porvenir de su linaje depositados en tan frágil vaso, cabalmente cuando el destino parecía que iba a convertir en bronce su vidrio delicado. (Enrique Gil y Carrasco, El Señor de Bembibre, 1844)

En el primer ejemplo, el hablante se queja de una desgracia. Asimismo, en el segundo ejemplo, la coincidencia desafortunada es regida por el destino: el hablante se equivocaba al interpretar su propia situación. En cambio, en el siguiente ejemplo, parece tratarse de una coincidencia desfavorable completamente intencionada por el condiscípulo del hablante:

(33) como me sucedió a mí con mi buen condiscípulo, que me fue a hacer quedar mal justamente cuando estaba yo queriendo quedar bien con su prima. Detestad, hijos míos, las amistades de semejante clase [...]. (José Joaquín Fernández de Lizardi, El Periquillo Sarniento, 1816-1827)

Con el fin de cuantificar esta nueva posición sintáctica, que supone un aumento de alcance de los adverbios de foco, buscamos el patrón [puntuación + adverbio + cuando] en el CDH. Así evitamos ocurrencias en las que el adverbio aparece como adverbio de modo antepuesto a cuando. Al aparecer tras un signo de puntuación, ya sea una coma o un punto, el adverbio incide claramente sobre la oración subordinada que sigue. No obstante, esta búsqueda excluye los ejemplos en los que no hay un signo de puntuación antes del adverbio de foco y solo es parcialmente representativa. Para comprobar la fecha de la primera documentación de este uso, tuvimos en cuenta también la búsqueda sin signo de puntuación.

Tabla 18: Frecuencia del patrón [puntuación + adverbio + cuando] en el CDH y siglo de aparición.

\begin{tabular}{rrrrr}
\hline precisamente & justamente & cabalmente & exactamente & justo \\
\hline 190 & 68 & 5 & 9 & 45 \\
\hline siglo XVIII & siglo XVIII & siglo XVIII & siglo XX & siglo XX \\
\hline
\end{tabular}

Como muestra la comparación en la Tabla 18, precisamente es el adverbio que más frecuentemente incide sobre una oración temporal subordinada y, junto con justamente y cabalmente, es el primero en aparecer en este contexto. En justo, este contexto no aparece hasta el siglo XX, o sea, cuando este adverbio corto vuelve a aceptarse en la lengua escrita. 
También exactamente aumenta su alcance en el siglo XX, aunque aparece con bastante menor frecuencia como focalizador de una oración temporal subordinada. Su valor sigue siendo el de focalización de exactitud minuciosa ('ni antes ni después'):

(34) Lo que ocurre es que el trabajo del campo lleva muchísimo tiempo, ha de hacerse poco a poco, por sus pasos contados, exactamente cuando toca, ni antes ni después, y así parece como si en realidad no hubiera habido un gran cambio, cosa que en cualquier ciudad del mundo no nos pasa; allí todo lo contrario es lo normal: (Eduardo Mendoza, La ciudad de los prodigios, 1986)

Asimismo, los adverbios de foco inciden sobre oraciones subordinadas introducidas por la conjunción donde. Buscamos el mismo patrón con un signo de puntuación antes del adverbio de foco. Los datos recogidos en la Tabla 19 muestran que el contexto locativo es menos frecuente y más tardío que el contexto temporal:

Tabla 19: Frecuencia del patrón [puntuación + adverbio + donde] en el CDH y siglo de aparición.

\begin{tabular}{rrrrr}
\hline precisamente & justamente & cabalmente $^{9}$ & exactamente & justo \\
\hline 21 & 14 & (existe) & 7 & 8 \\
\hline siglo XIX & siglo XIX & siglo XIX & siglo XX & siglo XX \\
\hline
\end{tabular}

En el siglo XIX, el alcance de precisamente, justamente y cabalmente aumenta otro paso más: focalizan toda la oración. Pasan, por lo tanto, de la modificación de oraciones subordinadas a la modificación de oraciones principales:

(35) Al día siguiente a la hora prefijada por el marqués, estaba éste en casa. Justamente era día de años del rey, o no sé qué; (José Joaquín Fernández de Lizardi, El Periquillo Sarniento, 1816-1827)

(36) Cada cual a votar se precipita;

Uno quiere que llueva enseguidita,

Otro que el sol se vele con celaje,

Porque tiene que hacer cierto viaje

Que le importa muy más que la cosecha,

Votando así que el día

Siguiente ha de llover de su regreso.

9 La búsqueda de cabalmente donde sin signo de puntuación da dos ocurrencias; por lo tanto, la focalización de subordinadas locales existe, pero no se recupera con el patrón de búsqueda especificado en la tabla. 
«iNo!, -le grita muy poco satisfecha

Una moza-; pardiez, no ha de ser eso;

Precisamente estoy de romería.» (Concepción Arenal, Fábulas en verso originales, 1851)

En ambos casos, los adverbios focalizan una coincidencia temporal, ya que se podría reponer un complemento circunstancial de tiempo: justamente aquel día/ precisamente mañana. En el segundo ejemplo, precisamente expresa, de nuevo, una coincidencia temporal desafortunada, mientras que la coincidencia temporal del primer ejemplo no parece expresar una valoración subjetiva.

Frecuentemente, los adverbios inciden sobre toda la oración cuando esta lleva una perífrasis verbal de tipo [estar + gerundio] o [estar + a punto de + infinitivo], así como [acabar $+d e+$ infinitivo]. Estas perífrasis verbales indican que una acción coincide temporalmente con otra acción y el efecto de la focalización consiste en indicar una casualidad temporal significativa:

(37) Ignorante yo de cuanto en esto había, por ser mi costumbre (y áun puedo decir mi falta) desentenderme con frecuencia de cuanto pasa detrás del telon del teatro político, siendo allí cabalmente donde se trabaja lo que es pura representacion en la escena, acudí aquel dia al Congreso sin esperar un lance ruidoso. Cabalmente acababa de pasar Istúriz, con quien había estrechado infinito mi amistad, una enfermedad aguda que puso su vida en peligro, y aquel dia, convaleciente, iba á sentarse en las Córtes, al cabo de algunas semanas de ausencia. (Antonio Alcalá Galiano, Memorias, 1847-1849)

(38) Ah, al fin llegas. Justamente estábamos hablando de ti con tu madre. (Mario Vargas Llosa, La ciudad y los perros, 1962)

(39) -Yo he oído decir que el hábito no hace al monje, don Carlitos- se atrevió a comentar Julia. Y Carlitos le respondió que no, claro que no, Julia, y que precisamente estaba a punto de contarles, ya para ir terminando, cómo a él le habían cambiado un hábito por otro y sigo siendo el mismo monje, je, aunque muchísimo más feliz ahora, valgan verdades, je, je. (Alfredo Bryce Echenique, El huerto de mi amada, 2002)

Asimismo, los adverbios de foco introducen la construcción [al + infinitivo], que subraya la simultaneidad de dos hechos:

(40) Justamente al entrar don Álvaro y el abad la despertó el relincho de Almanzor [...]. (Enrique Gil y Carrasco, El Señor de Bembibre, 1844)

Estos usos aparecen también en el adverbio corto justo, aunque solo se documenta desde finales del siglo XIX:

(41) -Ya, pues, no se hagan las difíciles -insistió Francisco-. ¿Quieren ir a tomar un traguito? -Ay, no sé - dijo Lupe, haciéndose la interesante-. La verdad que justo estaba con una sed bárbara. (Jaime Bayly, Los últimos días de «La Prensa», 1996) 
En este ejemplo, la coincidencia destacada es temporal: toda la situación en sí es oportuna, coinciden temporalmente la pregunta y la circunstancia de tener sed. Asimismo, en el siguiente ejemplo, justo también alcanza toda la oración, pero el efecto pragmático es de una situación desafortunada causada por una coincidencia temporal desafortunada:

(42) Nunca me había entusiasmado tanto con una telenovela. Durante ocho meses tuve una certeza al despertarme: entre las tres y las cuatro de la tarde iba a sentirme bien. Y justo vine a perderme el último capítulo. (Ana María Bovo, Rosas colombianas, 2001)

En otros ejemplos, simplemente hay simultaneidad ('en este mismo momento'):

(43) Somaira me pide que me mueva de la sala, que la deje ver televisión, que justo están pasando la novela. (Juan Carlos Méndez Guédez, Una tarde con campanas, 2004, CORPES XXI)

También en estos ejemplos, cabe suponer una elipsis de un complemento circunstancial de tiempo: justamente en este momento estábamos hablando de ti; justo ahora están pasando la novela; precisamente ahora estaba a punto de contarles; cabalmente aquel día acababa de pasar, etc. Dado que la coincidencia de tiempo es la circunstancia que más frecuentemente focalizan precisamente, cabalmente, justo y justamente, estos adverbios parecen haber absorbido e incorporado el valor de coincidencia temporal significativa. Por consiguiente, pueden prescindir de explicitar el complemento circunstancial de tiempo (en este momento, ahora, etc.), sobre todo, en combinación con determinadas perífrasis temporales. Los adverbios de foco sitúan a toda la situación descrita por la oración en un momento significativo, coincidente.

La combinación del adverbio de foco con la perífrasis acabar de permite cuantificar este uso en el CDH (nuclear y extensiones). Como indican los números de la Tabla 20, precisamente es con diferencia el adverbio de foco más frecuente en la construcción acabar de. De nuevo, precisamente, cabalmente y justamente, se documentan por primera vez en esta secuencia a mediados del siglo XIX. En cambio, justo aparece a finales del siglo XX y exactamente no se usa en esta construcción.

Tabla 20: Frecuencia de [adverbio + acabar (lema) + de] en el CDH: criba manual de los usos focalizadores.

\begin{tabular}{lllll}
\hline precisamente & justamente & cabalmente & exactamente & justo \\
\hline 27 & 4 & 5 & - & 2 \\
\hline siglo XIX & siglo XIX & siglo XIX & - & siglo XX \\
\hline
\end{tabular}


Consideramos que los adverbios precisamente, justamente, cabalmente y justo son intercambiables en los ejemplos citados, aunque cabalmente ha quedado anticuado. La última documentación de cabalmente antepuesto a la perífrasis verbal acabar de es de 1972. En este ejemplo, cabalmente indica una coincidencia oportuna, favorable:

(44) «¿Quiere usted un pitillo?», dijo el hombre alto que caminaba a su lado, y Bastida le respondió: «Muchas gracias. Cabalmente acaban de terminárseme, y, a estas horas, están cerrados los estancos» [...]. (Gonzalo Torrente Ballester, La saga/fuga de J. B., 1972)

Otra construcción recurrente es la del adverbio de foco en posición inicial y seguido por el verbo estar (Justo estábamos). La Tabla 21 muestra la frecuencia de esta secuencia:

Tabla 21: Frecuencia de [Adverbio (mayúsculas) + estar (lema)] en el CDH: criba manual de los usos focalizadores.

\begin{tabular}{lllll}
\hline precisamente & justamente & cabalmente & exactamente & justo \\
\hline 21 & 5 & 3 & - & 2 \\
\hline siglo XIX & siglo XIX & siglo XIX & - & siglo XX \\
\hline
\end{tabular}

En los ejemplos citados, el adverbio se antepone al verbo de la oración y su alcance es, cuanto menos, el predicado. Así, el adverbio aparece después de marcadores discursivos o conjunciones (La verdad que justo estaba con una sed bárbara; Y justo vine a perderme el último capítulo; que justo están pasando la novela) o relativos (véase ejemplo 45). Como muestran los siguientes ejemplos, cuando el sujeto de la oración está explícito, puede quedar o fuera o dentro del alcance del adverbio de foco. En el primer caso, el adverbio incide sobre el predicado y en el segundo sobre toda la oración, incluido el sujeto:

(45) Por el momento Mateo no podía conducir y se le asignó un chófer llamado Hernando, quien precisamente acababa de separarse de su mujer. (José María Gironella, Los hombres lloran solos, 1986)

(46) El rey había leído una y muchas veces aquel severo juicio que contenía el segundo memorial. Precisamente acababa de inclinarse el monarca por la expulsión de los moriscos con motivo de la consulta que le presentó el Consejo de Estado á 3 de enero de 1602, y, aunque la junta que entendía en el negocio de los moriscos de Aragón, Valencia y Castilla, deliberó acerca del contenido en el primer memorial del Patriarca, es indudable que el parecer de éste acabó de inclinar el ánimo de los consejeros [...]. (Pascual Boronat y Barrachina, Los moriscos españoles y su expulsión, 1901) Cabalmente acababa de pasar Istúriz [...] (véase ejemplo 37) 
Para verificar si el alcance del adverbio es toda la oración o solo el predicado, insertamos un sujeto explícito en aquellos ejemplos que llevan un sujeto nulo. Como muestra esta prueba, el alcance de los adverbios de foco suele ser más bien el predicado verbal, encabezado por la perífrasis verbal, ya que la posición más natural del sujeto estaría fuera del alcance del adverbio:

Ah, al fin llegas. (Nosotros) justamente estábamos hablando de ti. (compárese con ejemplo 38)

Y (yo) justo vine a perderme el último capítulo. (compárese con el ejemplo 42)

[...] y que (yo) precisamente estaba a punto de contarles [...] (compárese con ejemplo 39)

No obstante, la alteración sintáctica también permite posponer el sujeto:

Ah, al fin llegas. Justamente estábamos (nosotros) hablando de ti. (compárese con ejemplo 38)

Y justo vine (yo) a perderme el último capítulo. (compárese con el ejemplo 42)

[...] y que precisamente estaba (yo) a punto de contarles [...] (compárese con ejemplo 39)

En algunos ejemplos del corpus, los adverbios de focalización modifican, efectivamente, a toda la oración incluido el sujeto:

(47) Toma, sí estuve en Dartford y sí sé de ese mesón; cabalmente es un hijo mío el que lo tiene de su cuenta. (Pedro Montengón, Eusebio, 1786)

(48) Un día se presentó en el cuchitril de Belarmino Froilán Escobar, alias el Estudiantón y también Aligator, a que le pusiese palas y medias suelas a un par de botas, que para llegar a ser un verdadero par de botas no necesitaban, además de las palas y de las medias suelas, sino refuerzo en el contrafuerte, unos trozos de la caña y unos cuantos botones. Justamente, la única afición de Belarmino al arte zapateril consistía en restaurar calzado viejo, cuanto más viejo mejor, y con unos miserables despojos crear un par flamante. Era una afición pareja a su vocación filosófica. Y así, acogió aquellas valetudinarias botas del Estudiantón o Aligator con marcada reverencia y afectuosidad. (Ramón Pérez de Ayala, Belarmino y Apolonio, 1921)

En ambos ejemplos, el adverbio llama la atención sobre una coincidencia favorable y oportuna. Como muestra el ejemplo (47), cabalmente ya aparecía en el siglo XVIII como focalizador de oraciones.

Las búsquedas por las estructuras [adverbio + acabar $+d e]$ y [adverbio + estar] muestran que la focalización de una oración o del predicado no se documenta en exactamente. Este adverbio no puede sustituir a los demás adverbios en ninguno de los ejemplos citados:

^Exactamente estoy de romería. (compárese con ejemplo 36)

^Exactamente acababa de pasar Istúriz [...] (compárese con ejemplo 37) 


\footnotetext{
${ }^{\star}$ Ah, al fin llegas. Exactamente estábamos hablando de ti con tu madre. (compárese con ejemplo 38)

${ }^{\star}$ y exactamente estaba a punto de contarles [...] (compárese con ejemplo 39)

*[...] que exactamente están pasando la novela. (compárese con ejemplo 43)
}

En todo caso, habría que reconstruir un complemento circunstancial de tiempo como exactamente en este momento o exactamente hoy. El adverbio exactamente no ha desarrollado el uso como adverbio de foco de coincidencias y, al parecer por eso, no ha aumentado su alcance sintáctico en la misma medida que los demás adverbios de foco, que están en una etapa pragmática más avanzada. Exactamente tampoco puede aparecer en posición inicial y destacada, con alcance sobre toda la oración:

^Exactamente es un hijo mío el que lo tiene de su cuenta. (compárese con ejemplo 47)

En este ejemplo, la pausa prosódica convirtiría al adverbio de foco en un marcador de afirmación:

*Exactamente, la única afición de Belarmino al arte zapateril consistía en restaurar calzado viejo. (compárese con ejemplo 48)

En conclusión, el adverbio exactamente no se integra en este nuevo (sub)paradigma sintáctico de los adverbios focalizadores.

\subsubsection{Adjetivos de exactitud como operadores de focalización}

En nuestra muestra base, los adjetivos justo, preciso y exacto aparecen, sobre todo, en complementos circunstanciales de tiempo y de lugar. También aportan focalización enfática, sobre todo, antepuestos a sustantivos como momento, lugar o instante. Por eso, Fuentes Rodríguez (2009, s.v. preciso, justo) incluye preciso y justo como operadores informativos de enfatización que indican precisión o exactitud referencial. Focalizan el sustantivo al que acompañan e indican precisión en el decir. Estos adjetivos aparecen, sobre todo, en sintagmas que funcionan como complementos circunstanciales de tiempo:

(49) Pero en el preciso instante en que Rosalba iba a decir esto cambió repentinamente de parecer, y salió vanagloriándose de que doña Ángela, en su desamparo, encontró un hogar en su casa, donde se quedaría a vivir definitivamente [...]. (Gabriel Casaccia, La Babosa, 1952)

(50) largo y angustiado, porque la negra noche del saloncito parecía mostrármelo todo. Y cuando, en ese justo momento, las espantadas chicas metían velas encendidas en el cuarto, ya estaba junto a él, porque había rastreado [...]. (Darío Fernández-Flórez, Lola, espejo oscuro, 1950) 
Estas colocaciones equivalen a formulaciones como en ese mismo momento. Como indica la interpretación 'en este mismo momento, ni antes ni después', justo y preciso mantienen su significado base de exactitud. Además, a veces también conllevan la interpretación de una coincidencia significativa: la acción ocurre precisamente en un momento o instante (in)oportuno. Coinciden, pues, con el valor más frecuente de los correspondientes adverbios: la focalización de exactitud o coincidencia en datos temporales y espaciales.

Para que estos adjetivos adopten un valor enfático, es crucial su posición respecto al sustantivo: generalmente, la anteposición del adjetivo al sustantivo suele aportar una actitud valorativa por parte del hablante (Martínez 2009, 1230) y, en general, a la expresión de subjetividad (Hummel 2013c, 65-66). Por tanto, los adjetivos que funcionan como operadores aparecen con más frecuencia antepuestos que pospuestos (Fuentes Rodríguez 2009, s.v. justo, preciso). De hecho, son varios los adjetivos antepuestos que se convierten en operadores: ciertos adjetivos calificativos como enorme, fundamental y absoluto intensifican el contenido del sustantivo, aportan más fuerza y lo focalizan informativamente (Fuentes Rodríguez 2013a). Según Fuentes Rodríguez (2013a, 78), enorme, profundo, absoluto, etc., siguen siendo adjetivos con función gramatical dentro de la oración, pero no solo enfatizan y focalizan el sustantivo al que modifican, sino que su efecto «llega también al propio hablante y a su discurso»: marcan que este se expresa de forma tajante y energética y que su argumentación es fuerte. Por lo tanto, en posición antepuesta adquieren funciones macroestructurales de focalización y se subjetivizan; esto es, pasan al plano de la macrosintaxis (Fuentes Rodríguez 2013a, 82). Asimismo, en el caso de justo y preciso como adjetivos antepuestos y operadores enfáticos, cabe interpretar que aportan fuerza al hablante y a su discurso, ya que lo marcan como rigurosamente exacto en los datos. Además, pueden inferir la valoración subjetiva de una coincidencia.

La Tabla 22 muestra el número de ocurrencias de las combinaciones entre los adjetivos de exactitud preciso, justo, exacto y cabal y los sustantivos momento e instante. Elegimos estos dos sustantivos por ser los más frecuentes tanto en nuestro corpus base como en los ejemplos mencionados en los diccionarios. Son, por lo tanto, los contextos más representativos para el uso de estos adjetivos como operadores. De los tres adjetivos, preciso es el que más frecuentemente se documenta en estas combinaciones, lo cual prueba su cohesión con el respectivo adverbio: precisamente también es el más frecuente del grupo adverbial.

En casi todas las combinaciones, la posposición es más frecuente que la anteposición. Solamente en preciso instante, la anteposición es más frecuente. Desde el punto de vista cronológico, la anteposición (preciso/justo momento) es más 
Tabla 22: Ante- y posposición de los adjetivos respecto a los sustantivos momento e instante; número de ocurrencias en el CDH y siglo de la primera documentación.

\begin{tabular}{|c|c|c|c|c|c|}
\hline \multirow{2}{*}{$\begin{array}{l}\text { Combinación léxica } \\
\text { momento preciso (XVI) }\end{array}$} & \multicolumn{2}{|c|}{$\begin{array}{l}\text { número de } \\
\text { ocurrencias } \\
\text { (según } \\
\text { posición/total) }\end{array}$} & \multirow{2}{*}{$\begin{array}{l}\text { Combinación léxica } \\
\text { instante preciso (XIX) }\end{array}$} & \multicolumn{2}{|c|}{$\begin{array}{l}\text { número de } \\
\text { ocurrencias } \\
\text { (según } \\
\text { posición/total) }\end{array}$} \\
\hline & 379 & 711 & & 84 & 365 \\
\hline preciso momento (XVIII) & 332 & & preciso instante $(\mathrm{XIX})$ & 281 & \\
\hline momento justo (XVIII) & 116 & 182 & instante justo (XX) & 17 & 23 \\
\hline justo momento (XX) & 16 & & justo instante (XX) & 6 & \\
\hline momento exacto $(\mathrm{XX})$ & 103 & 112 & instante exacto $(\mathrm{XX})$ & 12 & 14 \\
\hline exacto momento $(\mathrm{XX})$ & 9 & & exacto instante $(\mathrm{XX})$ & 2 & \\
\hline momento cabal (XIX) & 1 & 1 & instante cabal (XX) & 2 & 2 \\
\hline cabal momento & - & & cabal instante & - & \\
\hline
\end{tabular}

tardía que la posposición (momento preciso/justo), es decir, el valor de focalización aparece posteriormente al valor base.

La Tabla 23 muestra las mismas búsquedas para los sustantivos lugar y sitio. En general, el uso espacial es menos frecuente que el uso temporal. En este sentido, los adjetivos siguen las tendencias marcadas por los respectivos adverbios focalizadores. Sin embargo, llama la atención que exacto sea el adjetivo más frecuente en estos contextos. Aparece, sobre todo, pospuesto, es decir: no focaliza.

La búsqueda por estos patrones en el CDH muestra que el uso focalizador de exactitud o coincidencia es mucho más frecuente en preciso que en exacto y justo.

Tabla 23: Ante- y posposición respecto a los sustantivos lugar y sitio; número de ocurrencias en el CDH y siglo de la primera documentación.

\begin{tabular}{|c|c|c|c|c|c|}
\hline \multirow{2}{*}{$\begin{array}{l}\text { Combinación léxica } \\
\text { lugar preciso (XVII) }\end{array}$} & \multicolumn{2}{|c|}{$\begin{array}{l}\text { número de ocurrencias } \\
\text { (según posición/total) }\end{array}$} & \multirow{2}{*}{$\begin{array}{l}\text { Combinación } \\
\text { léxica }\end{array}$} & \multicolumn{2}{|c|}{$\begin{array}{l}\text { número de ocurrencias } \\
\text { (según posición/total) }\end{array}$} \\
\hline & 98 & 115 & & 40 & 43 \\
\hline preciso lugar (XVI) & 17 & & preciso sitio $(\mathrm{XX})$ & 3 & \\
\hline lugar justo (XX) & 17 & 42 & sitio justo (XX) & 16 & 25 \\
\hline justo lugar (XVII) & 25 & & justo sitio (XX) & 9 & \\
\hline lugar exacto (XVII) & 167 & 178 & sitio exacto $(\mathrm{XX})$ & 71 & 73 \\
\hline exacto lugar (XX) & 11 & & exacto sitio $(\mathrm{XX})$ & 2 & \\
\hline lugar cabal & - & - & sitio cabal & - & 1 \\
\hline cabal lugar & - & & cabal sitio $(\mathrm{XX})$ & 1 & \\
\hline
\end{tabular}


Probablemente, la baja frecuencia de justo en esta estructura (por ejemplo, en este justo momento) se debe a que, para la función focalizadora, justo también puede usarse como adverbio corto: justo en este momento. Seguramente, el énfasis sea mayor en esta última variante.

Veamos los valores semánticos de estas colocaciones. Por un lado, preciso y justo significan 'adecuado, apropiado, correcto, indicado' cuando aparecen en posición pospuesta:

(51) Y mandé á Tolomeo que lo retuviera hasta el momento preciso, y mandé á mi lugarteniente Licaón que se visti(e)se mis ropas y se pusiese mi corona sobre su cabeza; (Anónimo, Leyenda de Alejandro Magno, 1550)

(52) ¡El Tajo! ¡Agustín, el Tajo! El tajo fuerte -que dijo don Antonio-. El tajo que te dio ¿quién?, ¿el agua?, ¿tus manos?, ¿el asfalto? El lugar preciso en el momento justo. (Max Aub, La gallina ciega. Diario español, 1971)

Por otro lado, preciso, exacto y justo pospuestos significan también 'exacto, no aproximado'. No hay focalización, sino que delimitan la referencia y la extensión del sustantivo:

(53) En esta consideración pedí en diferentes ocasiones a los religiosos de la Charidad, que cuidan de el hospital de la Marina en Brest, que notassen con exactitud el momento preciso en que morían los enfermos. (Benito Jerónimo Feijoo, Suplemento de el Theatro crítico, o adiciones y correcciones a muchos de los assumptos, que se tratan en los ocho tomos de el dicho theatro IX, 1740)

(54) Después, Román no recordaría el momento exacto en que sin habérselo propuesto la cargó en peso, la llevó hasta la recámara, la depositó en el lecho aún revuelto, y sin cerrar la puerta la fue despertando [...]. (Enrique Jaramillo Levi, Luminoso tiempo gris, 2002)

(55) También le hizo conocer los lugares exactos donde a determinadas horas nos encontraría con seguridad, el malísimo armamento que teníamos y las voces y señales convenidas en los diferentes campamentos y puestos militares. (Manuel Argüello Mora, «El río Barranca», 1898)

Antepuestos a los sustantivos momento e instante, los adjetivos se documentan en el CDH a partir del siglo XVIII (preciso) y XX (justo y exacto). En estos ejemplos, son focalizadores de exactitud ('en ese mismo momento, ni antes ni después'). El momento es importante y se enfatiza porque coincide exactamente con otra acción simultánea:

(56) el navío de guerra San Francisco de Paula, pasó tan inmediato, que, a no haber obedecido el San José, en que yo iba, a la guiñada del timón (que mandó en el preciso momento 
su capitán Don Juan Barona, que salió apresuradamente de la cámara al alcázar), con la prontitud que pudiera hacerlo el mejor bote, se hubieran hecho pedazos ambos navíos. (Conde de Fernán Núñez [Carlos Gutiérrez de los Ríos],Vida de Carlos III, 1790)

(57) Por lo mismo, el Aconcagua, el regimiento más sediento del ejército, como que el nombre de su tierra parecería significarlo, llenaba en esos precisos momentos sus caramayolas en un estanque vecino, dejando arrimadas sus armas. (Benjamín Vicuña Mackenna, La campaña de Lima, 1881)

(58) Di un grito terrible, largo y angustiado, porque la negra noche del saloncito parecía mostrármelo todo. Y cuando, en ese justo momento, las espantadas chicas metían velas encendidas en el cuarto, ya estaba junto a él, porque había rastreado su cuerpo tendido, roto, en la oscuridad de mi espanto. (Darío Fernández Flórez, Lola, espejo oscuro, 1950)

(59) Se irguió, se contempló a sí mismo; del guerrero que era sólo quedaba un santo desnudo. Miró hacia lo alto, levantó el rostro hacia el horizonte y en ese exacto momento vio venir una flecha que cruzaba el ocaso derecho hacia él y, extendiendo los brazos a la vez que cerraba los ojos, expandió el pecho y la saeta... dio en el blanco. (Mauricio Puerta R., Astrología, un camino para regresar, 1994)

Tal y como observa Fuentes Rodríguez $(2006,1298)$ para el caso de preciso, este adjetivo antepuesto se combina necesariamente con el artículo definido o con otros deícticos, porque concreta la referencia ('este y no otro'), y no puede aparecer con un artículo indefinido ( ${ }^{\star}$ un preciso momento). Se trata de un adjetivo cercano a los determinantes (Fuentes Rodríguez 2006, §3.a). Efectivamente, los ejemplos citados muestran que los adjetivos de exactitud antepuestos se refieren siempre a un momento o a una localización concreta, definida.

En ocasiones, la focalización de un determinado momento desencadena la inferencia pragmática de una casualidad significativa. Los ejemplos que encontramos con esta función aparecen en el siglo XX:

(60) Pasada la Cuaresma, fué el bizco para oír la misa, y entró en el preciso momento que el sacerdote se volvía a los fieles, diciendo: -Dominus vobiscum.

Al oír esto el bizco, creyó que se dirigía a él, y salió huyendo disparao a contárselo a su hermano. (Marciano Curiel Merchán, Cuentos extremeños, 1944)

Aparte de la colocación frecuente con momento o instante, los adjetivos también enfatizan otros sustantivos que expresan una coincidencia en el tiempo:

(61) «Avellaneda y yo» dije, despacito. Ella no entendió el porqué de esas tres palabras en esa precisa oportunidad, pero alguna oscura intuición le hizo saber que estaba aconteciendo algo importante. (Mario Benedetti, La tregua, 1960) 
En exacto, el valor de coincidencia significativa es poco frecuente, pero se documenta a veces:

(62) Lo inverosímil fue la entrada de R. en el café en ese exacto momento, como si hubiese estado espiándolo y esperando el instante en que terminara de descifrar el hierograma. (Ernesto Sábato, Abaddón el exterminador, 1974)

Como operadores de focalización informativa en el dominio del tiempo y del lugar, los adjetivos justo y preciso tienden a la posición antepuesta al elemento focalizado; hay por lo tanto un cierto grado de fijación sintáctica. Por lo general, la anteposición de un adjetivo manifiesta especialmente el punto de vista subjetivo del hablante sobre la entidad; consiguientemente, Martínez $(2009,1314)$ opina que «la opción por la anteposición puede asimilarse a un proceso de subjetivización». Asimismo, Hummel $(2012,183)$ habla de «subjetivización por anteposición» de ciertos adjetivos.

A pesar de la preferencia por la anteposición, los adjetivos de focalización enfática mantienen su flexibilidad sintáctica. También pueden aparecer, aunque con menos frecuencia, pospuestos:

(63) ¡Has interrumpido tú mismo! Has sido tú mismo... quien ha dejado el auricular. Lo has dejado, ¡Dios mío!..., en el momento justo en que yo te decía, frente a frente y por primera vez, todo lo que cualquier hombre oye siempre con la atención suprema... Yo había pensado semanas y meses en ese momento, $\mathrm{y}$ todas las palabras me parecían pobres y sin color para expresar lo que sólo se puede expresar con el acento... (Enrique Jardiel Poncela, Las cinco advertencias de Satanás, 1935)

Como muestra este ejemplo, el efecto de subjetividad no solo surge en la anteposición, sino que ocasionalmente también se da en los adjetivos pospuestos. Deducimos, pues, que la subjetividad es un efecto contextual; es facilitado y propulsado por ciertos mecanismos sintácticos, pero siempre está sujeto al contexto del enunciado concreto.

En resumen, los adjetivos y adverbios de exactitud forman un paradigma pragmático como operadores de focalización de exactitud en datos espaciotemporales, con una diferenciación interna según sus funciones sintácticas y su posición:

adjetivo pospuesto: en aquel momento [justo/preciso/exacto/cabal]

adjetivo antepuesto: en ese [justo/preciso/?exacto/?cabal] momento

adverbio corto:

$\left[j u s t o /{ }^{\star}\right.$ preciso $/{ }^{\star}$ exacto $/{ }^{\star}$ cabal] en aquel momento

adverbio en -mente:

[justamente/precisamente/exactamente/cabalmente] en este momento 
Mientras que el uso del adjetivo pospuesto es general en todos los lexemas, el uso antepuesto solamente parece ser habitual en justo y preciso, ya que estos dos se usan como operadores de foco antepuestos al sustantivo. En exacto y cabal, la anteposición es marginal. En cuanto a los adverbios, venimos observando que solamente justo ha desarrollado un uso pleno como adverbio corto que modifica sintagmas. En esta función, justo coincide con los tres adverbios en -mente. Respecto a la cronología, el uso focalizador (tanto de exactitud como de coincidencia) se desarrolla primero en los adverbios (véanse los apartados anteriores) y pasa después a los adjetivos. Por tanto, son los adverbios en -mente los que desarrollan usos pragmáticos nuevos, que más tarde se expanden también a los adjetivos base.

Cuando aportan significados distintos, los adverbios y adjetivos pueden combinarse en una misma oración:

(64) Si los creyeras, dirías que la naturaleza humana hizo una prodigiosa e increíble crisis precisamente a los mil y setecientos años cabales de su nueva cronología. (José de Cadalso, Cartas Marruecas, 1774-1778)

(65) Y precisamente en el exacto momento histórico en que fuerzas políticas vascas entienden sin compartir la violencia etarra y buscan la oportunidad para apearse del tren del terrorismo se dan argumentos de brutalidad que pueden llegar a contrapesar una brutalidad de otro signo. (El País, 02/01/1981)

(66) Cuando todo es captado justo en el momento preciso no existe situación más divertida y entretenida que se le compare. (Recuperado de https://www.recreoviral.com/risa/ fotos-tomadas-momento-preciso/ el 18/02/2018)

En estos ejemplos, los adjetivos preciso, exacto y cabal expresan precisión minuciosa: 'exactamente mil setecientos años, ni más ni menos' y 'en ese mismo momento y no en otro'. Además, los adverbios precisamente y justo aportan una valoración subjetiva como focalizadores de coincidencia: el momento es llamativo, significativo o inoportuno.

\subsection{Otros tipos de focalización enfática de identidad}

El ámbito temporal parece ser el que origina el cambio de focalización de exactitud a coincidencia significativa, ya que es tanto el primer contexto de la focalización de exactitud en el caso de precisamente, justamente, justo y cabalmente, como del efecto inferido de coincidencia significativa. Además, entre los ejemplos analizados, sigue siendo uno de los contextos más frecuentes en los ejemplos actuales. 
La denominación «operadores informativos» de Fuentes Rodríguez (2009, s.v. exactamente, justamente, precisamente) apunta a que los operadores en cuestión realzan alguna información. Consideramos que la focalización enfática del tiempo y del espacio es un subtipo de la focalización enfática de informaciones. Dicho de otro modo, el tiempo y el espacio son la información prototípica que enfatizan los focalizadores analizados, pero la información enfatizada puede ser también de cualquier otro tipo. En las siguientes secciones analizaremos la focalización de informaciones no temporales o espaciales: comparaciones, argumentos, personas, etc. Hay una extensión de uso: la focalización se generaliza a cualquier información que pueda ser relevante y significativa para la interpretación del discurso. En este sentido, la denominación aserción enfática de identidad (König 1991, 125-127) indica que hay una identidad coincidente significativa entre dos informaciones o proposiciones.

En lo que sigue, analizaremos los distintos valores de la focalización enfática de informaciones que no sean de tiempo o espacio y analizaremos en qué usos se da una inferencia de coincidencia significativa (casual o no) y, si se da, qué tipo de valoración subjetiva aparece (oportuna o desfavorable). El análisis se divide en dos grupos:

a) Por un lado, exactamente se usa como adverbio de focalización informativa de exactitud. Como ya mencionamos anteriormente, la focalización de datos temporales o espaciales no es el primer contexto en el que exactamente desarrolla valores de focalización, sino que aparece en otro uso distinto: el de las comparaciones, como analizaremos en el siguiente apartado. Exactamente muestra un camino de evolución divergente y propio y solo acaba convergiendo parcialmente con los demás adverbios del grupo.

b) Por otro lado, el grupo precisamente, justamente, justo y cabalmente desarrolla valores pragmáticos distintos: sorpresa, casualidad desafortunada, contradicción, inversión de la argumentación, etc., así como valores discursivos a nivel textual.

\subsubsection{Exactamente (y exacto) como focalizadores de exactitud en construcciones comparativas}

La aparición del adverbio exactamente como focalizador de exactitud es más tardía que la de precisamente, justamente y justo. Según los ejemplos en la muestra base, durante los siglos XVI y XVII, exactamente solo modifica verbos y adjetivos y tiene un significado plenamente conceptual. En el siglo XVII, exactamente desarrolla el matiz semántico ‘igual, muy parecido’ como adverbio de modo de verbos de tipo imitar, parecer, etc. (véase apartado 3.4.3). A finales del 
siglo XVIII, finalmente aparece como modificador de sintagmas en estructuras comparativas:

(67) Los coches que vi en el paseo eran exactamente como los que se ven en el Prado de Madrid, ni mejores ni peores; pero aquí hay más luxo en materia de criados, no hay señorcillo que no lleve su par de lacayos [...]. (Leandro Fernández de Moratín, Viaje a Italia, 1793-1797)

(68) En la tabla de mármol que sirve de balaústre se ven, entre otras labores de capricho, dos cruces floreadas, exactamente iguales a las que pintan las Ordenes de Calatrava y Alcántara. (Gaspar Melchor de Jovellanos, «Diario de 1793», 1793)

En estos ejemplos, exactamente se antepone a segmentos que expresan comparación o semejanza, como el adjetivo igual o el adverbio como. Exactamente focaliza la información proporcionada y destaca que la correspondencia con otra información u otro elemento es exacta, correcta y cierta. Se opone a los adverbios de foco de aproximación (García Pérez 2013a, 360-386; Espinosa Elorza 2014, \$9.4.2.4): los coches eran casi como los que se ven en el Prado; aproximadamente iguales a las que pintan...

En este sentido, el primer uso de exactamente como adverbio focalizador no se da en contextos de números (es decir, como focalizador de datos temporales o espaciales, como precisamente, cabalmente y justamente), sino que aparece primero como focalizador de comparaciones.

Este uso encaja en la aserción enfática de identidad, emphatic assertion of identity (König 1991, 127), entre dos argumentos de dos proposiciones distintas. Así, en el primer ejemplo citado, exactamente enfatiza la semejanza entre los coches de Italia y los coches de Madrid; en el segundo ejemplo, la semejanza entre las cruces pintadas en una tabla y las cruces de las órdenes de Calatrava y Alcántara. En este sentido, exactamente focaliza la identidad de una cosa porque coincide con otra cosa igual o muy semejante. Además, hay focalización de exactitud, ya que la correspondencia o comparación se presenta como rigurosamente exacta, y no aproximada.

Otro contexto frecuente es la anteposición al sintagma lo mismo:

(69) Es el motivo de esta carta recordar que no hace muchos días cierto periódico, con cuyo nombre me sucede exactamente lo mismo que a Cervantes con el lugar de Argamasilla, según los más sabios comentadores, echaba en cara a los redactores del Mundo que no diesen la susodicha cara para escribir al público. (Mariano José de Larra, Fígaro a los redactores de El Mundo, 1836)

En este ejemplo, el hablante alude a que Argamasilla supuestamente era el famoso lugar de cuyo nombre Cervantes no quería acordarse. La comparación se 
basa, pues, en que Larra tampoco quiere acordarse del nombre de cierto periódico. Esa comparación, algo rebuscada, es enfatizada por exactamente.

Este uso está vinculado al valor semántico 'correcto, igual y fiel a la realidad', que es propio de exacto y exactamente cuando comparan dos cosas entre sí (una copia y su original, por ejemplo), como en la construcción ser exacto a ‘igual, muy parecido’ (apartado 3.4.3). El hecho de que la comparación es un uso muy frecuente de exacto/exactamente parece facilitar la aparición esporádica del adverbio corto exacto en esta misma estructura comparativa. Es el único uso de exacto como adverbio de foco:

(70) En cambio ahora hay que amurallarse tras tapias, barrotes y revólveres -exacto como en una cárcel- pues de lo contrario te desvalijan en cualquier momento. (Jaime Fernández Leandro, Ardiente Caribe, 2003, CORPES XXI)

También en oraciones que no presentan ningún elemento que exprese comparación (igual, lo mismo, como), exactamente focaliza una correspondencia exacta:

(71) No sólo de ese crimen, sino de ese otro repetido fantasmalmente en noches de insomnio en la celda, cuando se veía enterrándole a Santoro un cuchillo cocinero en la garganta. ¿Por qué el viejo le había cantado esa imagen? Exactamente la figura de su sueño. ¿Acaso la angustia en vez de confundir a los hombres los transforma en videntes? ¿Habían soñado la víctima y él, su verdugo, el mismo sueño? (Antonio Skármeta, El baile de la Victoria, 2003)

No hay ningún elemento explícito de comparación en el alcance de exactamente, pero del contexto se infiere que hay una correspondencia exacta entre la imagen que describió el viejo y la figura que se le apareció al hablante en su propio sueño. En otro segmento, se alude explícitamente a la comparación: el mismo sueño.

En algunos ejemplos, exactamente aparece modificado por casi, es decir, el parecido no es absoluto, pero muy aproximado:

(72) Siguiendo la sugerencia de Aguirre, leí asimismo a Trapiello, y en uno de sus libros descubrí que él también contaba la historia del fusilamiento de Sánchez Mazas, y casi exactamente en los mismos términos en que yo se la había oído contar a Ferlosio, salvo por el hecho de que, [...]. (Javier Cercas, Soldados de Salamina, 2001)

La focalización de exactitud de una comparación no es un uso exclusivo de exactamente (y exacto), ya que también aparece en los demás adverbios de exactitud:

(73) De cuánto se pueda callar en cinco años podráse formar una idea aproximada con sólo repasar por la memoria cuanto hemos callado nosotros, mis lectores y yo, en diez años, esto es, en dos cursos completos de Platón que hemos hecho pacientemente desde el 
año 23 hasta el 33 inclusive, de feliz recuerdo; en los cuales nos sucedía precisamente lo mismo que en la cátedra de Platón, a saber, que sólo hablaba el maestro, y eso para enseñar a callar a los demás, y perdónenos el filósofo griego la comparación. (Mariano José de Larra, «El siglo en blanco», 1834, Fígaro. Colección de artículos dramáticos, literarios y de costumbres)

Este ejemplo muestra que Mariano José de Larra usaba exactamente y precisamente como sinónimos en los mismos contextos (compárese con me sucede exactamente lo mismo que a Cervantes, ejemplo 69). Es decir, todavía en el siglo XIX, precisamente se usaba como simple focalizador de exactitud, no siempre conllevaba una interpretación subjetiva.

Como ya observamos, el uso de exactamente en oraciones subordinadas temporales (exactamente cuando...) es marginal y no aparece antes del siglo XX (véase apartado 5.2.2.1). En cambio, se antepone frecuentemente a oraciones subordinadas comparativas introducidas por la conjunción como (si). Este uso aparece ya en el siglo XIX:

(74) Salía de mi casa y llegaba al sitio crítico, haciendo cálculos estratégicos, meditando la maniobra más conveniente, la actitud más imponente, exactamente como si se tratara de una batalla en la que debiera batirme cuerpo a cuerpo. (Lucio Victorio Mansilla, Una excursión a los indios Ranqueles, 1870)

(75) Uno de esos episodios es el que describo aquí, exactamente como me lo refirió quien aseguraba haber sido testigo presencial del hecho. (Magón [Manuel González Zeledón], «El cañón de roble», 1897)

Por tanto, exactamente aumenta su alcance sintáctico en el contexto de las estructuras comparativas, cuando el adverbio como pasa a funcionar como conjunción (como si). Este uso se documenta, aunque mucho menos frecuente, también en otros adverbios de grupo:

(76) Ya creemos olvidado un deseo, ya no lo acoge nuestra piel, desde hace siglos que no cerca nuestra inteligencia, y vuelve un día como un milagro, justo como si irrumpiera en el primer momento en que lo deseamos. Extraña correspondencia la que existe entre los deseos y la seducción. (Ángeles Mastretta, El cielo de los leones, 2003)

Para cuantificar algunos de los usos prototípicos de la focalización enfática de identidad en comparaciones, lanzamos búsquedas específicas para los contextos relevantes en el CDH. Los resultados muestran que ciertos patrones, efectivamente, son mucho más frecuentes en exactamente que en los demás adverbios. En primer lugar, buscamos la posición antepuesta al adjetivo igual (como lema para incluir la forma plural y variantes ortográficas). Según muestra la Tabla 24, es un contexto prácticamente exclusivo del adverbio exactamente. En segundo lugar, buscamos 
la anteposición de los adverbios al sintagma lo mismo (forma) y, en tercer lugar, la anteposición a como si. ${ }^{10}$ También estas secuencias prefieren exactamente.

Tabla 24: Adverbios de foco en estructuras comparativas: frecuencia de [adverbio + igual (lema)], [adverbio + lo mismo] y [adverbio + como si] en el CDH (nuclear y extensiones).

\begin{tabular}{lrrrrr}
\hline & exactamente & precisamente & justamente & justo & cabalmente \\
\hline igual & 811 & 4 & 3 & - & - \\
lo mismo & 268 & 21 & - & 1 & - \\
como si & 25 & 2 & - & 1 & - \\
suma & 1104 & 27 & 3 & 2 & - \\
\hline
\end{tabular}

Exactamente también enfatiza la comparación entre cosas diametralmente opuestas:

(77) España, Italia y Grecia, debido a su alargada forma peninsular, limitan con el mar en la mayoría de sus territorios. Por esta razón, suena muy raro a la oreja de estos pueblos marineros descubrir que hay un país, Bolivia, que se dice mediterráneo exactamente por la razón opuesta, es decir porque ya no tiene salida al mar. (Los Tiempos, 08/04/1997)

En este ejemplo, se comparan dos usos del adjetivo mediterráneo que significa literalmente ‘que está en medio de tierra' (DLE 2014, s.v. mediterráneo). La oposición se presenta como cuantificable y medible de manera exacta. Se trata de dos significados opuestos e incompatibles.

Además, exactamente experimenta un desarrollo semántico peculiar a mediados del siglo XX. Enfatiza la locución dar igual/lo mismo, que expresa indiferencia:

(78) Jaime me pidió plata. Nunca lo había hecho antes. Le pregunté para qué la precisaba. «No puedo ni quiero decírtelo. Si querés me la prestás y si no guardátela. Me da exactamente lo mismo». (Juan José Arreola, Bestiario, 1959)

(79) Es muy evidente que hay dos alternativas en el Sur de Europa: una que se llama «eurocomunista», y otra que ha seguido el señor Cunhal, que no sé cómo llamarla. Me da exactamente igual. (Triunfo, 25/06/1977)

10 El recuento en la tabla se limita a la combinación [adverbio + como si], ya que la simple combinación con como arroja demasiados resultados no pertinentes (por ejemplo, adverbios de modo). Para excluir en la medida de lo posible resultados no correspondientes, elegimos la opción «grafía original». Así, quedan fuera resultados de tipo saber exactamente cómo. 
Nótese que, desde el punto de vista gramatical (pero no semántico), estas estructuras son comparativas. Sin embargo, no se trata de comparaciones, sino de usos idiomáticos de lo mismo e igual en combinación con el verbo dar. Para cuantificar este uso, buscamos ambas secuencias en combinación con el verbo dar (lema). Hay 13 registros de dar exactamente igual, y 7 registros de dar exactamente lo mismo y aparecen en la segunda mitad del siglo $\mathrm{XX}$. Al parecer, el uso idiomático figurado es minoritario frente a los más de 800 casos de exactamente igual y más de 260 casos de exactamente lo mismo con valor semántico literal.

Creemos que el uso enfatizador de exactamente en esta construcción idiomática es producto de un cruce entre dos estructuras: la colocación exactamente igual/exactamente lo mismo y las locuciones idiomáticas dar igual/dar lo mismo. Resumimos este desarrollo particular en tres etapas:

a) La altísima frecuencia de las secuencias exactamente igual y exactamente lo mismo refleja que estas se fijan como colocación. Indican exactitud rigurosa en comparaciones. Exactamente es un focalizador enfático de identidad y aparece en este contexto entre mediados del siglo XVIII e inicios del XIX.

b) Aparte, dar lo mismo y dar igual desarrollan un nuevo significado no transparente, como locuciones verbales idiomáticas que expresan indiferencia. En el $\mathrm{CDH}$, este uso ya está consolidado en la primera mitad del siglo XX.

c) Debido a la alta frecuencia de las colocaciones exactamente igual y exactamente lo mismo, el adverbio exactamente se «recicla» como enfatizador en la nueva estructura idiomática: da exactamente igual/lo mismo aparece en la segunda mitad del siglo XX.

Es el uso que más se aleja del significado originario de exactamente, ya que el valor conceptual semántico de exactitud se pierde por completo: me da exactamente igual no conserva rasgos de 'con exactitud, ni más ni menos'. Hay, por lo tanto, desemantización (semantic bleaching) y el adverbio adopta un significado puramente procedimental como focalizador enfático. No obstante, este cambio semántico no se puede localizar en el propio adverbio, sino en el uso idiomático de las frases dar igual y dar lo mismo. El uso puramente enfático de exactamente no se desarrolla gradualmente por inferencias, sino que ocurre en el momento en que exactamente se inserta en la expresión idiomática ya existente. Este desarrollo es propio de exactamente, no aparece en los demás adverbios de exactitud.

Al parecer, el uso puramente enfático de exactamente no queda restringido a la estructura idiomática dar igual/dar lo mismo, sino que se está extendiendo a 
contextos nuevos. Por ejemplo, cuando se antepone al adverbio nada, adopta un valor parecido a 'nada en absoluto' o 'literalmente nada':

(80) No pude ver la última cara del morón/mendigo/ladrón con su temible asimetría, y estaba contento. La Sra. Campbell dijo (por la primera y única vez en todo el viaje) exactamente nada y parecía ocupada en pasar cuenta mental de sus muchos regalos -los hechos por el hombre, no por Natura. (Guillermo Cabrera Infante, Tres tristes tigres, 1964-1967)

(81) Y yo en realidad no hacía nada. Exactamente nada. (Vicente Verdú, No Ficción, 2008, CORPES XXI)

En estos ejemplos, exactamente aporta solo énfasis, ya que una lectura de tipo ?ni más ni menos que nada es cuestionable. Tampoco funciona la focalización opuesta: \#aproximadamente nada. En un sentido estricto, el concepto nada no es graduable ni escalar. Creemos que exactamente nada subraya, sobre todo, la veracidad de nada y el hablante insiste en que nada se debe interpretar de manera literal. Igual que en el caso de los números redondos, pero no redondeados, quizás la enfatización de nada se debe a que este concepto generalmente no se usa en un sentido literal, sino que en el lenguaje común puede significar 'casi nada' o 'un poco'. En realidad, es físicamente imposible no estar haciendo absolutamente nada. Este uso enfatizador también es propio de exactamente, no aparece con justamente y en el caso de precisamente nada, siempre hay otro valor (de coincidencia significativa o negación).

\subsubsection{Exactamente como focalizador de exactitud en preguntas}

Es muy frecuente el uso de exactamente en preguntas:

(82) Hubo un interrogatorio. Mas, ¿cuáles fueron exactamente las preguntas? ¿El color de los ojos? A veces sí. A veces no. (Rafael Acevedo, Exquisito cadáver, 2001, CORPES XXI)

(83) No recuerda cómo, cuándo, qué fue exactamente lo que pasó. (Jacinta Escudos, «El hombre de las bofetadas», 2001, CORPES XXI)

En estas preguntas, el alcance del adverbio exactamente recae sobre el interrogativo (cuáles, cómo, cuándo, qué), que indica y reemplaza el elemento por el que se pregunta. Los interrogativos representan una información que el hablante conoce solo aproximadamente. Quiere conocer un dato más exacto y preciso. Así, en las correspondientes respuestas, el adverbio focalizaría igualmente el adverbio, demostrativo o sintagma por el que pregunta el interrogativo: 
Lo que pasó fue exactamente eso; fue exactamente así; fue exactamente a las cinco de la tarde. (compárese con ejemplo 83)

Los siguientes ejemplos muestran claramente que el alcance de exactamente en las preguntas es el interrogativo:

(84) Cuando la pequeña niña dice que Mimzy contiene un muy serio mensaje del futuro, un examen científico revela que Mimzy es en parte de un alto nivel de tecnología electrónica y parte orgánico. Todos se dan cuenta que están involucrados en algo increíble... pero ¿exactamente qué? («Desde la butaca. The last Mimzy». Washington Hispanic, washingtonhispanic.com, Washington D. C., 16/03/2007, CORPES XXI)

(85) todo era una mierda, que tenía cáncer, que le quedaba poco tiempo de vida. ¿Cuánto exactamente? Los calendarios médicos suelen ser inexactos: poco. (Alberto Barrera Tyszka, La enfermedad, 2006, CORPES XXI)

En el último ejemplo, exactamente aparecería en la respuesta correspondiente como focalizador de exactitud de la información por la que se preguntó:

Me quedan exactamente tres meses. (compárese con ejemplo 85)

Sin embargo, en muchos casos no se puede formular una respuesta correspondiente con el mismo adverbio:

(86) - Lucita, ¿qué nombre es exactamente?

-Pues Lucía. Lucía supongo que será. Sí. Siempre la hemos llamado de esa otra forma. 0 Luci a secas. (Rafael Sánchez Ferlosio, El Jarama, 1956)

Sería rara una afirmación de tipo ?Lucita es exactamente Lucía. Solamente podría formarse una oración comparativa de tipo Lucita es exactamente el mismo nombre que Lucía.

Exactamente también aparece como focalizador de exactitud enfático del interrogativo por qué, pero no podría aparecer en las correspondientes respuestas como focalizador de la oración causal ( ${ }^{\star}$ estás preso exactamente porque...):

(87) preguntándole sobre el Penal, sobre cómo serían las celdas, sobre si será cierto que se ve el cielo (él dice que sí, pero ella, a lo mejor es para que Graciela y yo no lloremos) y por qué exactamente estaba preso si tanto Graciela como él, el tío Rolando, aseguraban que era tan bueno y quería tanto a su patria. (Mario Benedetti, Primavera con una esquina rota, 1982)

Al parecer, exactamente aparece como elemento enfático en preguntas, pero no siempre puede aparecer en las correspondientes respuestas, ya que sus 
posibilidades distribucionales como adverbio de foco de exactitud son limitadas. Puede focalizar y tener en su alcance a todo tipo de elementos interrogativos, es decir, adverbios como por qué, cuándo, quién, pero no puede tener en su alcance a personas, o sea, nombres propios (tal y como analizaremos más adelante, en el apartado 5.3.4.1) ni oraciones subordinadas causales (véase apartado 5.3.5.1).

El uso como focalizador enfático de exactitud en preguntas es propio de exactamente y no se da con los demás adverbios del grupo. Por ejemplo, precisamente, ${ }^{11}$ no apunta al interrogativo, sino a una información significativa dentro de la pregunta:

(88) «¿Quién es ese hombre?

-Un soldado

Que entró poco hace en la regla

De San Francisco, cansado

Del servicio y de la guerra.

- ¿Y porqué precisamente

En tal ocasion lo deja,

Pudiendo darle fortunas

Estos tiempos de revueltas? (José Zorrilla, Recuerdos y fantasías, 1844)

El adverbio de foco precisamente no enfatiza el interrogativo porqué, sino que focaliza lo inoportuno y sorprendente del momento en el que ocurre la acción, es decir, focaliza el sintagma nominal que sigue: el soldado dejó la guerra precisamente en esta ocasión, precisamente cuando podía ganar una fortuna. Asimismo, justamente no aparece como adverbio de exactitud de refuerzo del elemento interrogativo, sino que focaliza una información sorprendente y significativa dentro de la pregunta:

(89) ¿Por qué, por qué justamente hoy, cuando es importante que descanse, por qué? (José Donoso, El obsceno pájaro de la noche, 1970)

11 En francés, es el adverbio précisément el que se usa en preguntas: «Avec précision, nettement : En quoi consiste précisément votre projet ?» (Larousse en línea). Al parecer, précisément conserva el valor originario de exactitud y precisión en francés, mientras que el español precisamente apenas se usa ya con su valor originario (sino como adverbio de coincidencia). Hay, por lo tanto, una evolución divergente entre francés y español: mientras que en español precisamente se generaliza como adverbio de coincidencia sorprendente, inesperada, en francés este valor se generaliza en justement (Bruxelles et al. 1982; Serça 1996; GómezJordana 2012). 


\subsubsection{Focalización (de exactitud o coincidencia) de cualquier dato contable}

Cualquier información escalar y gradual o, más concretamente, cualquier información contable y cuantificable puede aparecer enfatizada por un adverbio de foco. Así, cualquier sintagma nominal encabezado por un numeral puede ser focalizado. Los valores pragmáticos son paralelos a los que observamos en la focalización de datos temporales o espaciales. Así, exactamente enfatiza, de nuevo, el número exacto y correcto de una información:

(90) Esta vez me metí en un café; conseguí una mesa junto a la ventana. En un lapso de una hora y cuarto, pasaron exactamente treinta y cinco mujeres de interés. Para entretenerme hice una estadística sobre qué me gustaba más en cada una de ellas. (Juan José Arreola, Bestiario, 1959)

El adverbio de foco enfatiza la exactitud rigurosa del número ('treinta y cinco, ni más ni menos'). Hay, al igual que en la focalización de datos temporales, una razón especial por la que el hablante se acuerda perfectamente de un número minuciosamente exacto y lo enfatiza: prestó especial atención contando el número de mujeres que pasaron por el café.

Asimismo, justo y justamente mantienen su uso como focalizadores de exactitud de un número preciso que encabeza un sintagma nominal:

(91) En su primer lustro, las Naciones Unidas admitieron como nuevos Miembros a 9 Estados, de los cuales justamente dos tercios fueron países afroasiáticos, y el tercio restante naciones más bien neutralistas, aunque occidentales dos de ellas, al menos. (Luis García Arias, La guerra moderna y la organización internacional, 1962)

(92) Las posibilidades de que sean rechazados los nombres son bajas, porque quienes pactaron la reforma, la Concertación y RN, cuentan con 21 y 11 escaños: justo 32 votos para encauzar el proceso. (Revista Hoy, 05-11/01/1998)

En cambio, en precisamente las inferencias pragmáticas van más allá de la exactitud, ya que a los números focalizados se les intenta buscar alguna interpretación significativa, como revela este ejemplo, ya del siglo XVIII, que cuestiona la utilidad de las reglas del teatro clásico:

(93) ¿por qué no podrá significar un espacio de tres o cuatro horas, que también es parte del giro solar? ¿Y por qué ha de ser este período precisamente de doce horas y no de menos? Si algún poeta hiciese una comedia con la más exacta verisimilitud, reduciendo la fábula al espacio de tres o cuatro horas, cuantas suele durar la representación, [...]

a fin de que ni deje poco satisfechos a los oyentes por lo breve, ni los canse por lo prolijo; porque cuanto a lo demás, no alcanzo razón alguna por la cual hayan de ser los actos precisamente cinco y no tres. (Ignacio de Luzán, La poética o reglas de la poesía en general y de sus principales especies, 1737-1754) 
En este ejemplo, las alternativas excluidas aparecen de manera explícita: menos de doce horas, tres actos. El propio autor se pregunta la razón por la cual el número cinco es mejor que el número tres. Asimismo, en el siguiente ejemplo, precisamente indica una interpretación del número tres como significativo: eran demasiadas.

(94) [...] las tres mujeres que había amado mil años atrás en Madrid [...] ¡Ah!, sus tres muchachitas, por qué las había abandonado. Bueno, tal vez por eso, porque eran precisamente tres, dos no habría estado mal, pero los líos en que se andaba metiendo... (Alfredo Bryce Echenique, La vida exagerada de Martín Romaña, 1981)

\subsubsection{Focalización enfática de identidad en construcciones copulativas}

A partir del siglo XVIII, precisamente, justamente y cabalmente extienden su uso enfatizador a nuevos contextos. Por ejemplo, inciden sobre un sintagma nominal no precedido por un numeral. La focalización de identidad en justamente y precisamente, en principio, enfatiza la identificación de un fenómeno o de un determinado comportamiento:

(95) Todo el conjunto de luces que prestan las ciencias auxiliares a la teórica de la medicina en el estado de los actuales conocimientos, es justamente lo que debe adornar al catedrático para ir preparando a los discípulos, por sus lecciones especulativas, al fin último de la medicina práctica. (José Celestino Mutis, «Al Virrey don Pedro Mendinueta», 1799)

(96) La tarea, pues, del traductor no es tan fácil como a todos les parece, y por eso es tan difícil hallar buenos traductores; porque cuando un hombre se halla con los elementos para serlo bueno, es raro que quiera invertir tanto trabajo sólo en hacer resaltar la gloria de otro. Entonces es preciso que sea muy perezoso para no inventar, o que su país tenga establecida muy poca diferencia entre el premio de una obra original y el de una traducción, que es precisamente lo que entre nosotros sucede. (Mariano José de Larra, «De las traducciones», 1836)

En los dos ejemplos que acabamos de citar, hay un verbo copulativo (es) que vincula un sujeto con un atributo; hay una identificación entre dos elementos. Según López Samaniego $(2007,59)$, las estructuras enfáticas de tipo esto/eso es lo $q u e . .$. son «oraciones copulativas identificativas»; la NGLE las llama «copulativas enfáticas de relativo» $(2009,3020)$. La información destacada por esta estructura coincide de manera exacta con algo dicho anteriormente: es exactamente este hecho $-\mathrm{y}$ no cualquier otro hecho alternativo- el que se identifica como significativo e importante. 
La estructura copulativa de relieve, en ocasiones, no solo enfatiza una información, sino que aporta también una valoración subjetiva, como en este ejemplo de cabalmente del siglo XVIII:

(97) - No es desquite, milord, sino tomar el mismo tono de franqueza que debe concederme la vuestra.

-Eso es cabalmente lo que me agrada: hombre franco, hombre de bien.

[...]

¡Dios inmortal! ¿Es sueño lo que me pasa o devaneo de mi imaginación? ¿La mayor prueba de mi amor para con vos, ha de ser cabalmente la más contraria? (Pedro Montengón, Eusebio, 1786)

En el primer caso, del contexto se infiere una valoración positiva, de agrado o incluso elogio, mientras que, en el segundo uso, la valoración subjetiva que aporta cabalmente es claramente negativa; indica una contradicción penosa. Como indican estos dos ejemplos en un mismo texto, la valoración subjetiva concreta siempre depende del contexto. Igual que en el caso de la focalización de informaciones espaciotemporales, los adverbios no codifican cuál es la valoración subjetiva intencionada.

Además, el ejemplo Eso es cabalmente lo que me agrada muestra el uso típico de expresiones anafóricas. En estructuras de relieve de tipo [esto/eso + ser + adverbio de foco + lo que], los demostrativos esto o eso apuntan anafóricamente a un elemento anterior, y este elemento se identifica con una nueva información que se presenta como importante y relevante. Como observa König (1991, 127-128), la aserción enfática de identidad entre dos elementos coincidentes ocurre con frecuencia en oraciones complejas (subordinadas, relativas) en las cuales se apunta al antecedente y en las cuales pronombres demostrativos y expresiones anafóricas expresan identidad referencial entre dos entidades. Esa identidad es enfatizada por el focalizador. Asimismo, López Samaniego $(2007,54)$ llama la atención sobre el hecho de que la relación de coincidencia entre dos elementos discursivos, destacada por los focalizadores precisamente y justamente, se refuerza frecuentemente también por expresiones anafóricas.

En este tipo de ejemplos, el alcance del adverbio de foco parece coincidir con el foco de la estructura informativa de la oración: mientras que el elemento anafórico (eso, esto) remite a la información presupuesta (el tema), el segmento focalizado representa la información nueva, el rema. Por lo general, las oraciones escindidas (cleft) separan la oración en trasfondo y foco (Heidinger 2018, 60-63). 
En el caso de precisamente, predomina la valoración subjetiva negativa:

(98) Tampoco apruebo los acasos de la música, que entreteje su canto con la representación tan a tiempo, que precisamente el verso que se canta es el que le tocaba decir al representante para concluir el concepto de unas décimas o coplas. (Ignacio de Luzán, La poética o reglas de la poesía en general y de sus principales especies, 1737-1754)

En este ejemplo, el verso que se canta es el mismo verso que le tocaba decir al representante. Mediante el adverbio, se focaliza la identidad entre ambos versos. Precisamente como adverbio de focalización enfática de identidad conlleva una valoración subjetiva, en este caso, negativa: la coincidencia es inapropiada.

Asimismo, en el siguiente ejemplo se enfatiza la desnudez de los indígenas filipinos, que para el autor es escandalosa, despreciable e indecente. Hay, por lo tanto, un valor subjetivo negativo en la aserción enfática de identidad entre el vestido y el que les dio la naturaleza:

(99) Los naturales, en su gentilidad, no conocían el fuego, ni otro calor que el que les subministraba el sol; y así el pescado y todo lo demás lo comían crudo, y lo restante dejaban el sol, para que se pusiese algo más tratable. El vestido era precisamente el que les dió la naturaleza, sin usar para la decencia, ni aun de las hojas de los árboles; aun ahora en sus casas, sementeras y en sus viajes usan del mismo traje. Y lo que causa admiración es que siendo gente tan miserable, desnuda é inútil para todo, sea tal su altivez y soberbia, que pienso no habrá en el mundo otros semejantes. (Juan José Delgado, Historia general sacro-profana, política y natural de las islas del Poniente llamadas Filipinas, 1754)

Hay alternativas que se mencionan explícitamente (las hojas de los árboles), pero los indígenas optan por no llevar vestido ninguno -la alternativa más chocante para este autor-. Podemos suponer, de acuerdo con la Teoría de la Argumentación (Anscombre/Ducrot 1994), que existe un topos (estereotipo o tópico) cultural compartido por la sociedad del siglo XVIII: <cuánto más tapado, mejor>, es decir, cuanta menos carne se enseña, más decencia y civilización muestra un individuo. Las diversas alternativas se ordenan en una escala gradual, desde la desnudez pasando por hojas de árboles a vestimentas cada vez más cerradas y decentes. De todo el continuo, los indígenas filipinos se encuentran en el extremo absoluto de la escala.

En el siguiente ejemplo, el hablante destaca y critica la contradicción que hay en la actitud de determinadas personas, desenmascarando un comportamiento hipócrita: las personas que critican los castigos y suplicios en la religión musulmana, al mismo tiempo, los defienden para el Santo Oficio:

(100) ¿Con que teníais por seguro que la Religion aprobaba las maldades del Santo Oficio? ¡Ah! guardaos, hijo mio, de pensar de ese modo, porque es indubitable que una secta que para hacer prosélitos, ó que para conservar los que tiene, recurre á los castigos y suplicios, 
tiene contra sí unos titulos muy sospechosos; y esto es precisamente lo que reprochábamos nosotros á Mahoma. Una Religion, le decíamos, que permite al hombre el forzar la creencia del hombre, es una religion falsa. (Luis Gutiérrez, Cornelia Bororquia. Historia verídica de la Judith española, 1799)

Dos comportamientos opuestos en dos proposiciones distintas coinciden, por lo tanto, en un mismo grupo de personas. La estructura sintáctica de relieve pone de manifiesto la identificación entre estas dos proposiciones. El adverbio precisamente aporta énfasis y una valoración subjetiva (negativa, en este caso) sobre la identidad del elemento enfatizado, es decir, sobre esta identificación entre dos proposiciones.

En el siguiente ejemplo, precisamente también enfatiza una valoración subjetiva negativa. Es una crítica que alude a la leyenda negra que se estaba propagando en el resto de Europa:

(101) Acabo de leer algo de lo escrito por los europeos no españoles acerca de la conquista de la América. Si del lado de los españoles no se oye sino religión, heroísmo, vasallaje y otras voces dignas de respeto, del lado de los extranjeros no suenan sino codicia, tiranía, perfidia y otras no menos espantosas. [...] los pueblos que tanto vocean la crueldad de los españoles en América son precisamente los mismos que van a las costas de África; compran animales racionales de ambos sexos a sus padres, hermanos, amigos, guerreros victoriosos, sin más derecho que ser los compradores blancos y los comprados negros; los embarcan como brutos; los llevan millares de leguas desnudos, hambrientos y sedientos; los desembarcan en América; los venden en público mercado como jumentos, [...] toman el dinero; se lo llevan a sus humanísimos países, y con el producto de esta venta imprimen libros llenos de elegantes inventivas, retóricos insultos y elocuentes injurias contra Hernán Cortés por lo que hizo; (José de Cadalso, Cartas Marruecas, 1774-1778)

El adverbio focaliza la identificación de un grupo de personas (probablemente, alude a franceses e ingleses) en dos proposiciones distintas:

«critican la crueldad de los españoles contra los indígenas americanos»

«son crueles contra sus esclavos negros africanos»

Son dos proposiciones opuestas, adversativas e incoherentes: ser cruel, pero al mismo tiempo criticar la crueldad de otros. Mediante la focalización de identidad, se pretende desenmascarar este comportamiento hipócrita. En este ejemplo, el valor semántico de exactitud todavía es transparente, ya que un colectivo es identificado exactamente con otro colectivo. Hay una coincidencia exacta entre varias personas en dos proposiciones distintas. No obstante, la interpretación que insinúa precisamente va más allá de una simple correspondencia exacta: hay una interpretación concesiva o adversativa entre dos proposiciones opuestas, que normalmente se excluyen mutuamente. Lo llamativo no está en la exactitud 
con la que se delimita un grupo de personas, sino en la interpretación adversativa entre las dos proposiciones.

Como muestran los ejemplos citados, la focalización enfática conlleva frecuentemente una disonancia o incongruencia entre la eventualidad denotada en la oración y una eventualidad dada por el contexto o mencionada explícitamente (König 1991, 134-135). La información focalizada se presenta como la menos adecuada y apropiada entre todas las posibles variantes. Hay una contradicción o paradoja, cuando coinciden dos proposiciones valoradas como incompatibles.

La tendencia a combinar la aserción enfática de identidad con una interpretación adversativa o concesiva se puede explicar mediante mecanismos pragmáticos generales y concretamente mediante el principio comunicativo de cooperación de Grice (1975), según explica König (1991, 133). La aserción enfática de identidad entre dos entidades por lo general sobra y no tiene importancia. Sin embargo, cuando se unen dos proposiciones que generalmente no aparecen conjuntas, la aserción enfática de identidad sí que cobra importancia. El oyente tiene que ampliar el contenido informativo del mensaje, ya que, según las máximas conversacionales de cantidad, de relevancia y de manera, si el hablante enfatiza algo tan obvio como la identidad entre dos elementos, tiene que haber alguna interpretación significativa más allá de la simple identificación. Para encontrar la información adicional, el oyente se basa en suposiciones estereotípicas de lo que suele ir junto y lo que no. Consecuentemente, las implicaturas adversativas o concesivas son «standard interpretative enrichments» (König 1991, 133).

En este sentido, la identidad o coincidencia entre las dos proposiciones distintas en los ejemplos citados es obvia, ya que se sobreentiende por el contexto o se expresa explícitamente; por ejemplo, el adjetivo mismo en los mismos que (véase ejemplo 98) o por estructuras anafóricas como esto es lo que (véase ejemplo 97). Consiguientemente, cuando precisamente focaliza la identidad de algo que es obvio o que ya se expresa mediante otros recursos, tiene que haber un valor añadido. Precisamente muestra un enriquecimiento interpretativo, ya que añade una valoración subjetiva sobre lo dicho, que por lo general suele ser una crítica o un rechazo de una contradicción absurda o incoherente.

Estos ejemplos se documentan con precisamente, cabalmente y justamente a partir del siglo XVIII. El adverbio justo también se inserta en este grupo, pero no se documenta hasta el siglo XX como focalizador enfático de identidad. Puede aportar una valoración subjetiva tanto negativa como positiva:

(102) -Va a haber protestas en el extranjero, justo lo que no conviene al régimen - dijo el coronel Espina-. ¿No sabías que el Presidente quiere evitar líos? (Mario Vargas Llosa, Conversación en la catedral, 1969) 
(103) El de «siga usted siempre, señorita Montalvo» es un siempre recién cortado, vitamina fresca, ya me está haciendo efecto hace un rato, por eso se me han saltado las lágrimas. Era justo lo que necesitaba oír. ¡Qué alivio más fulminante! (Carmen Martín Gaite, Nubosidad variable, 1992)

En cambio, exactamente se documenta por primera vez en el siglo XIX en la estructura copulativa de relieve. No aporta ninguna valoración subjetiva, sino que presenta la comparación entre dos hechos como una observación exacta y objetiva:

(104) ya no es difícil entender con claridad lo que dice y lo que no dice, lo que oculta y lo que expresa, lo que quiso decir y lo que quisiéramos que hubiese dicho. Esto es exactamente lo que sucede con la carta del Madrileño que ha tenido la desgracia de disgustar a tantas señorías y excelencias. (Sebastián de Miñano, Sátiras y panfletos del Trienio Constitucional, 1820-1823)

Asimismo, exactamente enfatiza la exactitud de una información. En el siguiente ejemplo, el personaje destaca como rigurosamente exacta y correcta la correspondencia entre la descripción de un hombre y lo que ha visto:

(105) -Diga usted; el que montaba el caballo castaño, ¿era uno pequeño, moreno, con algunas canas y hoyoso de viruelas?

-Si, señor; exactamente esas son sus señas. (Julián Zugasti y Sáenz, El Bandolerismo. Estudio social y memorias históricas, 1876-1880)

En el siguiente ejemplo, exactamente focaliza la exactitud de la información a la que remite este adverbio así. Además, la exactitud rigurosa, casi literal, de la descripción se refuerza por la expresión fraseológica sin quitar ni poner ápice:

(106) Por fuera me suelen acusar de que soy rebuscado y exagerado, y tú habrás notado que ya yo hablo muy poco. ¿Qué culpa tengo yo de que sea así mi naturaleza, y de que al influjo de tu cariño enseñe todas sus flores? [...] Así exactamente, y sin quitar ni poner ápice, era como sentía y hablaba Juan Jerez. (José Martí, Lucía Jerez, 1885)

Como muestran los tres ejemplos citados, exactamente enfatiza principalmente que la información emitida es rigurosamente exacta, correcta y adecuada, se corresponde exactamente con la realidad o con otra proposición anterior. Conserva, pues, el matiz comparativo (véase apartado 5.3.1). Es decir, la focalización de identidad enfatiza la correspondencia absoluta entre dos informaciones. Al 
contrario de los demás adverbios de focalización, exactamente no parece aportar una valoración subjetiva de ningún tipo, sino que enfatiza la exactitud absoluta y la precisión minuciosa. No se trata de una identificación curiosa, sorprendente, desagradable, etc., sino de una identificación exacta.

Así, en el siguiente ejemplo, precisamente, justamente o justo probablemente aportarían una valoración más bien subjetiva (de ironía o casualidad oportuna), mientras que la interpretación de la oración es estrictamente literal con exactamente, que refuerza y enfatiza que esto realmente era lo que necesitaba el personaje:

(107) Germánico terminó su desayuno bruscamente y decidió buscar a Yiorgos. Un émpata joven, autodestructivo y drogadicto era exactamente lo que necesitaba ahora. (Alexánder Obando Bolaños, El más violento paraíso, 2001)

En resumen, la focalización enfática de identidad se da en todos los adverbios del grupo. Aparece, sobre todo, en oraciones copulativas y estructuras de relieve sintáctico, ocasionalmente con algún elemento anafórico que apunta a una información anterior que se identifica con la información focalizada por los adverbios. En este sentido, los adverbios focalizan la coincidencia entre dos proposiciones. Los valores pragmáticos que aporta el adverbio de foco son inferidos del contexto y del conocimiento extralingüístico, ya que dependen de si las dos proposiciones son, por ejemplo, incompatibles o disonantes. Mientras que exactamente focaliza una correspondencia o identificación exacta, literal y absoluta, los demás adverbios suelen aportar, además, una valoración subjetiva, tanto positiva como negativa. Sobre todo, precisamente presenta la coincidencia como inoportuna, contradictoria o paradójica.

Para cuantificar este uso, recurrimos a la secuencia de búsqueda [ser + adverbio de foco + lo que], ya que este patrón específico coincide plenamente con el uso que nos interesa; no hay ambigüedad con otros usos adverbiales como, por ejemplo, adverbios de modo. Buscamos ser como lema (para abarcar todas las variantes: era, es, fue, soy, etc.) y también lo como lema, que incluye las formas la, los y las. Así, esta secuencia de búsqueda arroja todo tipo de variantes de la construcción: fue precisamente la que, soy justo lo que, es exactamente lo que, son justamente los que, etc. En el caso de justo descontamos manualmente los resultados en los que ser justo lo que remite al uso del adjetivo justo ${ }_{1}$ 'según la justicia'.

Según muestra la Tabla 25, precisamente predomina también en este patrón; es con diferencia el adverbio más usado en la construcción copulativa de relieve, aunque su aparición cronológica es paralela a justamente y cabalmente: los tres adverbios se documentan por primera vez en el siglo XVIII en esta construcción. 
Tabla 25: Frecuencia de la construcción [ser (lema) + adverbio + lo que] en el CDH (nuclear y extensiones).

\begin{tabular}{lcl}
\hline precisamente & 414 casos & desde el siglo XVIII \\
\hline justamente & 103 casos & desde el siglo XVIII \\
\hline cabalmente & 28 casos & desde el siglo XVIII hasta 1930 \\
\hline exactamente & 170 casos & desde el siglo XIX \\
\hline justo & 32 casos & desde el siglo XX \\
\hline
\end{tabular}

Cabalmente cae en desuso a principios del XX. Exactamente, a pesar de su aparición más tardía, se usa incluso con más frecuencia que justamente, aunque con un valor distinto. Por último, el adverbio corto justo es el más tardío, pero adopta los valores subjetivos de precisamente, justamente y cabalmente.

\subsubsection{Focalización enfática de la identidad de una persona}

Los adverbios de foco que analizamos también inciden sobre sintagmas cuyo referente es una persona. En estos casos, el alcance del adverbio suele ser el sujeto u objeto de la oración, o el atributo de una construcción copulativa de relieve. Consideramos que se trata de un subtipo particular de la focalización enfática de identidad: en este caso, la identidad destacada es la de una persona.

En la segunda mitad del siglo XVIII, justamente aparece como focalizador que infiere una coincidencia significativa cuando incide sobre sintagmas nominales que refieren a personas. En el siguiente ejemplo, que reproduce una conversación entre las vecinas y una mujer que ha venido porque quiere ver una casa para alquilarla, justamente marca lo oportuno de la aparición de la persona adecuada:

(108) JOAQUINA. Por verla nada se pierde.

¿Bartolo?, ten aquí cuenta

y arrecoge luego el puesto.

PACA. Justamente ese que llega

es el casero. (Ramón De La Cruz, Las bellas vecinas, 1767)

Hay una coincidencia significativa, una aserción enfática de identidad o identificación oportuna: se ve llegar una persona y esa persona es el mismísimo casero. Los adverbios de foco también excluyen alternativas implícitas cuando focalizan personas: no llega una persona cualquiera, sino las más indicada para la situa- 
ción. Las alternativas (esto es, las demás personas) se ordenan, por lo tanto, en una escala de más a menos oportuno.

Esto se ve aún más claro en el siguiente ejemplo, en el que Leonor pregunta por qué Martín se compara precisamente con los señores Mendoza y Valencia (alternativas más significativas), y no con Agustín (alternativa menos significativa):

(109) -Señorita - repuso Martín-, yo me coloco en la posición que usted parece querer señalarme, porque aún estoy lejos de tener una alta idea de mi importancia social.

- ¿Se compara usted con alguien que le parezca muy superior?

-Con esos caballeros que vienen hacia nosotros, por ejemplo.

- ¿Con Agustín?

-No, señorita, con los otros, con los señores Mendoza y Valencia.

- ¿Y por qué con ellos precisamente? - preguntó Leonor, con una ligera turbación que disimuló con maestría.

-Porque ellos, por su posición, pueden aspirar a lo que yo no me atrevería. (Alberto Blest Gana, Martín Rivas. Novela de costumbres político-sociales, 1862-1875)

La elección de estas dos personas no es casual, sino intencionada, como explica el mismo Martín. Además, la pregunta de Leonor parece insinuar otra interpretación significativa más secreta y disimulada (preguntó Leonor, con una ligera turbación que disimuló con maestría): también en una escala mental secreta (¿emocional?) de Leonor, los señores Mendoza y Valencia son las alternativas más significativas.

La misma interpretación se observa en el siguiente ejemplo de justo como adverbio de foco antepuesto a un nombre propio - en este caso, no de una persona, sino de un club atlético-:

(110) - No sé, pero creo que hoy me gané definitivamente el cariño de la hinchada de Danubio. Porque fue una victoria con un fútbol espectacular.

-Que fuera justo Peñarol el que estaba enfrente, ¿tuvo algún significado para usted?

-Todo el mundo sabe que soy hincha de Peñarol, allí me formé y soy muy agradecido al club, pero trabajo en Danubio y me debo a Danubio. Y si hay algo que nadie me puede cuestionar es que soy un excelente profesional en todo lo que hago. (Silvia Pérez, «Gustavo Matosas: «Los jugadores se recibieron de cracks con letras de oro»». El País digital, elpais.com.uy, Montevideo, 11/12/2006, CORPES XXI)

Justo insinúa que podría haber una interpretación significativa, aunque en la respuesta se niega y rechaza tal interpretación. El adverbio de foco revela una presuposición del entrevistador, quien da por supuesto que la presencia de este club de fútbol en particular sería especialmente comprometedora para su entrevistado. Supuestamente, sería la alternativa más significativa. 
A veces, las alternativas se mencionan explícitamente. Por ejemplo, entre todos los hombres del mundo abre un conjunto de alternativas muy amplio, lo cual destaca aún más lo (estadísticamente) improbable y sorprendente del suceso:

(111) La respuesta me sobresalta, me duele. ¿Mauricio? ¿Justamente Mauricio, entre todos los hombres del mundo, se suicidó? (Ana María Shua, Historias verdaderas, 2004, CORPES XXI)

La alternativa focalizada se sitúa, de nuevo, en la posición más alta de una escala de alternativas (aquí: personas) más o menos significativas. Como muestra este ejemplo, la valoración (sorpresa inesperada, en este caso) que aporta el adverbio de foco es sumamente subjetiva: lo que para unos podría parecer totalmente sorprendente - el suicidio de Mauricio-, para otros quizás sería esperable. Consiguientemente, el valor subjetivo insinuado por la focalización enfática de identidad se basa en una escala puramente subjetiva.

Este uso también se documenta en cabalmente en el siglo XIX. De todas las alternativas (mujeres, en este caso), destaca la más significativa y la valoración subjetiva es negativa. Es una crítica o queja:

(112) La mujer a que se ama es cabalmente la mujer a quien menos se le dice. (Santa Catalina, 1876, citado en el DHLE [1933-1936, s.v. cabalmente])

Asimismo, precisamente aporta una valoración subjetiva de contradicción sorprendente:

(113) - ¿ ¿Te das cuenta? No sabemos nada de él. Ni de su pasado ni de sus propósitos. [...] -Sabes, Marcos, es posible que tengas razón. Y que hayas apuntado al núcleo del problema. Porque se da la paradoja que la persona más visible es precisamente la persona de quien menos se sabe. (Juan Ramón Zaragoza, Concerto Grosso, 1981)

En este ejemplo, podemos suponer un topos general <cuanto más presente está alguien, más se sabe sobre él>; es decir, a mayor presencia, mayor conocimiento. El adverbio de foco llama la atención sobre el hecho de que se incumple tal topos.

En los ejemplos que acabamos de citar, los adverbios de foco enfatizan una contradicción paradójica. Como observa König (1991, 131-132), la aserción enfática de identidad en ocasiones implica disonancia o incompatibilidad; las dos proposiciones generalmente no ocurren juntas, sino que normalmente son adversativas. Hay, pues, focalización de identidad coincidente entre dos cosas normal- 
mente incompatibles (König 1991, 131-132). En el siguiente ejemplo, justamente focaliza una contradicción curiosa en la denominación criada de adentro:

(114) La criada de adentro (llamada así porque justamente son las que más tiempo pasan afuera) salió muy de mañana a atravesar una buena carretada de leña a la entrada [...]. (Magón [Manuel González Zeledón], «El principio de autoridad», La propia y otros cuentos, 1911)

Los conceptos adentro y afuera son incompatibles. El adverbio de foco llama la atención sobre esta identificación sorprendente, absurda, y le aporta un valor irónico.

Una coincidencia desafortunada parecida se observa en el siguiente ejemplo:

(115) Para conseguir que ellas modificaran sus conductas agresivas desatadas durante una fiesta, ese hermano apela a la desdicha que le provocan esas mujeres; para ello grita (por primera vez): «Justamente, las tres personas que más amo se odian entre sí» (su esposa, su hermana y su sobrina). (Clarín, 12/03/1997 [Argentina])

En este ejemplo, las tres personas que más amo debería ser incompatible con el hecho de que se odian entre sí. Hay una incongruencia, una coincidencia desafortunada entre amor y odio.

En el siguiente ejemplo, la expresión de sorpresa es reforzada por la modalidad deóntica (tenía que ser) y, además, por la expresión de focalización mira por donde (Fuentes Rodríguez 2016, 882):

(116) y en el Ministerio, júbilo, felicitaciones y, como es de cajón, esto que aquí ves (Señala la banda.), y mira por donde tenía que ser justamente mi mujer quien viniese a decirme que, a su juicio, se habían excedido y que la Banda de Honor Agrícola debe ser algo muy tirado cuando me la han dado a mí sola y exclusivamente por lo de la uva de Almería. (J. Calvo Sotelo, Una muchachita de Valladolid. Comedia en dos partes, 1993, CREA, citado en Fuentes Rodríguez [2016, 882])

De todas las personas que estaban presentes, de quien menos se espera una crítica así es de la propia mujer. La acumulación de hasta tres estrategias de focalización revela sorpresa absoluta. El adverbio de foco enfatiza que, entre todas las personas posibles, un determinado hecho ocurre precisamente con la persona más significativa. Estamos, de nuevo, ante una regla o convención social: cuanto más cercano estás a alguien, menos le criticarás en público. Es una correlación escalar y gradual que no solo se incumple en el ejemplo citado, sino que se incumple de manera extrema, es decir, por la persona más cercana de todas. En este ejemplo, la valoración que aporta el adverbio de foco es una sorpresa desagradable, pero esa valoración - como en los demás ejemplos- no está codificada, sino que se 
infiere por todo el contexto, de acuerdo con el conocimiento del mundo. Lo que está codificado es solo la sorpresa (mira por donde, justamente y estructura copulativa de énfasis), pero no de qué tipo.

Asimismo, el siguiente ejemplo llama la atención sobre una aparente contradicción curiosa:

(117) Según Weston, una buena parte de las grandes obras fotográficas del pasado se deben, precisamente, a autores que apenas llegaron a sentir la más mínima preocupación por la estética, ni la angustia desolada por la futura e incierta trascendencia de su propio trabajo. (Publio López Mondéjar, Historia de la fotografía en España, 1997)

No es de esperar que los fotógrafos menos esforzados y preocupados hagan las mejores fotografías. De nuevo, se incumple un topos que podríamos definir como <cuanto más esfuerzo, mejor resultado>. Además, este ejemplo muestra nuevamente que precisamente aporta una valoración completamente subjetiva al interpretar este hecho como sorprendente e inesperado y no como, por ejemplo, una consecuencia lógica y esperable. Las dos proposiciones (grandes obras fotográficas; autores despreocupados) son hechos extralingüísticos observables de manera objetiva. En cambio, la correlación entre ellos, esto es, la interpretación de cómo se conectan, es individual y subjetiva.

La focalización enfática de identidad de alguna persona se documenta en precisamente, justamente, cabalmente y justo, pero no existe en exactamente. No hemos encontrado ejemplos de exactamente como focalizador enfático de identidad de alguna persona en el CDH o el CORPES XXI. En los ejemplos citados en este apartado, exactamente tampoco puede sustituir a los demás adverbios:

La mujer a que se ama es [cabalmente/precisamente/justamente/justo/*exactamente] la mujer a quien menos se le dice. (compárese con ejemplo 112)

Que fuera [justo/justamente/precisamente/(cabalmente)/*exactamente] Peñarol el que estaba enfrente, ¿tuvo algún significado para usted? (compárese con ejemplo 110)

¿[Precisamente/justamente/justo/(cabalmente)/*exactamente] Mauricio, entre todos los hombres del mundo, se suicidó? (compárese con ejemplo 111)

[...] y mira por dónde tenía que ser [justamente/precisamente/justo/cabalmente/*exactamente] mi mujer [...]. (compárese con ejemplo 116)

Mientras que cabalmente sí se documenta en este contexto, aunque queda anticuado, no es posible usar exactamente como focalizador enfático de identidad de una persona. Creemos que exactamente no puede aparecer en este contexto porque es incompatible con una interpretación subjetiva, ya que en la focaliza- 
ción enfática de identidad siempre expresa la exactitud matemáticamente rigurosa de la información. Recordemos este ejemplo citado en el apartado 5.3.3:

En un lapso de una hora y cuarto, pasaron exactamente treinta y cinco mujeres de interés. (véase ejemplo 90)

En este ejemplo, exactamente no enfatiza la identidad de las personas referidas, sino que focaliza la exactitud del numeral que encabeza el sintagma nominal ('exactamente 35, ni una más ni una menos').

Asimismo, en otro ejemplo ya citado, precisamente puede sustituirse por exactamente, ya que se trata de una comparación que engloba un grupo de personas. La extensión referencial de un grupo de varias personas se puede delimitar con más o menos exactitud; sería posible decir son aproximadamente los mismos:

los pueblos que tanto vocean la crueldad de los españoles en América son precisamente/ exactamente los mismos que van a las costas de África [...]. (compárese con ejemplo 101)

Además, la descripción de una persona puede ser exacta, por lo tanto, exactamente puede aparecer como focalizador de identidad, cuando hace referencia a las características concretas de una persona, como en este ejemplo citado en el apartado anterior:

-Diga usted; el que montaba el caballo castaño, ¿era uno pequeño, moreno, con algunas canas y hoyoso de viruelas?

-Si, señor; exactamente esas son sus señas. (véase ejemplo 105)

Es posible cuantificar y graduar la descripción de una persona, que se puede acercar en mayor o menor medida a la realidad. Hay una escala de rasgos personales más o menos exactos, es decir, más o menos correspondientes con la realidad.

No obstante, cuando los adverbios precisamente, justamente, cabalmente y justo focalizan la identidad misma de una persona, el valor que aportan necesariamente es de algún tipo de coincidencia significativa, ya que la interpretación de exactitud ('exactamente $\mathrm{x}$, ni más ni menos') no es posible con una sola persona: la propia identidad de una persona no se puede determinar en una escala de manera más o menos exacta o aproximada:

\#exactamente ('no aproximadamente') mi mujer (compárese con ejemplo 101)

\# exactamente ('no aproximadamente') Mauricio (compárese con ejemplo 116).

En este sentido, los adverbios precisamente, justamente, cabalmente y justo pierden el rasgo semántico de exactitud y hay debilitamiento semántico (seman- 
tic bleaching) del significado conceptual en contextos donde la interpretación de 'exacto, no aproximado' es imposible. El nuevo valor de coincidencia y el debilitamiento semántico del concepto base permite a estos adverbios de foco extenderse a contextos nuevos, como la enfatización de identidad en personas, $y$ aparecer en contextos semánticos en los que no pueden aparecer como adverbios de exactitud. En cambio, exactamente no funciona como focalizador enfático de identidad de personas, porque mantiene el valor semántico base de exactitud como una cualidad estrictamente cuantificable y medible.

La única manera de cuantificar al menos una parte de este uso en el corpus consiste en buscar la combinación de los adverbios con nombres propios. Recurrimos al CORPES XXI, ya que este corpus - al contrario del CDH - especifica la marca de «nombre propio». Aparte de nombres propios de personas, algunos ejemplos también son de países o ciudades. La Tabla 26 resume los resultados de la búsqueda del patrón [adverbio + nombre propio] en el CORPES XXI, es decir, en el español actual: ${ }^{12}$

Tabla 26: Frecuencia de adverbios de foco antepuestos a nombres propios en el CORPES XXI.

\begin{tabular}{lr}
\hline precisamente + nombre propio & aprox. 170 casos \\
\hline justamente + nombre propio & 28 casos \\
\hline justo + nombre propio & 6 casos \\
\hline
\end{tabular}

De nuevo, el adverbio más frecuente en esta construcción es precisamente. No encontramos ningún caso de exactamente que corresponda a la función de focalización enfática de identidad de personas (sí aparece en combinación con la negación, véase apartado 5.5). Ya que el CORPES XXI abarca registros de los años 2001 a 2012, no sorprende que cabalmente ya no aparezca documentado, aunque los datos históricos muestran que sí se usaba como focalizador enfático de identidad de personas.

12 Recontamos manualmente para limpiar resultados no pertinentes de justamente y justo. En el caso de precisamente, calculamos un número aproximado: en total, [precisamente + nombre propio] devuelve 201 casos, pero no todos son de focalización de una persona. Redondeando, un $85 \%$ de los resultados, es decir, unos 170 casos, corresponden a la focalización enfática de identidad de una persona. El porcentaje surge, por un lado, de un recuento manual de las primeras 40 ocurrencias de [precisamente + nombre propio], de las cuales 6 no eran pertinentes (15\%). Además, el recuento manual de justamente mostró una proporción parecida: de los 33 casos de justamente antepuestos a un nombre propio, 28 casos son pertinentes (85\%). Generalizamos ambas observaciones y presuponemos, pues, que aproximadamente el $85 \%$ del total de precisamente (201) correspondería a la función buscada; esto es, aproximadamente 170 casos. 


\subsubsection{Focalización enfática en la combinación [adverbio de foco + porque/por]}

La focalización de contradicciones aparece frecuentemente en combinación con por eso y porque. La estrategia comunicativa de esta estructura consiste en contradecir, insistiendo en lo contrario de lo esperado (López Samaniego 2007, 72-73). Como observa López Samaniego (2007, 73), precisamente/justamente por eso funcionan como «inversores argumentativos» en términos de la Teoría de la Argumentación (Bruxelles et al. 1982; Anscombre/Ducrot 1994, 228): invierten la orientación argumentativa hacia la consecuencia opuesta.

De nuevo, este uso surge primero en precisamente, en el siglo XIX. En el siguiente ejemplo, precisamente incide sobre una oración subordinada causal, introducida por el nexo porque:

(118) Desde Cowper hasta el día presente, quizá es la poesía británica la más rica entre las modernas, así por la abundancia cuanto por el valor de sus producciones, precisamente porque, abandonando los autores reglas erróneas, y no cuidándose de ser clásicos ni románticos, han venido a ser lo que eran los clásicos antiguos en sus días, y lo que deben ser en todos tiempos los poetas. (Antonio Alcalá Galiano, fragmento [Ángel de Saavedra, Duque de Rivas, El moro expósito o Córdoba y Burgos en el siglo décimo, 1834])

Es el nexo porque el que establece la relación causa-efecto entre las dos proposiciones:

CAUSA (porque): abandonando los autores reglas erróneas, y no cuidándose de ser clásicos ni románticos

$\rightarrow$ EFECTO: han venido a ser lo que eran los clásicos antiguos en sus días

El adverbio de foco precisamente focaliza la información que aparece en la causa, es decir, ejerce de focalizador enfático de identidad. Llama la atención sobre esta información porque es significativa y sorprendente por ser paradójica: no es de esperar que los autores que no siguen el canon clásico se conviertan finalmente en autores considerados como clásicos. El adverbio aporta, por lo tanto, una valoración subjetiva. Una consecuencia que, a priori, parece ser contradictoria o ilógica se afirma como lógica.

Asimismo, en el siguiente ejemplo, precisamente focaliza el sintagma preposicional por eso y destaca lo paradójico de la causa:

(119) - ¡Ah! - dice Daniel, acabando de vendar a su amigo-. Su Excelencia inglesa se divierte. - ¡Mientras a sus puertas se asesina a los ciudadanos de este país! - exclama Eduardo. 
$-\mathrm{Y}$ es precisamente por eso que se divierte. Un ministro inglés no puede ser buen ministro inglés sino en cuanto represente fielmente a la Inglaterra; y esta noble señora baila y canta en derredor de los muertos como las viudas de los hotentotes; con la sola diferencia que éstas lo hacen de dolor, y aquélla de alegría. (José Mármol, Amalia, 1851-1855)

En este ejemplo, un asesinato supuestamente debería causar una reacción de rechazo (horror, preocupación, dolor...), pero la reacción es todo lo contrario a lo esperable: diversión. El personaje Eduardo otorga a las dos proposiciones una interpretación adversativa: Su Excelencia inglesa se divierte es incompatible con Mientras a sus puertas se asesina a los ciudadanos de este país. Sin embargo, el personaje Daniel se opone a esta presuposición y convierte la interpretación adversativa en una interpretación distinta, de causa-efecto:

CAUSA: a sus puertas se asesina a los ciudadanos de este país

$\rightarrow$ EFECTO (por eso): Su Excelencia inglesa se divierte

El elemento que indica la interpretación causa-efecto es el nexo por eso y el adverbio de foco precisamente llama la atención sobre esta interpretación causa-efecto. Focaliza, por lo tanto, la interpretación causal como significativa, ya que es sorprendente e inesperada, paradójica. La valoración que aporta precisamente es, de nuevo, subjetiva, como muestra este ejemplo: lo que para unos sería una contradicción, para otros es una consecuencia lógica. Las dos proposiciones son objetivamente observables en la realidad, pero la conexión establecida entre ellas es individual y subjetiva.

De acuerdo con König (1991, 131-132), hay disonancia o incompatibilidad. Se focaliza la identidad entre dos proposiciones normalmente incompatibles: por ejemplo, una relación que se espera como concesiva se convierte en causal (König 1991, 131-132). Es decir, la alternativa excluida (la relación concesiva) es menos significativa y menos sorprendente que la alternativa focalizada (la relación causal).

En el siglo XIX, este uso aparece igualmente en el adverbio cabalmente:

(120) Don Juan Montalvo le acusa de estafa, robos muchos y muy grandes, embriaguez consuetudinaria, ineptitud lastimosa, ignorancia irremediable; le acusa de falta de patriotismo, de superchería y traición, le echa al rostro crímenes y vicios, pecados y defectos los más negros y ruines: el jesuíta no afirma que las acusaciones son infundadas, ni sostiene que su héroe es inocente; lo que da a entender es que con todo eso, y cabalmente por eso, el consabido malhechor es más digno de admiración y aplauso. (Juan Montalvo, Las catilinarias, 1880-1882)

En este ejemplo, un personaje es acusado prácticamente de todos los delitos posibles: estafa, robos, embriaguez, ineptitud lastimosa, ignorancia irremedia- 
ble, falta de patriotismo, superchería, traición, crímenes, vicios, pecados y defectos. Esta proposición, en general, es incompatible con la proposición es más digno de admiración y aplauso. La relación entre ambas proposiciones debería ser concesiva (con todo eso). Sin embargo, la relación que establece uno de los personajes que intervienen en el juicio, el jesuita, entre ambas proposiciones es causal (por eso). El adverbio de foco cabalmente focaliza esa interpretación causal, ya que es significativa y llamativa por presentar una contradicción. Excluye, además, la alternativa menos llamativa, la que sería esperable: la relación concesiva.

En términos de la Teoría de la Argumentación (Anscombre/Ducrot 1994), estaríamos ante un topos generalizado: <cuanto peor se comporta una persona, menos admiración recibe> o, en términos positivos, <cuanto mejor se comporta una persona, más admiración recibe>. Hay una correlación gradual entre dos escalas; y la orientación es clara: <cuanto peor, más $>/<$ cuanto mejor, menos $>$. Sin embargo, en el ejemplo citado, este topos no se cumple, porque la orientación se invierte: cuanto peor se comporta dicho personaje, más aprobación recibe. Además, se sitúa en un extremo de la escala, como indica la acumulación de delitos. En las dos escalas contraorientadas (la acumulación de delitos y el grado de aprobación social), los dos extremos opuestos, supuestamente antiorientados, coinciden. Esta coincidencia es la focalizada por cabalmente.

En el siglo XX, la focalización enfática de identidad en dichas construcciones se extiende a justo y justamente. En estos dos ejemplos, ambos dialógicos, la presuposición de uno de los interlocutores es negada y contradicha por otro interlocutor:

(121) ¿Piensas que necesito dioses de carne y hueso para adorarlos? Yo adoro las ideas hechas dioses...

- ¿Aun cuando nunca esos dioses veas?

- ¡Quién sabe si los amo justamente por eso! (Amado Nervo, Serenidad, 1914)

(122) -Sería formidable - dijo.

- ¿Por qué dice que sería formidable? Solo es el cambio de un nombre.

-Justo por eso.

- ¿Por qué, señor Spielberg?

-Oye, grábatelo, porque un nombre muchas veces basta para darle otra dimensión a la vida o cambiar rotundamente una historia. No lo olvides: un solo nombre. (Roberto Quesada, Big Banana, 2000)

De nuevo, los adverbios enfatizan la interpretación causal como relevante y significativa, porque se opone a la interpretación adversativa. 
El adverbio corto justo, al igual que los adverbios en -mente, también incide sobre oraciones subordinadas. Consiguientemente, también aparece antepuesto a porque:

(123) «Cuando dice que la guerra la hacen los niños, por un lado dice una cosa evidente, que los soldados son muy jóvenes. Pero dice también algo más terrible: que la guerra es una cosa que viene de la infancia, que la infancia es el modo de entender el mundo que da lugar a la guerra.» "Aunque los niños no lo sepan», asentí yo. «Claro, justo porque no lo saben», dijo Cora. (Gonzalo Garcés, El miedo, 2012, CORPES XXI)

También hay variantes del sintagma por eso, como por ello:

(124) [Teresa] Se expresaba con cierta dificultad, debatiéndose en una confusión mental que iría en aumento a lo largo de la noche y que Manolo, desde un principio, creyó que sólo era sueño y efecto del sol. Por lo demás -o quizá precisamente por ello mismo- la muchacha estaba esa noche más hermosa que nunca. (Juan Marsé, Últimas tardes con Teresa, 1966)

En este ejemplo, la interpretación causal se presenta como sospecha no confirmada (quizás), pero sería significativa, ya que la relación causal podría explicar la relación que hay entre las dos proposiciones: Teresa estaba confusa y Teresa estaba más hermosa que nunca. Al contrario de la simple observación de estas dos proposiciones paralelas, simultáneas, que no están relacionadas (por lo demás), la relación causa-efecto establece una conexión entre ellas y ofrece incluso una explicación de una de las proposiciones. Por eso, la interpretación causal es más significativa y relevante que la mera coincidencia sin ninguna correlación.

En resumen, como muestran los ejemplos citados, los adverbios de foco enfatizan la interpretación causal que hay entre dos proposiciones como significativa y sorprendente. La secuencia precisamente (justamente, justo, cabalmente) por eso/ porque sirve para contradecir. Las alternativas excluidas son otras interpretaciones más esperables, como la relación adversativa o concesiva, o incluso la ausencia de alguna relación entre dos proposiciones independientes. Es decir, la relación adversativa o concesiva es la que cumple con los estereotipos, mientras que la relación causal infringe de manera inesperada los esquemas esperables. Además, frente a una interpretación adversativa-concesiva o frente a la ausencia de relación, la relación causa-efecto se destaca como la que conlleva más carga informativa, ya que en ocasiones explica el porqué de un determinado comportamiento.

El rasgo semántico de exactitud sigue siendo algo transparente en los adverbios de foco: hay exactitud y precisión en la interpretación causa-efecto. La interpretación causal es más exacta y precisa que la interpretación adversativa o concesiva. No obstante, el énfasis que aportan los adverbios precisamente, 
justamente, justo y cabalmente implica tanto exactitud como una interpretación significativa: la relación causal es, sobre todo, sorprendente e inesperada, por ser contraria a lo esperado. En este sentido, exactamente raras veces aparece en este contexto, ya que este adverbio, tal y como venimos observando en este capítulo, no aporta una interpretación significativa, sino que focaliza principalmente una exactitud minuciosa. Solamente hemos encontrado un ejemplo de exactamente en esta posición, con un valor enfático de contradicción:

(125) -Pero, ¿por qué un director de prestigio internacional como usted acepta dirigir una orquesta que apenas es conocida fuera de España?

-Exactamente por eso: es una de las cosas más interesantes que se pueden hacer. La orquesta debería ser conocida porque Barcelona es ahora mismo una de las ciudades más importantes del mundo [...]. (La Vanguardia, 02/11/1995)

En este ejemplo se incumple una presuposición estereotípica según la cual cuanto más famoso es un director, más querrá colaborar con orquestas igualmente famosas. Estos usos son escasos en exactamente y solo se da la combinación exactamente por eso. El adverbio exactamente no tiene en su alcance a oraciones subordinadas causales, por lo cual no aparece antepuesto a porque.

Para obtener datos cuantitativos, recurrimos a las búsquedas específicas en el $\mathrm{CDH}$. No resulta fácil delimitar este uso con un determinado patrón, ya que la colocación con por o porque arroja muchos ejemplos coincidentes con otros usos distintos; es decir, los adverbios no siempre inciden sobre la oración o el sintagma que sigue. Ese es especialmente el caso de justo, ya que ocurre frecuentemente como adjetivo o sustantivo en este contexto, lo cual distorsiona los resultados. Consiguientemente, tuvimos que limitar el recuento cuantitativo a dos construcciones especialmente representativas de la focalización de interpretaciones causales significativas:

Por un lado, buscamos la secuencia [signo de puntuación + adverbio + porque], ya que, al aparecer en posición inicial (detrás de un punto o de una coma), los adverbios en cuestión introducen la oración subordinada o el sintagma que sigue. Sin embargo, el uso de un signo de puntuación no es obligatorio en estos casos y consiguientemente no se representan en esta búsqueda todos los ejemplos pertinentes en los que no hay un signo de puntuación. Por otro lado, buscamos la secuencia [adverbio + por eso].

Según muestra la Tabla 27, precisamente es con diferencia el adverbio más frecuente y es el primero en adoptar este contexto. En cambio, cabalmente es muy poco frecuente y su uso se limita al siglo XIX (la última documentación de cabalmente porque es de 1900). El segundo adverbio más frecuente es justamente, cuyo uso en este contexto sin embargo se consolida más tarde, en el siglo XX. El adverbio corto justo no aparece hasta finales del siglo XX, pero presenta la misma polifun- 
cionalidad que los adverbios en -mente, ya que también puede incidir sobre oraciones subordinadas introducidas por porque. Por el contrario, exactamente no incide sobre oraciones subordinadas causales (porque) y su uso con por eso es marginal.

Tabla 27: Frecuencia de las secuencias [puntuación + adverbio + porque] y [adverbio + por eso] en el $\mathrm{CDH}$.

\begin{tabular}{llllll}
\hline & precisamente & justamente & cabalmente & exactamente $^{13}$ & justo \\
\hline poreso & 249 & 37 & 4 & 1 & 2 \\
porque & 338 & 36 & 3 & - & 2 \\
\hline suma & 587 & 73 & 7 & 1 & 4 \\
\hline siglos & desde el XIX & desde el XX & solo en el XIX & finales del XX & desde finales del XX \\
\hline
\end{tabular}

A pesar de la alta frecuencia de precisamente por eso en el $\mathrm{CDH}$, no es la colocación más usada para destacar una causa inesperada y sorprendente: por eso mismo, que funciona también como «inversor argumentativo» (López Samaniego 2007, 73; Briz Gómez/Pons Bordería/Portolés Lázaro 2008, s.v. por eso mismo), ocurre con bastante más frecuencia en el CDH: supera los 800 casos. Además, su aparición es anterior y se da ya en el siglo XVI.

\subsubsection{Focalización de oraciones con valor de contradicción}

El valor paradójico y contradictorio también aparece en precisamente, cabalmente y justamente cuando su alcance es toda la oración. Este valor se da especialmente en diálogos, cuando el enunciado que introducen es un argumento contraorientado al enunciado, a la intervención anterior. En el siguiente ejemplo, precisamente incide sobre una oración cuyo contenido se opone a lo que espera el interlocutor, es decir, enfatiza una aserción que contradice a las expectativas y presuposiciones del interlocutor:

(126) - ¿Es que tienes algo que decir en contra de Perico? - provoqué.

- ¡Oh!, no, de ninguna manera - rechazó, con esa curiosa dignidad justiciera tras la que los hombres suelen ocultar la violencia de su odio-. Precisamente creo que es un buen chico. Pero nunca te lo aconsejaría. (Darío Fernández-Flórez, Lola, espejo oscuro, 1950)

13 No hay resultados de [puntuación + exactamente + porque], pero sí los hay sin puntuación anterior. Estos casos se combinan con la negación: no exactamente porque... (véase apartado 5.5 para el análisis de esta función). Además, el patrón exactamente por eso devuelve otros ejemplos que corresponden al uso particular de la negación: no fue exactamente por eso, sino... Después de limpiar manualmente los resultados, solo queda uno que pertenece al uso que analizamos en este apartado. 
Este uso de precisamente y justamente como focalizador de una contradicción o de un argumento inesperado es definido por Moliner (1998, s.v. precisamente) como estrategia que «impide acceder a una petición»:

Dame cien pesetas si las tienes. -Precisamente, acabo de cambiar el último billete que llevaba. (Moliner 1998, s.v. precisamente)

En este caso, precisamente indica que toda la información que sigue expresa alguna coincidencia inoportuna y esa es la que sirve de excusa para rechazar la petición. En este sentido, el hablante atenúa su rechazo justificándose. El adverbio de foco aporta énfasis al marcar la coincidencia como inoportuna; su alcance es toda la oración que sigue. Según López Samaniego (2007, 64-65), «el poder justificativo de precisamente y justamente» radica en que ponen de relieve una excusa indirecta, ya que señalan una coincidencia fortuita que imposibilita acceder a la petición y esta no depende del hablante sino del azar.

Este uso surge en el siglo XIX en precisamente, como muestra el siguiente ejemplo:

(127) - No hay remedio; tengo un coche a la puerta, ja las máscaras! Iremos a algunas casas particulares, y concluiremos la noche en uno de los grandes bailes de suscripción.

-Que te diviertas: yo me voy a acostar.

-¡Qué despropósito! No lo imagines: precisamente te traigo un dominó negro y una careta. -¡Adiós! Hasta mañana. (Mariano José de Larra, «El mundo todo es máscaras. Todo el año es carnaval», 1833)

El adverbio enfatiza la información como importante y significativa, ya que la intención del hablante es oponerse a las intenciones de su interlocutor. Focaliza, por lo tanto, un fuerte argumento contraorientado.

Sin embargo, durante el siglo XIX, el valor de precisamente todavía puede ser positivo, esto es, coorientado y favorable:

(128) - Pero contra los ochentines, el Gobierno tiene los empleos públicos. Póngame usted en la cárcel de la Corona a un empleado que se preste a favorecer nuestro plan.

-Precisamente hay una vacante. Me he informado hoy. (Benito Pérez Galdós, El grande Oriente, 1876)

En este ejemplo, no hay rechazo, sino que la petición se cumple. Por lo tanto, cuando precisamente aparece en posición inicial en intervenciones reactivas durante el siglo XIX, su valor es todavía ambiguo, pero se acabará especializando en el valor contraorientado, negativo. 
A su vez, cabalmente aparece, ya en el XVIII, también con un valor coorientado, es decir, enfatiza una coincidencia favorable:

(129) Ocurrió entonces a Hardyl preguntar a Bridway si había cesteros en Londres, no habiendo visto ninguno en las calles por donde había pasado. Cabalmente, le responde el viejo, hay uno en este barrio, y cerca de mi tienda. Me haríais, pues, un singular favor, si os informaseis de él del lugar en que se provee de materiales. (Pedro Montengón, Eusebio, 1786) ${ }^{14}$

En este ejemplo, cabalmente tiene en su alcance toda la oración (Cabalmente hay uno en este barrio, y cerca de mi tienda) y equivale a 'por casualidad' o 'da la casualidad de que'. En este ejemplo, la coincidencia oportuna se da en la localización: da la casualidad de que hay un cestero no demasiado lejos. Por lo tanto, el interlocutor colabora con la petición, no la rechaza. Sin embargo, también cabalmente puede aparecer con el valor contraorientado e introducir una réplica de rechazo:

(130) - ¿Me lo cuentas? - le pidió Eva, sin pensar lo que decía.

-No, porque se lo revelarás a tu marido.

- iCabalmente, lo que estoy deseando es tener algo que ocultarle! Eso lo haría mucho más manejable, y no sería tan orgulloso y tan serio. Sospecho que un secreto en mis manos me permitiría hacer de él mi real gana. (Gonzalo Torrente Ballester, Don Juan, 1963)

En este ejemplo, el adverbio de foco enfatiza un argumento que se contrapone a las dudas del interlocutor y a sus presuposiciones.

En cuanto a justamente, según Gómez-Jordana (2012, 64-66), la función de rechazo es mucho menos frecuente que en precisamente y se limita al español de Argentina. Efectivamente, justamente se usa como focalizador de argumentos contraorientados en países del Cono Sur:

(131) -Buenos días, hermosa señorita!

- ¿Cómo se atreve? Yo no te conozco y no hablo con extraño.

-Que no me conoces todavía, es verdad, mas ya no soy un extraño porque desde hace mucho tiempo que te diste cuenta de que soy como tu sombra porque no hago otra cosa que seguirte.

14 Este ejemplo podría interpretarse como un marcador de afirmación (véase capítulo 6). Sin embargo, no nos parece que cabalmente afirme la pregunta, ya que es una pregunta abierta que no implica la expectativa de afirmación, como suele ser el caso de los marcadores de afirmación que provienen de los adjetivos y adverbios de exactitud. Cabalmente parece destacar, sobre todo, una coincidencia local oportuna y su alcance es la oración que sigue. 
-Justamente, eso no hace gente bien educada.

-Tengo que reconocer que de educación sofisticada no tengo gran cosa, mas mis intenciones contigo son de puro amor y casamiento. (José Amado Delgado Vera, Yvate, [Paraguay] 2003, CORPES XXI)

En resumen, la interpretación que se ha convencionalizado y prácticamente automatizado en los adverbios de foco que aparecen al inicio de una reacción en intervenciones dialógicas es la de rechazo de una petición. El rechazo se justifica por una coincidencia desfavorable que impide al hablante cumplir con lo pedido. Al aparecer en posición inicial en intervenciones dialógicas, este valor de negación o rechazo se contagia a los adverbios precisamente, justamente y cabalmente como marcadores afirmativos (véase el capítulo 6 y especialmente el apartado 6.2.2).

\subsubsection{Focalización como mecanismo de conexión y coherencia temática}

Ocasionalmente, la focalización indica una adecuación y cohesión temática. El elemento focalizado enlaza con el tema de la conversación y se presenta como pertinente (Fuentes Rodríguez 1995-1996, 775; Santos Río 2003, s.v. precisamente; Briz Gómez/Pons Bordería/Portolés Lázaro 2008, s.v. precisamente, justamente). En este sentido, adverbios de foco como precisamente operan en un nivel mayor a la sintaxis, ya que conectan entre párrafos y dan coherencia a un texto (Fuentes Rodríguez 1995-1996). Para López Samaniego (2007, 67-70), se trata de un valor digresivo, ya que precisamente y justamente marcan una relación de semejanza o identidad entre dos bloques informativos del texto. $\mathrm{Su}$ función es textual, dado que marcan un cambio de tema, generalmente, en la transición entre dos párrafos. Asimismo, Kovacci (1999, 771-772) compara precisamente y justamente con casualmente, a propósito y por cierto: son adverbios continuativos digresivos que identifican el contexto precedente como tópico del miembro que encabezan. Este puede orientarse hacia la especificación o hacia la contraposición u oposición.

Este valor aparece, de nuevo, primero en precisamente, en el siglo XVIII. En este ejemplo, el autor ilustra una observación general con un caso concreto. Enlaza, pues, dos bloques temáticos; el segundo es una especificación del primero:

(132) Por lo cual otros, fiados de las relaciones que leyeron en la suposición y buena fe de que se hicieron con la debida averiguación y prudente discernimiento, trasladaron lo que hallaron escrito. Otros dejan advertido lo que experimentaron al tomar las primeras 
noticias de una lengua nueva, y no pudiendo tomar tino en poco tiempo, la calificaron luego por un ininteligible guirigay. Esto último sucedió precisamente al P. Luis Coronado acerca de la lengua Omagua, que tiene en el día de hoy un arte y vocabulario copioso y aun es una de las más fáciles de aprenderse, dulce, suave y armoniosa. (José Chantre y Herrera, Historia de las misiones de la Compañía de Jesús en el Marañón español, 1786)

La conexión se establece mediante el elemento anafórico Esto último, que identifica el segmento que sigue como un caso concreto y específico de una hipótesis anterior. Además, precisamente funciona como adverbio de focalización enfática de identidad: focaliza la identidad de una información que coincide exactamente con algo dicho anteriormente. Así, precisamente enfatiza que el ejemplo es totalmente pertinente. Al focalizar la información que sigue, la identifica como el tema de la siguiente unidad discursiva y así aporta coherencia temática.

Citamos otro ejemplo en el cual la aserción enfática de identidad, con un adverbio de foco en posición destacada, sirve para construir un texto coherente:

Concedemos sin la menor repugnancia que en la cualidad que constituye nuestra especie, el hombre recibió de la naturaleza la superioridad de fuerza física, y ni aún queremos disputarle en este breve artículo la mayor potencia intelectual, que con poca modestia se adjudica. Nos basta, lo declaramos sinceramente, nos basta la convicción de que nadie puede, de buena fe, negar a nuestro sexo la supremacía en los afectos, los títulos de su soberanía en la inmensa esfera del sentimiento.

«Las almas grandes - ha dicho un poeta - aspiran a descender, no por laxitud, sino por instinto de la verdadera elevación, que consiste en el sacrificio.» Tal es, precisamente, el carácter de la mujer; ella posee aquella intuición de la verdadera grandeza, aquel instinto del supremo heroísmo, que hace se complazca descendiendo; que hace se glorifique en el dolor; que hace, en fin, que consagre su corazón altar secreto de holocausto continuos. (Gertrudis Gómez de Avellaneda, «La mujer», 1860, Novelas y leyendas)

La identificación se da entre una cita literal, que caracteriza de manera general a las personas que se sacrifican, y el supuesto carácter de la mujer. La cita se inserta en la línea de argumentación de la autora para respaldar sus observaciones, aplicándose al caso concreto del carácter de la mujer. Mediante el elemento anafórico tal, la autora enlaza la cita con el discurso que sigue y el adverbio precisamente enfatiza que la identificación del carácter de la mujer con la cita es pertinente y acertada. Además, precisamente focaliza el tema del discurso siguiente, que coincide con el tema del párrafo anterior (nuestro sexo... los afectos...), donde ya se introducía el tema de este texto: en qué se diferencia la mujer del hombre.

Este uso también se da en justamente:

(134) Pocos podían jactarse de conocer la casa del Provisor de arriba abajo; casi nadie había visto más que el vestíbulo, la escalera, un pasillo, la antesala y el salón de cortinaje verde 
y sillería con funda de tela gris; y aun el salón medio se veía porque estaba poco menos que a oscuras. Uno de los argumentos que empleaban los que defendían la honradez del Provisor, consistía en recordar la modestia de su ajuar y de su vida doméstica.

Justamente se había hablado de esto la tarde anterior en el Espolón, en un corrillo de murmuradores, clérigos unos, seglares otros.

-Entre su madre y él, puede que no gasten doce mil reales al año -decía muy serio Ripamilán, el venerable Arcipreste-. Él viste bien, eso sí, con elegancia, hasta con lujo, pero conserva mucho tiempo la ropa, la cuida, la cepilla bien [...]. (Leopoldo Alas Clarín, La Regenta, 1884-1885)

En este ejemplo, se pasa igualmente de una observación general a un ejemplo concreto, y el elemento anafórico que apunta al contenido anterior es el demostrativo esto. Hay, por lo tanto, conexión temática entre dos párrafos. Justamente focaliza la información que sigue y aporta una valoración como oportuna y pertinente, ya que la información que sigue respalda la descripción anterior. La focalización llama la atención sobre el hecho de que una determinada observación coincide con la opinión expresa de varios personajes.

En los ejemplos citados, precisamente y justamente no expresan sorpresa ni aportan una valoración subjetiva de una casualidad inesperada. No se trata de focalizar la más significativa (sorprendente, oportuna, etc.) entre varias alternativas, sino que el adverbio focaliza la información relevante: el tema de una unidad discursiva previa coincide con el tema de la unidad discursiva presente. Hay, por lo tanto, coincidencia en el tema del discurso, mientras que las alternativas excluidas implícitamente son temas no coincidentes con el discurso. En este sentido, precisamente y justamente ayudan a procesar el caudal de informaciones en el discurso, ya que focalizan la identidad temática entre varios bloques de información (a menudo repartidos en varios párrafos), lo cual ayuda a contextualizar los bloques temáticos. Su significado es procedimental: marcan la cohesión discursiva. Para detectar este valor, hay que ampliar bastante el co-texto, ya que en su mayoría son ejemplos largos que muestran un alto grado de planificación y elaboración.

No obstante, no en todos los ejemplos hay un alto grado de planificación. En el siguiente ejemplo de un periódico deportivo, se pasa de un tema (la estrategia para el inminente juego) a otro tema distinto, pero relevante (el tiempo meteorológico). El cambio de tema parece surgir de una manera más bien improvisada, en el mismo momento de enunciación:

(135) El técnico dijo a El Observador que «la idea es seguir siendo protagonistas, pero tenemos que ser conscientes que jugar de local es distinto. Por eso aquí en Ecuador, no podemos quemar las naves en el primer tiempo». Por eso la consigna será «no presionar tan arriba, aunque también vamos a depender del clima». Hablando precisamente del clima, en 
Quito ayer llovió por momentos pero la temperatura a la hora del encuentro de hoy, se situó en unos agradables 17 grados. (El Observador, 12/02/1997 [Uruguay])

El alcance del adverbio de foco es el sintagma preposicional del clima, que constituye la información que se repite entre el enunciado anterior y el enunciado presente. De toda la información anterior, se selecciona un elemento concreto (el clima) y se focaliza como la información coincidente entre dos bloques temáticos. En este ejemplo se ve claramente un valor digresivo, ya que el segundo bloque de información (el tiempo meteorológico) difiere temáticamente del primer bloque (los entrenamientos y preparativos), pero hay una conexión real.

La estrategia de cohesión temática se verbaliza explícitamente mediante un complemento periférico de la enunciación (hablando precisamente del clima) ${ }^{15}$ que enmarca el tema de la siguiente oración. En este complemento de la enunciación se revela el matiz metalingüístico del adverbio de foco que enfatiza la coherencia temática del discurso. Se trata de una topicalización: el complemento de la enunciación que presenta el tema o tópico se disloca a la izquierda.

En este tipo de ejemplos se observa claramente que la información focalizada no es nueva. Esto contradice a la definición tradicional del foco y de la focalización, según la cual el foco es la información nueva, no conocida (Cifuentes Honrubia 2002, 26; Ferrari/Giammatteo/Albano 2011, 32; López Carretero 2016, 575). Como observa López Samaniego $(2007,56)$, justamente y precisamente focalizan un elemento coincidente (y consecuentemente, temático, que ya ha aparecido en el discurso previo) y este elemento adquiere de nuevo la categoría de información nueva o remática, no presupuesta. En este sentido, los focalizadores presentan una información temática como si fuera remática y de ahí surgiría su fuerza enfatizadora.

No obstante, como prueba el ejemplo hablando precisamente del clima..., los focalizadores se asocian más bien con el tópico, es decir, «focalizan» el tópico de la oración. Al presentar el tópico mediante estructuras de tipo hablando precisamente de... también se selecciona entre una serie de alternativas: hay varios temas que han sido aludidos anteriormente y se selecciona uno como tópico del discurso que sigue.

Este uso no solo aparece en la lengua escrita, sino también en la lengua hablada y en enunciados mucho más breves y, probablemente, más espontáneos. En el siguiente ejemplo, la presentadora de un programa televisivo de viajes se encuentra en París, enfrente de un restaurante. Cambia de tema: de la topografía

15 Los complementos de la enunciación son complementos no oracionales, que no dependen del verbo de la oración, sino que caracterizan la propia actividad enunciativa. Para una definición y discusión sobre los complementos periféricos, concretamente, de la enunciación, véase el apartado 7.1.2. 
parisina pasa a la comida, pero hay un elemento coincidente que sirve de enlace temático para esta digresión:

(136) [en París] hay como 20 barrios en forma de caracoles. Y justo caracoles creo que es lo que sirven en este local [...]. (transcripción del reportaje Planeta Gastronómico en rtve.es, 21/06/2017)

En este ejemplo, justo funciona como adverbio de focalización enfática de identidad, su alcance es el sustantivo caracoles. Focaliza esta información porque es la que coincide con el enunciado anterior. De hecho, el sustantivo caracoles se repite en ambos enunciados. De todas las posibles alternativas gastronómicas, la alternativa focalizada es la más oportuna en esta situación. Sin embargo, la coincidencia es solo metafórica: los barrios se organizan en forma abstracta de caracol. Esta metáfora permite a la presentadora establecer una cohesión temática entre dos bloques informativos que, en realidad, no tienen nada que ver. De ahí que la transición de un tema a otro sea menos abrupta y la información focalizada cobre más relevancia. De acuerdo con lo observado anteriormente (apartado 5.3.6), el adverbio de foco enfatiza una relación subjetiva entre dos hechos extralingüísticos no relacionados. Probablemente, esta estrategia se relaciona con la máxima de relevancia, ya que otorga cohesión y pertinencia al enunciado.

Como muestran los ejemplos citados, la cohesión temática es un efecto que se produce en un nivel superior a la oración, el discurso. El patrón sintáctico de justamente, precisamente y justo es el mismo que en la focalización enfática de identidad (es decir, la focalización informativa) o en la focalización de circunstancias espaciotemporales. El alcance de los adverbios de foco sigue recayendo sobre sintagmas nominales, preposicionales, sustantivos, oraciones, etc. No obstante, el efecto que surge de la focalización es distinto: la información destacada es importante para la construcción del discurso. En este sentido, el valor discursivo de coherencia temática surge del valor pragmático de focalización, es un valor secundario. A pesar de que estos adverbios de foco sirvan para la conexión discursiva, no se trata de conectores, entendidos según el planteamiento de Fuentes Rodríguez (2003). Siguen siendo operadores de foco, que operan solamente sobre un segmento en la oración y no exigen un antecedente al que conectan con un nuevo segmento. El efecto de cohesión y conexión temática surge porque el elemento focalizado por estos adverbios ya apareció en el discurso anterior.

El valor de digresión o coherencia temática no se observa en exactamente. No se podría usar en ninguno de los ejemplos citados en este apartado, por ejemplo, ?hablando exactamente del clima. Creemos que esto se debe a que exactamente siempre indica correspondencia plena y absoluta entre dos cosas (temas, sucesos...) que coinciden exacta y minuciosamente. En este sentido, exactamente 
no enlaza dos temas que encajan solo parcial o metafóricamente. De ahí que no sirva para suavizar el «salto» temático de un tema a otro distinto. Como muestran estos ejemplos, el segmento que focaliza exactamente se corresponde plenamente con lo dicho anteriormente:

(137) Autoridad y decisión son los mejores atributos de este gobernante y eso es exactamente lo que la situación del país está demandando y ello aglutina todas las voluntades en el monolítico ideal de hacerlo el próximo presidente de Colombia, lo más pronto que sea posible. (Âlvaro Uribe Vélez, El Tiempo, 31/10/1996)

(138) Lo importante de Robic y los que son como él, Jabato entre ellos, era esa inscripción que llevaba en su anillo: «Kenbeo Kenmaro», que en bretón significa «A vida o muerte». Eso es exactamente lo que debe de estar pasando por su cabeza a lo largo de esta bajada. (Javier García Sánchez, El Alpe d'Huez, 1994)

La referencia del elemento anafórico que aparece con exactamente se queda siempre dentro de una misma oración o, al menos, en dos oraciones inmediatamente sucesivas. No hemos encontrado casos en los que la comparación o relación que focaliza exactamente traspase a párrafos distintos ni a temas distintos. Ya que la correspondencia que focaliza exactamente siempre es absoluta e inmediata, no puede aparecer en correspondencias metafóricas como la de los caracoles (véase ejemplo 136). De hecho, en contextos parecidos al del ejemplo de los caracoles (gastronómicos), la interpretación de exactamente es estrictamente literal:

(139) Snacks, tapas y raciones dice el logo, y eso es exactamente lo que sirven. (Recuperado de http://malevamag.com/diez-restaurantes-mixtos-ideales-para-que-veggies-y-carnivorossean-felices-por-igual/ el 10/12/2017)

\subsection{Propiedades sintácticas de los adverbios de focalización}

En esta sección analizaremos algunos aspectos sintácticos de los adverbios de foco en cuestión: la opcionalidad de los focalizadores, su alcance sintáctico, la posibilidad de ser modificados y coordinados, así como su posición respecto al elemento focalizado.

\subsubsection{La opcionalidad sintáctica de los focalizadores}

Los adverbios analizados expanden el constituyente focalizado y no son estrictamente necesarios para la gramaticalidad y aceptabilidad semántica (García-Page 
1995, 169-170). Kaul de Marlangeon (2002, 120, 142-143) incluso prefiere llamar «adverbios pleonásticos» a los de precisión, ya que opina que, desde el punto de vista semántico, no agregan nada salvo énfasis; tienen una función puramente pragmática de focalización. Son adverbios omisibles y su función es de refuerzo (Kovacci 1999, 777-778). Esta es una propiedad generalizada en todas las partículas de foco, ya que las oraciones con partículas de foco engloban y conllevan las correspondientes oraciones sin partícula de foco (König 1991, 33). En especial, es el caso de los adverbios de exactitud, ya los propios adjetivos base como exacto - aplicados a un nombre de medida: tres metros exactos - no aportan información nueva, sino que son redundantes (Kovacci 1999, 719).

Por tanto, los adverbios de foco analizados en este capítulo se pueden eliminar sin que la oración cambie semánticamente o se vuelva agramatical, ya que su función es primordialmente pragmática. El contenido proposicional, es decir, el contenido informativo, también sería el mismo sin el adverbio de foco. Eso se ve claramente en este ejemplo:

y mira por donde tenía que ser justamente mi mujer quien viniese a decirme [...] (véase ejemplo 116)

Dado que los adverbios de foco excluyen alternativas implícitas, podemos asumir que, al eliminar el adverbio de foco, la interpretación se abre también a las alternativas:

El domingo veinticuatro de mayo de 1998, exaetamente a las cinco de la tarde. (véase ejemplo 11)

En este sentido, quedaría todavía abierta la posible interpretación de aproximadamente a las cinco de la tarde: a lo mejor, la acción ocurrió 10 minutos antes o después de las cinco de la tarde. Como mencionamos anteriormente (apartado 5.2.1), los hablantes tienden a usar datos redondeados y aproximativos, por lo cual a las cinco de la tarde - sin adverbio focalizador de exactitud - deja abierta la posibilidad de alternativas aproximadas. Lo que cambia al añadir o suprimir el adverbio de exactitud no es el contenido proposicional, pero sí la extensión referencial de la expresión.

En cambio, si eliminamos el adverbio de foco de coincidencia, se pierde la valoración subjetiva de la alternativa focalizada como la más significativa. Las alternativas implícitas ya no se ordenan en una escala de más a menos significativas:

-No, señorita, con los otros, con los señores Mendoza y Valencia. - ¿Y por qué con ellos precisamente? (véase ejemplo 109) 
(140) - No cabe duda de que usted es el del retrato - dijo sacando una voz lenta, pero decidida y volviendo a mirarme-. ¿Cómo es posible que venga precisamente hoy? (Carmen Martín Gaite, Entre visillos, 1958)

En ocasiones, la eliminación del adverbio focalizador puede dificultar el proceso inferencial, ya que el hablante deja de indicar cuál es la parte significativa del mensaje. En este sentido, tampoco se altera el significado proposicional, sino la relevancia de lo comunicado. Sin el adverbio de foco, no queda claro cuál es la información relevante de esta pregunta (hoy) y se podría interpretar como pregunta por la posibilidad de que este hecho ocurra en general, y no específicamente tal día.

Hemos observado que los adverbios de foco ocurren frecuentemente en oraciones copulativas de relieve, una de las estructuras que marcan el foco con algún recurso sintáctico de focalización (NGLE 2009, 3016), por ejemplo, [ser + adverbio de foco + lo que] (apartado 5.3.4). En estos casos, la focalización se consigue tanto con recursos sintácticos de relieve informativo como, además, con recursos léxicos: un adverbio de foco. Los adverbios focalizan el atributo de la construcción copulativa, no son gramaticalmente necesarios para esta estructura y aportan simplemente énfasis. También podrían eliminarse y se perdería la valoración subjetiva.

Otro recurso sintáctico de relieve e intensificación es la repetición del miembro focalizado. El segmento se repite, aparece en posición destacada y con un adverbio de foco que vuelve a insistir sobre la relevancia de este segmento:

(141) A continuación extrajo la libreta verde, precisamente verde, donde anota los nombres de los difuntos recién llegados, las referencias de los nichos que habrán de ocupar y la hora de admisión en su cementerio. (Álvaro Colomer, Mimodrama de una ciudad muerta, 2004, CORPES XXI)

(142) Es fácil decir «tenía que pasarme a mí, justamente a mí»; (César Aira, Varamo, 2002)

\subsubsection{Alcance sintáctico}

En cuanto a la sintaxis, ya observamos en el apartado 5.2.2.1 un aumento sucesivo del alcance de los adverbios de foco, que va de la mano del surgimiento de funciones pragmáticas nuevas. Frente al pradigma sintáctico de los adverbios de modo, que siempre caracterizan la acción verbal y, por lo tanto, inciden necesariamente sobre un verbo o adjetivo deverbal, el alcance del paradigma sintáctico de los adverbios de foco es más flexible y prácticamente cualquier 
elemento oracional puede ser modificado por los adverbios: desde una palabra o un constituyente (sujeto, complemento, predicado) hasta toda la oración (subordinada y principal). Los constituyentes focalizados pueden desempeñar cualquier función en la oración: en su mayoría, se trata de complementos circunstanciales (de tiempo, lugar o causa), de atributos en construcciones copulativas o de sujetos de la oración. Cuentan, pues, con una gran flexibilidad y polifuncionalidad sintáctica.

Con frecuencia, los adverbios analizados focalizan oraciones subordinadas temporales introducidas por la conjunción cuando o subordinadas causales introducidas por la conjunción porque. En estas oraciones subordinadas, los adverbios tienen, pues, la misma función que en la modificación de sintagmas: la focalización de coincidencias temporales o de una contradicción. Hay, por lo tanto, continuidad semántico-pragmática entre la modificación de sintagmas y la modificación de oraciones subordinadas: en ambos casos, la primera función y la más frecuente de precisamente y justamente es la focalización de coincidencias temporales y la focalización de algo paradójico.

El adverbio exactamente solo aparece como modificador de determinadas oraciones subordinadas, introducidas casi siempre por como (si), en las cuales la base conceptual de exactitud es transparente. Por tanto, no se integra del todo en este nuevo (sub)paradigma sintáctico: la flexibilidad sintáctica y la polifuncionalidad de exactamente son más limitadas que las de precisamente, cabalmente, justamente y justo. Estos muestran un mayor alcance sintáctico que exactamente: pueden introducir también oraciones principales y focalizar una oración completa: Precisamente acababa de...; Justo estaba a punto de...; Justamente estábamos hablando de ti; Cabalmente, hay un cestero por aquí.

Iglesias Bango (2004, 1651) opina que los adverbios focalizadores no inciden sobre sintagmas o agrupaciones de sintagmas, sino sobre las mismas funciones sintácticas en las que estos se insertan. Efectivamente, creemos que precisamente, justamente, etc., inciden, por ejemplo, sobre el predicado, el sujeto, el atributo o un complemento circunstancial. Por eso, no hay restricciones en cuanto a qué forma ocupa tal función sintáctica (un pronombre, un adverbio, un sintagma...). Por ejemplo, los adverbios analizados focalizan frecuentemente un complemento circunstancial de tiempo y, con ello, cualquier categoría que pueda aparecer en esta función sintáctica: ocurrió precisamente ayer (adverbio), ocurrió justamente en aquel momento (sintagma preposicional), ocurrió exactamente tres minutos más tarde (sintagma nominal), ocurrió justo cuando aparecía... (oración subordinada). Incluso en la focalización de oraciones, focalizan un complemento circunstancial de tiempo implícito o elíptico: Justamente estábamos hablando de ti. 
Los adverbios de foco de coincidencia también focalizan al verbo, pero al contrario de los adverbios de modo no caracterizan el modo de la acción verbal, sino que destacan el verbo como la información relevante:

(143) - ¿Regresar? ¿Adónde?

-A mí. Al que eras. Todo esto te aleja de quien eras. ¿No te das cuenta?

-Sí, me doy cuenta.

- ¿Entonces?

-Parece que no puedo evitarlo. Quizás lo que quiero es precisamente alejarme. (Juan José Flores, El corazón del héroe, 2009, CORPES XXI)

(144) Además quería seguir estudiando economía en San Marcos, [...] A eso había que agregar, que no tenía ningún interés en casarse de momento, en general, ninguna prisa, si lo que tenía era la vida por delante, ¿o no? Y que si algún día se casaba, sería con alguien afín a ella, con quien supiese que se iba a sentir a gusto las veinticuatro horas del día. Con alguien de quien estuviese bien enamorada, en una palabra. Si no, prefería quedarse sola, subrayó, justamente estudiar le permitiría no depender de nadie en el futuro, no tener que aceptar un marido sólo para que la mantenga. ¿O vivíamos en el siglo diecinueve? (Teresa Ruiz Rosas, La mujer cambiada, 2008, CORPES XXI)

(145) un hecho que se va definiendo a medida que descubre que existe el espectador, aquel gracias al cual subsiste el instante, aquel que tiene por función justo prolongar el tiempo. (Margarita Ledo Andión, Cine de fotógrafos, 2005, CORPES XXI)

Esto es posible gracias a que los adverbios no inciden sobre el verbo, sino sobre la función sintáctica que desempeña el infinitivo: atributo (lo que quiero es alejarme), sujeto (estudiar le permite...) u objeto directo (tener por función prolongar el tiempo). Esta posición se documenta para precisamente, justamente y justo. El adverbio corto es, pues, igual de polifuncional que los adverbios en -mente. Por ejemplo, es aceptable la oración quizás lo que quiero es justo alejarme. ${ }^{16}$ Además, sería posible la sustitución por cabalmente, aunque hoy en día suena anticuado. En cambio, el adverbio exactamente no aparece antepuesto como focalizador a un verbo, sino que sigue siendo un adverbio modal:

(146) eh pequeñitos / que tampoco / sabes muy bien // mmm tú exactamente clasificar todo aquello / que estás viviendo (PRESEGAL SCOM_M33_005, España, 2007, CORPES XXI)

Creemos que el valor semántico-pragmático de precisamente, cabalmente, justo y justamente es el que permite tal polifuncionalidad: cuando expresan alguna

16 Asimismo, el adverbio corto solo puede aparecer en esta posición: quizás lo que quiero es solo alejarme. 
coincidencia significativa, su alcance puede recaer sobre cualquier elemento oracional, no parece haber restricciones sintácticas. El valor de 'coincidencia significativa' es más abstracto que el valor original de 'exactitud minuciosa', es un significado más general que se puede aplicar a todo tipo de informaciones, no solo a elementos cuyo referente es gradual y cuantificable. En cambio, exactamente no tiene la misma flexibilidad sintáctica y no ha aumentado su alcance en la misma medida. Ya que exactamente conserva su significado conceptual base, solo incide sobre segmentos que permiten ser clasificados y cuantificados de exacto 'no aproximado'.

Como observa Fuentes Rodríguez (1995-1996, 779) en su corpus de lengua hablada, precisamente ha llegado a usarse también con un valor solamente enfatizador, como un elemento expresivo, una muletilla con función retardataria, sin explicación sintáctica. Este uso de precisamente como «muletilla» podría explicar, en parte, su alta frecuencia en el español de España (en comparación con las variedades americanas), tal y como ilustramos en el apartado 4.1.3. En el CDH no encontramos tales ejemplos, ya que el adverbio mantiene claramente funciones gramaticales en la lengua escrita; no hay usos «sin explicación sintáctica» o «sin sentido». Por ejemplo, en ambas oraciones del siguiente ejemplo, precisamente tiene alcance sintáctico. De todas formas, su valor parece ser simplemente de énfasis y la repetición indica un uso excesivo, más bien como un tic idiolectal o muletilla:

(147) - Siempre estaré aquí a tu lado y esperando -le dijo, mirándolo apenas y besándole muy suavemente la frente.

- Mañana es domingo, día de guardar.

-Te llevaré a misa, mi amor.

-De eso se trata precisamente, Natalia. Porque yo creo que, precisamente mañana, Dios nos ha exonerado...

- ¿Qué dices?

-Quedamos en que iba a contarte el sueño que tuve mientras te duchabas. Hay en él un par de opiniones de Dios que merecen mucha atención... (Alfredo Bryce Echenique, $E l$ huerto de mi amada, 2002)

En un corpus oral, sí se encuentran usos de precisamente sin ninguna explicación sintáctica aparente:

(148) Señor señor Spencer, usted dice que en precisamente la selección, esta selección es mucho mejor a la selección que tuvo en los años sesenta la ocasión de clasificar al Mundial, ¿por qué? (Impacto deportivo del domingo, La voz de los Andes, 04/11/01, HCJB, 2001, CORPES XXI) 


\subsubsection{Modificación y coordinación}

Generalmente, los adverbios de foco no admiten modificadores, pero documentamos una excepción en la muestra base, en la que muy aporta también énfasis:

(149) Y apareció en una terraza sabiamente iluminada y deliciosamente florida, en un baile para siempre, un eterno Siboney de lejanas maracas, de disimuladas y nocturnas palmeras, de arrulladora brisa de mar tropical y piña colada. Muy precisamente ahí, apareció Carlitos Alegre. Chino de risa y de bondad. Había que verlo. La viva imagen de la felicidad [...]. (Alfredo Bryce Echenique, El huerto de mi amada, 2002)

Por lo general, los adverbios de foco no suelen coordinarse con otro adverbio. Sí se documenta esporádicamente la coordinación de dos adverbios de foco, como precisamente y justamente:

(150) Quiero recordar que el día que Artur Mas comunica que ya no quiere un pacto fiscal, que adelanta las elecciones y que lo que quiere es un Estado propio es precisa y justamente el día que la prima de riesgo ha estado más alta en la historia de España. (Entrevista periodística, recuperada de https://www.elcatalan.es/girauta-odio-espana-ha-calculadofinanciado-promovido-poder-cataluna/ el 22/08/2017)

En el siglo XIX, también se combinan cabalmente y precisamente:

(151) Esas mismas penosas sensaciones que desenvuelve esta irritación, según dice el mismo Broussais, son precisa y cabalmente las que nos dan la idea de que (aunque ignoremos su modo de sensibilidad) su manera de sentir comunmente no es muy fuerte ni muy viva; (José Antonio Piquer, Cuatro reflexiones sobre la nueva doctrina médico-fisiológica, 1827, recuperado de Google books el 08/12/2017).

Como muestran estos ejemplos, los adverbios de foco se coordinan cuando expresan el mismo valor pragmático. La coordinación de dos focalizadores parece otorgar un énfasis especial, ya que aumenta el peso fónico y alarga el segmento que aporta la valoración subjetiva. Además, un adverbio de foco de coincidencia puede combinarse con otro adverbio que expresa una valoración subjetiva cuando el alcance sintáctico de ambos adverbios es el mismo:

(152) Como curiosidad, el auténtico Jim Garrison tiene un cameo en la película, precisamente e irónicamente como Earl Warren. (Santi, «JFK: Caso Abierto», ¿Por qué y cómo?». Videa bien..., 2008, CORPES XXI)

En cambio, no es posible coordinar dos funciones sintácticas distintas, como un adverbio de foco y un adverbio de modo, ya que el adverbio de foco enfatiza toda la acción descrita por el verbo, mientras que el adverbio de modo caracteriza su 
realización. Por ejemplo, la acción descrita por el verbo alejarse podría caracterizarse por un adverbio de modo como rápidamente:

Quizás lo que quiero es precisamente alejarme. (véase ejemplo 143)

Quizás lo que quiero es alejarme rápidamente.

El adverbio de foco y el adverbio de modo pueden coocurrir:

Quizás lo que quiero es precisamente alejarme rápidamente.

En este ejemplo, precisamente focaliza todo el predicado, toda la acción caracterizada por el adverbio de modo; por eso, su alcance también recae sobre el adverbio rápidamente. Dado que rápidamente queda bajo el alcance de precisamente, se encuentra en otro nivel sintáctico, lo cual impide la coordinación entre ambos:

*Quizás lo que quiero es precisa y rápidamente alejarme.

\subsubsection{Posición respecto al elemento focalizado}

En cuanto a su posición respecto al elemento focalizado, los adverbios en cuestión prefieren la anteposición (Santos Río 2003; Fuentes Rodríguez 2009), ya que esta es la posición marcada para la enfatización y subjetivización (Hummel 2012, 147). En general, la anteposición marca un énfasis especial, como se ha observado en el caso de muchos adjetivos que llegan a realzar y enfatizar el contenido del sustantivo al que se anteponen (véase apartado 5.2.3).

Efectivamente, los adverbios se anteponen en la gran mayoría de los casos analizados en la muestra base. Ocasionalmente, también se encuentran pospuestos (García-Page 1995, 171; Iglesias Bango 2004, 1648), como muestran las siguientes ocurrencias:

(153) Primeramente se ha acordado que Mos de Espinán, Mariscal de Campo de los Exércitos del Rey Cristianíssimo i Governador del Castillo i Fortaleça de Salsas, saldrá con toda la Guarnición, Cabos, Oficiales i Soldados, i otras Personas de qualquier suerte i condición que sean a los seis de Enero de 1640, a las Nueve de la mañana precisamente, en caso que la Plaça no sea socorrida este mismo Día i esta misma Hora. (José Pellicer de Ossau Salas i Tovar, Avisos de 1640, 1640)

(154) Así exactamente, y sin quitar ni poner ápice, era como sentía y hablaba Juan Jerez. (José Martí, Lucía Jerez, 1885)

(155) y todos estaban entre los dieciséis y veinte años; pero uno en particular, el más gracioso cabalmente, y como músico era pito, dijérase que dejó en su casa las carnes y que se trajo sólo consigo para el viaje los huesos y la piel; (Braulio Foz, Vida de Pedro Saputo, 1844) 
(156) La gobernadora había leído la reseña de un gran baile de gala, celebrado hacía un siglo justamente, y tuvo el vivo deseo de reproducirlo en aquellos mismos salones. (Virgilio Piñera, Cuentos fríos, 1956)

En cuanto al adverbio justo, solo puede posponerse cuando modifica un adverbio, ya que, cuando se pospone a sintagmas nominales, justo funciona como adjetivo:

(157) ¡No sabéis con qué alegría vi la tierra firme! Allí justo, debajo de nosotros se extendía una pista de aterrizaje, vacía, libre de obstáculos [...]. (Juan Pedro Aparicio, Retratos de ambigú, 1989)

(158) Sea como fuere, Baro murió desternillado a la semana justa de haberse declarado su risueño mal. (Virgilio Piñera, Cuentos fríos, 1956)

La flexibilidad sintáctica es propia de los adverbios de foco. Como mencionamos en la introducción, las partículas de foco como solo inciden sobre múltiples expresiones, tanto a distancia como de forma contigua (NGLE 2009, 2990). Recordemos que en oraciones como Juan solo compró una camisa de cuadros, el focalizador solo puede asociarse con cualquiera de los constituyentes que lo siguen (solo una y no dos; solo de cuadros y no de rayas; etc.) (López Carretero 2016, 581). En el caso de los adverbios de foco analizados en este capítulo, el elemento focalizado suele ser el constituyente contiguo. Son escasos los ejemplos en los que focalizan un elemento no contiguo:

(159) En nuestros días, Tolstoi se ha hecho el apóstol de las mismas doctrinas. Y ahora verás una carta, precisamente dirigida á revolucionarios españoles, en que está condensado todo su ideal en breves líneas, y que es interesantísimo comparar con el texto citado de Platón... (Azorín [José Martínez Ruiz], La voluntad, 1902)

(160) ¿Por qué justamente es ahora, en medio de tantos conflictos, cuando ustedes deciden hacer este gran ataque [...]? (El Nacional, 17/09/1996)

(161) Abrí el tomo y cabalmente fue por una página donde leí este título. (Hartzenbusch, Cuentos y Fábulas, 1862, citado en el DHLE [1933-1936, s.v. cabalmente])

Cuando el focalizador aparece en posición no contigua, también cabe interpretar que el alcance del adverbio recae sobre todo el segmento que sigue, sin embargo, opinamos que indica claramente una coincidencia de tiempo (justo hoy):

(162) Puta qué bronca. Le estuve jugando a la cifra uno hasta el sábado pasado, y justo sale hoy. (Mario Benedetti, La tregua, 1960) 
En este tipo de ejemplos, López Samaniego $(2007,58)$ opta por separar el alcance (scope) del foco (focus): el primero es el fragmento discursivo al que modifica el adverbio, esto es, el alcance es siempre lo que sigue inmediatamente al adverbio. En cambio, el foco es el segmento que realmente es destacado por el adverbio. Así, el alcance sintáctico de los adverbios de foco en los ejemplos que acabamos de citar sería todo el predicado verbal, como por ejemplo sale hoy. En cambio, su foco - la información destacada - sería solo una parte concreta del predicado verbal: hoy. Sin embargo, no nos parece necesario separar el foco pragmático del alcance sintáctico. Consideramos que ambos suelen coincidir y que los adverbios de foco simplemente aparecen en posición no contigua, como es propio de ellos.

Hemos constatado que los adverbios de foco precisamente, justamente, justo y cabalmente aumentan su alcance y pueden incidir sobre todo el predicado: justamente estábamos hablando de ti. En esta posición, el foco pragmático y el alcance sintáctico son todo el predicado verbal. No obstante, en el ejemplo abrí el tomo y cabalmente fue por una página donde lei este título, el alcance y foco del adverbio parece ser solo el sintagma preposicional: fue cabalmente por una página donde leí este título.

Además, el alcance sintáctico puede no ser automáticamente el segmento que sigue inmediatamente al adverbio de foco, ya que - como acabamos de ejemplificar- los adverbios de foco también aparecen en posición pospuesta y su alcance recae entonces en algún segmento anterior. Por lo tanto, consideramos que el alcance sintáctico de los adverbios de foco coincide por lo general con su foco, o, en palabras de Hummel $(2012,157)$, «la unidad enfocada cae en el alcance atributivo». Aun así, en algunos ejemplos nos decantamos por separar el alcance sintáctico (scope) del alcance pragmático (foco):

En un lapso de una hora y cuarto, pasaron exactamente treinta y cinco mujeres de interés. (véase ejemplo 90)

Sintácticamente, el adverbio modifica a todo el sintagma nominal al que se antepone y en la posposición se colocaría al final (pasaron treinta y cinco mujeres de interés, exactamente). Sin embargo, el alcance pragmático - esto es, el valor enfatizado como exacto- es solo el numeral treinta y cinco, dado que exactamente no puede focalizar la exactitud de personas (véase apartado 5.3.5). En este caso, el foco pragmático es más reducido que el alcance sintáctico del adverbio.

Exactamente no ha aumentado su alcance en la misma medida que los demás adverbios de foco y no focaliza a predicados verbales ( ${ }^{\star}$ exactamente estábamos hablando de ti). Por tanto, cuando se antepone a un verbo copulativo, su alcance 
solo puede ser una parte del predicado y el adverbio se coloca en una posición no contigua al foco:

(163) - ¡Naturalmente! Cualquier persona sensible, que nos conozca, sabe que nunca hemos estado enamorados, Bert y yo. Sólo los alcoholizados se empeñan en negar la evidencia. Durante algún tiempo Bert y yo parecía que nos casaríamos.

-Exactamente es eso lo que estabas diciendo, antes de que yo me fuese a los lavabos. Que Bert y tú estuvisteis al borde del matrimonio. (Juan García Hortelano, El gran momento de Mary Tribune, 1972)

Asimismo, la posición del focalizador exactamente en preguntas (apartado 5.3.2) es flexible. Aparece en posición no contigua al interrogativo y podría aparecer en cualquier posición oracional, pero su alcance siempre es el interrogativo, en este caso, cuáles:

¿cuáles fueron exactamente las preguntas? (véase ejemplo 82)

¿cuáles fueron las preguntas exactamente?

¿exactamente cuáles fueron las preguntas?

¿cuáles exactamente fueron las preguntas?

En diálogos que imitan la conversación espontánea, los adverbios de foco a menudo aparecen pospuestos y en posición no contigua al elemento focalizado. Parece que añaden «con retraso» énfasis en algún elemento anterior:

(164) -Con la sangre que lleva dentro no quiero tener esa responsabilidad.

- ¿De verdad cree usted que tengo mala sangre?

-Realmente sí, don Pedro.

-Le probaré que no es cierto. Déjemelo aquí. Sobra quien se encargue de cuidarlo.

-En eso pensé, precisamente. Al menos con usted no le faltará el sustento. (Juan Rulfo, Pedro Páramo, 1955-1980)

(165) -Mañana es domingo, día de guardar.

-Te llevaré a misa, mi amor.

-De eso se trata precisamente, Natalia. (Alfredo Bryce Echenique, El huerto de mi amada, 2002)

En ambos ejemplos, el segmento focalizado (que comprende un elemento anafórico: eso) aparece en posición inicial del enunciado, siendo la dislocación a la izquierda un recurso sintáctico de enfatización. El adverbio de foco enfatiza lo oportuno y pertinente de este segmento; puede encabezarlo (precisamente en eso pensé; precisamente de eso se trata) o aparecer en posición final, como un anexo 
retrasado. De acuerdo con Narbona Jiménez (2015, 124-125), la sintaxis coloquial no se rige por la gramática y el orden gramatical de los constituyentes, sino que las secuencias entonativas se ordenan según la jerarquía de las informaciones que aportan: de más a menos importantes o relevantes. Probablemente por eso, el simple enfatizador precisamente, sin valor realmente informativo, se añade al final.

En determinadas construcciones, los adverbios de foco incluso interrumpen los elementos que forman un sintagma preposicional, lo cual muestra que tienen cierta independencia sintáctica (NGLE 2009, 2237-2238). Por ejemplo, precisamente focaliza todo el sintagma preposicional encabezado por la locución $a$ causa de, en el que se inserta:

(166) Pero no hay mal que por bien no venga: a causa precisamente de tal fracaso adaptativo, el gorila se ha ganado nuestra compasión y también una protección que Mosterín quisiera más eficaz. (El País, 02/02/1986)

Según López Samaniego (2007, 60), precisamente solo aparece en posición interior cuando su valor es digresivo, tal y como se observa, efectivamente, en el ejemplo citado. En este ejemplo, es posible sustituir precisamente por justamente, exactamente y cabalmente. Incluso el adverbio justo aparece en esta posición:

(167) Poco ha durado la conmoción de que una chica italiana se suicidara hace unos días $a$ causa justo de esto, del acoso. (Recuperado de http://www.eldiario.es/zonacritica/ aniston-cotillard-jolie-pitt-barbijaputa_6_561753839.html el 22/09/2016)

En conclusión, los adverbios focalizadores son sintácticamente flexibles y pueden aparecer en posición contigua o no a su foco. Aparecen, sobre todo, antepuestos, pero también pospuestos o incluso insertos. Consideramos que su foco coincide, con algunas excepciones puntuales, con su alcance sintáctico.

\subsubsection{Posición destacada}

Los adverbios de focalización enfática de identidad también aparecen en posición destacada, es decir, entre pausas prosódicas en la lengua hablada o entre comas en la lengua escrita. Cuando aparecen entre pausas, son comentarios que se resaltan por motivos de énfasis (Fuentes Rodríguez 2009, s.v. justamente, precisamente). Tal y como observa Fuentes Rodríguez (1995-1996, 777), precisamente en posición destacada enfatiza la información que viene detrás y el efecto pragmático suele ser de casualidad, de contradicción o de pertinencia:

(168) Obsérvase muchas veces que aquellos acontecimientos que menos parecen prestarse a la consecución de algún objeto son, precisamente, los precursores de ella; tal fue la revolución de julio del año 1830 en Francia. De su sangriento foco salió escapado como por 
milagro quien debía descubrir el oro de California. (Vicente Pérez Rosales, Recuerdos del pasado [1814-1860], 1882)

El adverbio de foco destacado suele aparecer después del verbo copulativo que une las dos informaciones coincidentes y antes del atributo de la oración. Asimismo, cabalmente y justamente aparecen en posición destacada:

(169) Ahora, a mediados del siglo XX, el hombre le tiene todavía un terror pánico al hombre; y con razón, porque de todos los seres de la creación, el que ha demostrado ser el más cruel y el más temible es, cabalmente, el hombre. (Gutierre Tibón, Aventuras en las cinco partes del mundo [con un brinco a Úbeda], [México], 1986) ${ }^{17}$

(170) Es un caso de malversación de fondos, de dineros que han ido para ayuda a sectores más necesitados del país, a sectores rurales del país que viven en condiciones dramáticas y todos conocemos la gravedad de la pobreza rural en Bolivia y fondos que han sido destinados para aliviar, justamente, ese problema han sido objeto de esta malversación. (Los Tiempos, 23/01/1997)

El uso destacado también se da en exactamente:

(171) A este recinto quisiera retirarse; eso es, exactamente, lo que pide al campo y a la sierra altísima. Filosofía y poesía, y naturaleza, bello reflejo de la divina serenidad. (Dámaso Alonso, Poesía española. Ensayo de métodos y límites estilísticos, 1950)

Sin embargo, también encontramos casos en los que los adverbios destacados focalizan un elemento anterior y aparecen, pues, como un anexo retrasado:

(172) -Amigo, como se lo dije yo, muy pronto voy a salir en libertá, crealó: pues ya me ve sin cadena, y el viernes, sepaseló, que en compaña de un soldao saldré a pasiar, sí, señor:

sin falta...

-Pues, aparcero -

dijo ufano Masramón-: el viernes, precisamente, acá de guardia entro yo;

17 Este ejemplo es de un escritor mexicano; prueba, pues, la mayor vitalidad de cabalmente en el español mexicano actual. 
de modo, que si usté gusta

el que salgamos los dos,

francamente, sin rodeos

desde ahora digameló [...]. (Hilario Ascasubi, Santos Vega, el payador, 1872)

En este ejemplo, precisamente expresa una coincidencia temporal. El alcance concreto del adverbio es el complemento circunstancial de tiempo: precisamente el viernes. Además, el elemento coincidente, el viernes, se repite entre el enunciado anterior y el enunciado seguido. La coincidencia (oportuna, en este caso) se produce porque de todas las alternativas posibles (miércoles, jueves, sábado, etc.) ambos personajes coinciden el mismo día. En este sentido, el adverbio de foco destacado llama la atención sobre el segmento anterior: el viernes, precisamente. Hay una pausa y un adverbio de foco con un contorno prosódico propio, que enfatiza lo que se acaba de decir.

Como venimos observando a lo largo de todo el capítulo, la anteposición es la posición prototípica del énfasis subjetivo: [adverbio focalizador + segmento focalizado] (precisamente el viernes), pero cuando el adverbio de foco aparece pospuesto, este énfasis se perdería. Creemos que es por eso por lo que se hace una pausa que crea el efecto de énfasis mediante la prosodia: [segmento focalizado + pausa + adverbio focalizador] (el viernes, precisamente). Lo mismo se observa en esta pregunta:

-Me gustaba comer contigo una sopa de verduras. Voy a extrañarte.

- ¿Por qué la sopa de verduras, precisamente? (Antonio Skármeta, El baile de la Victoria, 2003)

En el caso de justo, Hummel $(2012,147)$ también observa que la entonación y el uso de pausas permiten la posposición del focalizador (entonces, justo) y considera que esta es una variante marcada. Independientemente de su posición destacada, consideramos que los adverbios siguen teniendo una función sintáctica, ya que modifican un segmento oracional. Es decir, no se convierten en marcadores discursivos extraoracionales. El orden invertido, que conlleva una pausa, es simplemente una variante marcada, pero que no se vincula a usos nuevos.

Asimismo, en el siguiente ejemplo, el alcance del adverbio de foco justamente puede ser o bien el adverbio entonces (el elemento anterior) o bien la oración subordinada temporal:

(174) A veces, como hoy, quiero pensar que eso nunca sucedió. Pero entonces, justamente, es cuando mi malestar crece. (Augusto Roa Bastos, Hijo de hombre, 1960)

$\rightarrow$ Pero justamente entonces es cuando mi malestar crece.

$\rightarrow$ Pero entonces es justamente cuando mi malestar crece. 
Nos parece más natural la primera interpretación, que remite de nuevo a la secuencia invertida [segmento focalizado + pausa + adverbio de foco]. Es decir, el elemento enfatizado es entonces. La coincidencia temporal consiste en la simultaneidad significativa de la acción descrita en la primera oración y la indicación temporal entonces de la segunda oración: en este momento y no en otro crece el malestar. Asimismo, en el siguiente ejemplo, el alcance lógico de exactamente es el adverbio anterior (entonces):

(175) Fatalmente hay que llegar a la última décima parte de la acción, en la que el hombre juega física y moralmente en toda su plenitud; y es entonces, exactamente, cuando se decide la lucha. (Vicente Rojo, Elementos del arte de la guerra, 1947)

$\rightarrow$ y es exactamente entonces cuando se decide la lucha.

En el siguiente ejemplo, el adverbio aparece destacado y la interpretación de su alcance concreto es ambigua: puede ser el complemento circunstancial de lugar anterior (siguiendo la pauta [segmento focalizado + pausa + adverbio de foco]) o el objeto directo posterior:

(176) Un hecho digno de notarse en nuestra época es la poca confianza que en sus propias fuerzas tiene la industria privada. ¿Es modestia, debilidad ú otro sentimiento del que sea la base el interes el que produce esto? No podemos decirlo, pero el hecho existe: hoy dia los particulares se han acostumbrado á apelar á la proteccion del Gobierno y á que éste tome siempre la iniciativa, hasta que, probada hasta la saciedad la utilidad y ganancia de un negocio, la industria particular lo toma por su cuenta. Hay, sin embargo, honrosas excepciones; y en España, precisamente, tenemos un ejemplo de ellas.

Nuestro particular amigo D. Federico Muntadas es, indudablemente, una de éstas, y al que le cabe la gloria de haber sido el primero en introducir y poner en práctica la fecundacion artificial en España.

(El Conde de Fabraquer, «Piscicultura», El Campo, 1 de septiembre de 1878)

$\rightarrow$ Y precisamente en España tenemos un ejemplo de ellas.

$\rightarrow \mathrm{Y}$ en España tenemos precisamente un ejemplo de ellas.

Nos inclinamos por la primera interpretación: el autor conduce su argumentación desde una observación general hacia un ejemplo concreto, que se da precisamente en su propio país. No hay que ir muy lejos para encontrar una «excepción honrosa».

En algunos ejemplos, los adverbios en posición destacada no parecen tener alcance sobre un elemento concreto de la oración, ya que precisamente y justamente son tan polifuncionales que podrían asociarse con casi todos los constituyentes oracionales o también podrían tener a toda la oración en su alcance. En estos casos, el adverbio de foco tiñe a toda la oración con un matiz subjetivo de 
alguna coincidencia significativa o alguna acción inesperada, llamativa, sorprendente, inoportuna, etc.:

(177) Muerto el farmacéutico, su íntimo amigo don Juan Gorón, padre de Orencia, dejó a ésta y a la viuda en una miseria cruel que no tenía más salvación que la farmacia. Eusebio, justamente, terminaba tal carrera. [...] Resolvió casarlo con Orencia: ella tendría al boticario que le faltaba a la botica, y Eusebio la botica que le hacía falta al boticario. (Felipe Trigo, Jarrapellejos, 1914)

En este ejemplo, el adverbio de foco alcanza a toda la oración (sujeto y predicado), ya que la coincidencia se da también con la persona involucrada. En cierto modo, la coincidencia es triple: en el momento oportuno, la persona indicada termina la formación buscada. Justamente podría reemplazarse por casualmente o por por casualidad.

A pesar de que los adverbios cortos no suelen aparecer en posición destacada, sí se da ocasionalmente en la secuencia ser justo lo que:

(178) Sacar naturales de irreprochable templanza a una partida de mulos constituye un auténtico milagro. Y eso - un milagro- es, justo, lo que obró Rafael de la Viña, torero, taumaturgo y natural de Albacete. (El País, 22/07/1996 [España])

Creemos que esta posición destacada entre comas reproduce gráficamente la prominencia fónica que tendría este adverbio de foco en la lengua hablada.

\subsection{La construcción [negación + adverbio de foco]: no precisamente y no exactamente}

Cuando aparecen en combinación con el adverbio de negación no, precisamente y exactamente adoptan funciones pragmáticas peculiares como focalizadores del elemento negado. La negación afecta al constituyente destacado por el adverbio (Kovacci 1999, 777):

(179) se me acercó completamente borracho y me dijo: - «Supongo que un cura no va a negarle pan a un pobre hombre hambriento». Tú sabes que Julián Rojo no es precisamente católico y para entonces se había enterado que yo, el domingo pasado prediqué contra la borrachera y dije que no debíamos confundir caridad con fomentar el vicio. (Federico Henríquez Gratereaux, Empollar huevos históricos, 2001)

(180) Rieron a carcajadas, hecho que no escandalizó a nadie en el restaurante dominicano, pues el silencio no es precisamente una de las virtudes de los caribeños. (Roberto Quesada, Big Banana, 2000) 
Según López Samaniego (2007, 65-66), no precisamente focaliza el elemento negado e implica que el hablante quiere decir todo lo contrario. Esta estrategia relaciona dos elementos opuestos: el primero aparece explícitamente y se rechaza (no precisamente $x$ ), el segundo elemento se afirma implícitamente (sino todo lo contrario $=y$ ). El elemento afirmado suele quedar implícito, pero es fácilmente recuperable para el oyente, ya que se interpreta como el perfecto contrario del elemento introducido por precisamente. Es una estrategia con gran poder retórico: el elemento cierto y verdadero queda implícito y confiado a la inferencia del receptor, la inferencia es obligada y sorprendente, por lo tanto, potencia el efecto retórico (López Samaniego 2007, 56-66). También Fuentes Rodríguez (2009, s.v. precisamente), observa que no precisamente indica el elemento contrario.

En este sentido, Julián Rojo no es precisamente católico se interpreta automáticamente como todo lo contrario a católico: Julián Rojo no es en absoluto católico (es anticatólico). Es, por lo tanto, una manera indirecta de expresar, por ejemplo, una crítica. Además, esta estrategia suele aportar ironía, como muestra claramente el segundo ejemplo (el silencio no es precisamente una de sus virtudes), en el que se niega algo positivo para expresar indirectamente algo negativo. Efectivamente, ironía se define como 'expresión que da a entender algo contrario o diferente de lo que se dice, generalmente como burla disimulada' (DLE 2014, s.v. ironía).

Consideramos que esta construcción consiste en una combinación de dos instrucciones procedimentales: la negación y la focalización informativa. ${ }^{18} \mathrm{El}$ adverbio de negación no también suele clasificarse como adverbio de foco (NGLE 2009, §40.6), es decir, la negación es un operador que se asocia con el foco (Rooth 1996, 293). En concreto, esto significa que el alcance sintáctico del adverbio de negación no es su foco, y este corresponde a la información que se niega, excluye o rechaza. El adverbio aparece en posición contigua al foco o a distancia, y en ocasiones coaparece con un segmento contrastivo introducido por sino:

Vi no uno, sino dos.

No vi uno, sino dos. (NGLE 2009, 2993) [Marcas tipográficas nuestras]

Aunque el adverbio de negación aparezca antes del predicado, su alcance suele ser reducido: solamente un segmento concreto del predicado se niega (Rooth 1996, 293-294). Igual que los demás adverbios de foco, los de negación implican una serie de alternativas al elemento expresado. Es más, la semántica del adverbio de negación indica que alguna de las alternativas es verdadera (Rooth 1996, 294). El adverbio de negación no efectúa, pues, una focalización contrastiva

18 Agradezco a Catalina Fuentes que me haya dado esta pista de análisis tan fructífera. 
(NGLE 2009, §40.6.c.ss.): una de las alternativas es la que se corresponde con la verdad y esta puede aparecer explícita en un segmento contrastivo (sino dos).

Consiguientemente, analizaremos no precisamente y no exactamente como combinación de dos focalizaciones contrastivas, que coinciden en el mismo foco: el alcance del adverbio de focalización de negación (no) es el mismo que el alcance del adverbio de focalización de exactitud (precisamente, exactamente). En este sentido, la interpretación de enunciados de tipo Julián Rojo no es precisamente católico supone una combinación compleja de las inferencias pragmáticas de dos instrucciones procedimentales: negación y focalización informativa, siendo el adjetivo católico el alcance de ambas. Hay dos operaciones discursivas, una combinación de dos operadores: el operador de negación no y el operador de focalización precisamente. En los apartados que siguen, analizaremos cómo se combinan ambas operaciones procedimentales para llegar a la inferencia de 'todo lo contrario'.

Las estructuras sintácticas analizadas suelen ser de dos tipos, dependiendo de si el verbo (por lo general, un verbo copulativo) aparece entre la negación y el adverbio o no. El adverbio de focalización informativa (precisamente) suele aparecer en posición contigua al foco, mientras que el adverbio de negación no aparece también a distancia del foco:

no + verbo + adverbio de foco + sintagma (nominal o adjetival) al que afectan negación y focalización

no + adverbio de foco + sintagma (nominal o adjetival) al que afectan negación y focalización

Consideramos que el efecto pragmático es el mismo en ambos patrones. Así, la interpretación sería la misma en

Julián Rojo no es precisamente católico. (compárese con ejemplo 179)

Julián Rojo es un hombre no precisamente católico.

En ambos ejemplos, el alcance semántico-pragmático del adverbio de negación no es el adjetivo católico, lo que se niega es este adjetivo. En general, el foco de la negación se correlaciona con el foco de la oración, es decir, se correlaciona con la organización informativa foco-presuposición (Heidinger 2018, 239). El segmento negado por no es a la vez el foco de la oración. Consiguientemente, en estos casos, el adverbio precisamente enfatiza necesariamente el segmento que es foco de la oración.

Como muestra la oración Julián Rojo no es católico, la eliminación del adverbio de foco precisamente no cambia la veracidad del enunciado. Consecuentemente, el adverbio de foco precisamente parece añadir solo un matiz interpretativo a la negación. Creemos que indica cuál es la variante afirmada. En concreto, precisamente indica que la negación pretende afirmar la alternativa más contraria 
a católico. El adverbio de foco precisamente ayuda a resolver la negación y desencadena el proceso inferencial que lleva a la interpretación intencionada: la inversión. En esto consiste el significado procedimental de (no) precisamente.

Por otra parte, la estrategia tras no exactamente no consiste en una inversión, sino más bien en una matización:

- ¿Por qué ha dicho que no hay alma?

-Pero, mujer, si yo no he dicho exactamente eso.

-Sí lo ha dicho. (Carmen Martín Gaite, Entre visillos, 1958)

Al matizar lo dicho y clasificarlo como inexacto, el hablante intenta mitigar un malentendido. No exactamente corresponde a 'aproximadamente': ha dicho algo parecido, pero no exactamente esas mismas palabras. En este sentido, no exactamente no conduce a la interpretación ‘todo lo contrario', sino a ‘aproximadamente, pero no del todo exacto'. Dado que no exactamente equivale a 'aproximadamente', nos planteamos la hipótesis de que podría usarse como estrategia de atenuación. ${ }^{19}$ En concreto, según la terminología empleada por Caffi (2007), funcionaría como bush: los bushes operan sobre el contenido proposicional para hacer los términos referenciales menos precisos o minimizarlos (Schneider 2010, 253; Kaltenböck/Mihatsch/Schneider 2010, 5). La figura retórica que se sirve de la negación para negar lo contrario de lo que se afirma indirectamente se llama litote o lítotes, como en no está bien en lugar de está mal (Schneider 2013, 346). La litote es clasificada como bush por Caffi (2007), es decir, en ocasiones atenúa. No obstante, la litote puede funcionar de dos maneras: o intensifica o atenúa, dependiendo del contexto y dependiendo de si la expresión evitada es negativa o positiva (Gatti 1999, 130).

\subsubsection{La diacronía de no precisamente y no exactamente}

En el siglo XVI, encontramos no precisamente todavía como adverbio de modo y su significado es, por lo tanto, conceptual. Equivale a imprecisamente, 'de manera inexacta, imprecisa':

19 El concepto de mitigación o atenuación hace referencia a las estrategias empleadas por los hablantes para minimizar los riesgos y las posibles ofensas causadas por sus actos de habla. Reducen su responsabilidad y su compromiso para con su acto de habla. El concepto de mitigación cubre, según Caffi (2007), todas las estrategias lingüísticas mediante las cuales el hablante intenta evitar los riesgos que surgen de la interacción verbal (Schneider 2010, 255). 
(182) la differencia es un poco más o un poco menos, de suerte que, siendo por sí misma multiplicada, hará el número, cuya raíz buscávamos, no precisamente, mas será tan chica la differencia, que para la práctica de lo que se trata bien se puede tomar por raíz [...]. (Pedro Núñez, Libro de Álgebra en Aritmética y Geometría, 1567)

En el siglo XVII, no precisamente aparece como adverbio modificador de adjetivos. Su significado es conceptual y se asemeja a 'del todo' o 'completamente':

(183) Y aunque comúnmente se dice que hay dos flujos en veinticuatro horas y dos reflujos, no es precisamente cierto, porque en ello se ocupan poco menos de veinticinco horas. (Antonio de Herrera y Tordesillas, Historia general de los hechos de los castellanos en las islas y tierra firme. Década primera, 1601)

En este ejemplo, 'no precisamente cierto' equivale a 'aproximadamente cierto', ya que los datos ofrecidos son casi exactos, pero no del todo: los números son ligeramente incorrectos e imprecisos, no hay veinticuatro horas sino poco menos de veinticinco horas. La incorrección es mínima. En conclusión, no precisamente todavía mantiene un significado conceptual en el siglo XVII.

Este uso conceptual se prolonga en no exactamente hasta el siglo XIX:

(184) Los templos paganos se llaman pagodas. - Profesan las religiones politeistas un número mucho más considerable que las monoteistas, pero no exactamente conocido. (Manuel Merelo, Nociones de geografía descriptiva, 1865)

En este ejemplo, un número no se conoce con exactitud, sino solo aproximadamente. Consiguientemente, exactamente es un adverbio de modo.

En cambio, precisamente desarrolla usos pragmáticos vinculados a la negación ya a mediados del siglo XVII. Citamos las primeras ocurrencias en las que no precisamente tiene un valor enfático al focalizar un sintagma nominal negado:

(185) MUNDO Yo

ni obedezco ni replico, que aunque enemigo del Hombre

soy, no lo soy positivo, pues por ser Mundo, no soy

precisamente enemigo, sino respeto de aquellas ocasiones que en mí admito; (Pedro Calderón de la Barca, El año santo de Roma, 1650)

(186) Por tanto, los que se dedican a la Philosofía, mirándola, no precisamente como escala para subir a la Theología escolástica, sino como un instrumento para examinar la naturaleza, pueden, sin sujetarse servilmente al peripatetismo, buscar la verdad por el camino 
que les parezca más derecho [...]. (Benito Jerónimo Feijoo, Theatro crítico universal o discursos varios en todo género de materias, para desengaño de errores comunes II, 1728)

En estos ejemplos, se afirma explícitamente una alternativa al valor negado y esta aparece en un segmento contrastivo (sino respeto/sino como un instrumento), tal y como es propio del adverbio de negación no. Puesto que respeto no se concibe como lo contrario a enemigo, ni instrumento como lo contrario a escala, más bien se trata de una matización o corrección. Por lo tanto, no precisamente empieza a usarse primero para matizar o corregir lo dicho, restándole exactitud.

Además, en el siglo XIX, no precisamente aparece en diálogos, y también en estos casos se explicita la alternativa afirmada:

(187) - ¿Yo «juzgar»? - dijo el mediador-. No lo permita el cielo. Si fuera «conciliar»...

-Mira que si no quieres ser nuestro juez serás su reo... ¡Esos hipócritas!...

-¡Oh!, no; hipócritas precisamente, no... «seductores» - dijo el mediador. (Mariano José de Larra, Fígaro, 1834)

En este ejemplo, parece haber una atenuación o matización: seductores en lugar de hipócritas suena menos despreciable, es un adjetivo con connotaciones menos negativas. Como indica el mismo nombre del personaje (el mediador), este trata de suavizar y reconciliar. Asimismo, en el siguiente ejemplo, no precisamente matiza el adverbio mal ('no del todo mal'):

-Efectivamente: la encuentro á Vd. algo pálida y desmejorada.

-Le aseguro á Vd. que no sé cómo me tengo de pié.

- ¿Se encuentra Vd. mal?

- Mal, precisamente, no; pero ayer tuve un disgusto con la cocinera, y estoy sufriendo hoy las consecuencias. Figúrese Vd. que á mí me gusta mucho la merluza, pues, señor, la condenada (Dios me perdone) de la chica, dále con que había de traerme siempre abadejo. (José María de Pereda, «Los buenos muchachos», Esbozos y rasguños, 1867)

En ambos ejemplos, se invierte el orden de la secuencia. El alcance tanto del adverbio de negación como del adverbio de foco recae sobre el segmento anterior, la lectura es anafórica:

[elemento negado + adverbio + no]: mal, precisamente, no

[no (+ verbo) + adverbio + elemento negado]: no (estoy) precisamente mal

Tal y como analizamos anteriormente, la inversión del orden habitual suele conllevar un contorno prosódico propio del adverbio de foco; esto es, una pausa 
marcada por comas en la escritura (el viernes, precisamente, véase apartado 5.4.4.1). Este también es el caso de mal, precisamente, no.

Según López Samaniego (2007, 65-66), no precisamente x ('sino todo lo contrario') destaca una coincidencia inesperada entre dos entidades opuestas: el hablante niega la coincidencia entre una presuposición del interlocutor (el elemento x) y la realidad (el contrario). Es decir, según esta autora, la información falsa recoge una posible expectativa del interlocutor; pero la realidad es opuesta a las expectativas del receptor.

La estrategia de recoger la expectativa del interlocutor y negarla es la que encontramos en los dos ejemplos que acabamos de citar: el hablante niega las presuposiciones de su interlocutor, hipócritas y mal. Sin embargo, no nos parece que se indique todo lo contrario, sino que hay una matización más o menos ligera: ayer tuve un disgusto con la cocinera, y estoy sufriendo hoy las consecuencias no es lo contrario a mal sino una matización o atenuación. Asimismo, seductores (véase ejemplo 187) es un eufemismo o una matización de hipócritas, pero no lo contrario.

En la muestra base, este uso de precisamente va desapareciendo en los ejemplos más recientes y a partir del siglo XX se suele usar exactamente para atenuar, matizar o corregir:

(189) -A no ser que se le haya hecho ya otra vez al paciente y que éste conozca su técnica.

-Quiere usted decir que los pacientes se resabian como las bestias, ¿no?

-No es eso exactamente. (Darío Fernández-Flórez, Lola, espejo oscuro, 1950)

(190) -Nunca he conocido a una persona menos egoísta que tú [...] Y es sorprendente, si recuerdo cómo te imaginaba cuando nos conocimos.

- Tonta.

-No exactamente, pero... Una muchacha convencional. (Juan García Hortelano, El gran momento de Mary Tribune, 1972)

En estos ejemplos, el hablante matiza diciendo que la realidad no fue exactamente como lo pinta el interlocutor. Restando exactitud, el asunto se vuelve menos ofensivo o comprometido. Así, por ejemplo, no exactamente tonta es una atenuación: la chica no es del todo tonta. Además, la negación viene resuelta por una alternativa menos ofensiva: sino convencional. Es un término aproximativo, cercano a tonta, pero no tan fuerte. Podría considerarse un eufemismo.

En cambio, si dijéramos no precisamente tonta, el oyente interpretaría que la chica es todo lo contrario a tonta: 'sino muy lista'. La alternativa que indica precisamente es una alternativa completamente opuesta. Al parecer, solo no precisamente desarrolla este uso particular: la matización se convierte en la estrategia para expresar todo lo contrario. La inferencia 'sino todo lo contrario' es más rebuscada que la matización o atenuación, ya que se basa en un «salto cognitivo» 
más grande. Este uso encaja con el valor frecuentemente contradictorio del adverbio de foco precisamente, cuando llama la atención sobre informaciones muy sorprendentes por ser completamente opuestas a lo esperado o a un topos (véase el apartado 5.3).

El primer ejemplo sin explicitación de la alternativa afirmada (es decir, sin el segmento contrastivo introducido por sino) lo encontramos ya en el siglo XVIII. Sin alternativa explícita, la interpretación de la construcción [negación + precisamente] depende del oyente y de qué inferencias contextuales capta. En un principio, es una formulación vaga, imprecisa, ya que deja abierta cuál es la alternativa afirmada. El siguiente ejemplo presenta una ambigüedad entre una interpretación matizadora 'sino más bien/también para adultos' o la inversión 'sino todo lo contrario: para adultos’:

(191) El tercer héroe de la magia, que debe salir al theatro, es el inglés Ambrosio Merlín, de quien hasta los niños tienen noticia, pero no es precisamente cuento de niños, como juzgarán algunos, pues son muchos los autores, entre ellos casi todos los ingleses, que dan noticia de este hombre. (Benito Jerónimo Feijoo, Theatro crítico universal o discursos varios en todo género de materias, para desengaño de errores comunes II, 1728)

El valor inversor de no precisamente 'sino todo lo contrario' aparece claramente durante el siglo XIX. En este primer ejemplo, hay un valor irónico en la inversión. La alternativa inferida es un vino impuro, aguado:

(192) En tercer lugar reíase a la menor palabra que decía el forastero. Y en cuarto le había sacado de las provisiones reservadas de su hostelería unas aceitunas algo aventajadas, y cierto vino, no precisamente puro, pero en fin, del que tenía menos agua en su bodega. (Mariano José de Larra, El doncel de don Enrique el Doliente, 1834)

En el siguiente ejemplo, también hay un matiz irónico, ya que la inversión infiere todo lo contrario, un olor apestoso:

(193) [...] algunas flores silvestres, cuyo aroma no será precisamente una delicia para nuestro olfato de cortesanos. (Ignacio Manuel Altamirano, Clemencia, 1869)

Al parecer, en la segunda mitad del siglo XIX, la construcción no precisamente ya ha automatizado y convencionalizado la inferencia de 'sino lo contrario': cuando focaliza un segmento negado que expresa una cualidad positiva, el oyente automáticamente entiende que la alternativa indicada es la negativa.

Veamos cómo funciona esta inversión hacia la alternativa opuesta:

(194) Tenía veintiseis años; y no era precisamente una hermosura, pero tenía un chisgo y un aquel, que al difunto militar lo volvieron loco. (Facundo, Historia de Chucho el Ninfo, 1871) 
El adverbio de negación no niega la alternativa mencionada (no era una hermosura) y abre una serie de alternativas: entre hermosa y fea hay todo un continuo de alternativas (regular, mediocre, feílla, etc.), ordenadas en una escala gradual. Ahora bien, el adverbio de foco precisamente indica que la alternativa afirmada implícitamente es la más lejana, la totalmente opuesta, es decir: fea. En este caso, la inversión quizás también corresponda a un intento de atenuación: se niega una cualidad positiva para evitar la ofensa de atribuirle explícitamente una cualidad negativa. Además, se crea un efecto irónico y el emisor compensa esta observación crítica por otra observación reconciliadora (pero tenía un chisgo). ${ }^{20}$

Cuando no precisamente focaliza a personas - en concreto, nombres propiosinfiere lo opuesto a alguna de las cualidades que se atribuyen a tal persona:

(195) Pero tú no eres precisamente Miguel Ángel o Platón. Tú sólo sabes algo de historia, pero eso no te convierte en genio; eres bastante mediocre. (Ernesto de Blasis, Cambiando la piel, 2004, CORPES XXI)

(196) Josquin fue por ello el primer gran cobrador de morosos. Por ejemplo, el rey Luis XII de Francia no era precisamente Billy el Rápido a la hora de pagar, y le debía una pasta a su fiel servidor Josquin. Así que nuestro héroe escribió una canción que era toda una indirecta contra su señorito, el rey. (Fernando Argenta, Pequeña historia de la música, 2010, CORPES XXI)

El significado procedimental de no precisamente consiste en elegir la alternativa más significativa, la más contraria y alejada. En los ejemplos que acabamos de citar, el hablante ya no suele recoger una expectativa o presuposición del interlocutor para negarla mediante una atenuación, sino que la estrategia que ha desarrollado es otra: ironía.

El desarrollo diacrónico de ambas estructuras da lugar a un reparto funcional y una especialización pragmática de cada estructura. Veamos ahora en qué se diferencian no precisamente y no exactamente. Partimos, por ejemplo, de un continuo entre tonta y muy inteligente (véase ejemplo 190). Entre ambos polos de la escala hay una serie de alternativas intermedias:

tonta - . - . - . - muy inteligente

\footnotetext{
20 Un estudio sistemático en una base de datos más amplia podría analizar si la construcción no precisamente/exactamente tiende a aparecer con denotaciones negativas o positivas. Si niegan, sobre todo, expresiones positivas para evitar la expresión negativa, su función predominante sería la atenuación. En el momento de la redacción final de este libro, está todavía en preparación un estudio comparativo de los valores pragmáticos de esta construcción en español con las del francés y del portugués.
} 
En este sentido, la simple negación no es tonta abre una serie de alternativas posibles, solo niega la alternativa que aparece explícitamente excluida por el adverbio de negación no. Es decir, no es tonta solo niega tonta, pero deja abierta cualquier otra alternativa. Los adverbios de foco exactamente y precisamente indican cuál de estas alternativas implícitas es la que se afirma. Aunque no se explicite la alternativa afirmada, el oyente consigue recuperarla gracias al contexto y al significado procedimental de ambos adverbios. Por un lado, como mencionamos más arriba, exactamente, en tonta... no exactamente, indica una aproximación. El adverbio de foco exactamente apunta hacia una alternativa cercana que se aproxima a tonta; en el ejemplo citado, la negación se resuelve por la alternativa convencional. Por otro lado, el adverbio de foco precisamente apunta hacia la alternativa más lejana y opuesta, y la resolución sería esta: no es precisamente tonta, sino muy inteligente.

Dicho de otro modo: no exactamente desencadena la inferencia hacia un sinónimo parcial o hacia una expresión aproximada, mientras que no precisamente desencadena la inferencia hacia el antónimo. En este sentido, frecuentemente hay atenuación o matización en no exactamente e inversión irónica en no precisamente, que también puede funcionar como estrategia de atenuación (no precisamente una hermosura). En esta construcción, precisamente y exactamente funcionan como adverbios de focalización enfática de identidad, ya que identifican cuál es la alternativa afirmada. Esta identificación ocurre de manera indirecta, a través de la selección de alternativas implícitas en una negación. Los adverbios focalizan la alternativa no coincidente con la realidad. Solo a través del juego con las alternativas es posible captar la inferencia intencionada por no precisamente o no exactamente.

Asimismo, si sustituimos precisamente por exactamente en el ejemplo (179) citado arriba, la interpretación más habitual sería probablemente de atenuación o incluso de disculpa:

Julián Rojo no es precisamente católico. [ $\rightarrow$ inversión irónica: 'sino todo lo contrario: anticatólico, no cuida los diez mandamientos, etc.']

Julián Rojo no es exactamente católico. [ $\rightarrow$ matización: ‘no es muy católico/es más bien de otra religión']

En este sentido, ambos adverbios se especializan y fijan en una interpretación distinta. El adverbio exactamente mantiene su valor como adverbio de foco de exactitud, ya que indica que el elemento focalizado no es exacto, sino aproximado. En este sentido, exactamente conserva su valor semántico base: la precisión informativa en una escala. Niega la exactitud, pero no conlleva una inversión. En cambio, el valor de inversión de precisamente encaja con la focalización enfática que aporta una valoración sorprendente (incoherencia, paradoja, contradicción), 
ya que la alternativa enfatizada es la menos esperada y la más opuesta, tal y como suele ser frecuente en precisamente (véase apartado 5.3.5).

\subsubsection{Perfil sintáctico y aumento de alcance}

De acuerdo con lo observado hasta aquí, el comportamiento pragmático de no precisamente y no exactamente está relacionado con el uso de precisamente y exactamente como adverbios de foco. Sin embargo, a nivel sintáctico, esto no es del todo cierto para no exactamente, ya que no aparece en los mismos contextos sintácticos que exactamente, como mostraremos en este apartado. Las construcciones no precisamente y no exactamente aparecen, sobre todo, con sustantivos (predominantemente concretos) y adjetivos calificativos, ya que estos suelen conllevar denotaciones negativas o positivas y organizarse en un continuo entre dos polos opuestos. Sin embargo, aparecen también con otros constituyentes sintácticos a los que exactamente como mero focalizador de exactitud no puede modificar.

Supongamos, por ejemplo, que hay una serie de seis alternativas: $a, b, c, d, e$, $f$. El valor $b$ es el focalizado por los adverbios:

es exactamente/precisamente b [quedan excluidas las alternativas a, c, d, e, f]

En este caso, exactamente fija el valor de $b$ con exactitud minuciosa; para ello el referente de $b$ tiene que ser algo medible o cuantificable (un número, un dato temporal, etc.) o algo que se pueda determinar con mayor o menor exactitud, como la cualidad de un adjetivo como igual. De acuerdo con nuestro análisis de los adverbios de foco en los apartados anteriores, exactamente $b$ significa 'no aproximadamente b'. Por el contrario, precisamente $b$ suele destacar esta alternativa como significativa, coincidente, inesperada, etc. De todas las alternativas, esta es la menos esperada. El referente de precisamente $b$ puede ser de cualquier tipo, también una persona o algo que no se puede medir con exactitud. Precisamente puede aparecer prácticamente con cualquier segmento oracional (véase apartado 5.4.2).

La negación excluye $b$ y abre toda la serie de alternativas implícitas:

no es $b[\rightarrow$ sino alguna de las alternativas: $a, c, d, e, f]$

Y el adverbio de foco indica cuál de las alternativas es la intencionada:

no es exactamente $b[\rightarrow$ sino una alternativa aproximada: $a, c]$

no es precisamente $b[\rightarrow$ sino la alternativa opuesta: $f]$ 
Ahora bien, el referente de $b$ en no es exactamente $b$ no tiene que ser medible o cuantificable. $B$ puede ser también un adjetivo no cuantificable, un sustantivo (incluso un nombre propio) o una oración subordinada. Es decir, no exactamente incide sobre categorías sintácticas sobre las que no puede recaer el alcance de exactamente como adverbio de foco de exactitud.

Por ejemplo, volviendo al ejemplo Julián Rojo no es precisamente/exactamente católico, llama la atención que la correspondiente oración sin negación solo es posible con precisamente:
Julián Rojo es precisamente católico.
Julián Rojo no es precisamente católico.
\#Julián Rojo es exactamente católico.
Julián Rojo no es exactamente católico.

Esta oración es perfectamente posible con precisamente, ya que este adverbio también focaliza adjetivos como una información significativa, quizás inesperada ('de todas las religiones, tenía que ser precisamente católico'). En cambio, el adverbio de foco de exactitud exactamente solo suele modificar adjetivos que remiten a una cualidad cuantificable o medible con exactitud. Adjetivos como católico y tonta - al contrario de adjetivos «medibles» como igual-difícilmente permiten la focalización mediante exactamente. No obstante, en combinación con el adverbio de negación no, exactamente extiende su alcance a adjetivos no medibles y la oración Julián Rojo no es exactamente católico es perfectamente aceptable.

Ya observamos en otro apartado (véase 5.4.2) que el alcance de precisamente puede recaer también sobre un verbo (en forma infinitiva) y que sigue siendo un adverbio de foco:

(197) Mientras ella asistía a la escuela, yo escribía. No era precisamente escribir lo que hacía; me pasaba la mayor parte del tiempo intentando ordenar de forma coherente los cientos de recuerdos que se congregaban en mi cabeza. (Carla Guelfenbein, La mujer de mi vida, 2011, CORPES XXI)

Mientras que exactamente a secas funciona como adverbio modal en este contexto (véase ejemplo 146 en el apartado 5.4.2), sí llega a funcionar como adverbio de foco cuando se combina con la negación:

(198) Lo he estado pensando. Dices que os fuisteis de copas pero ir a cenar y tomarse una copa en el mismo restaurante no es exactamente ir de copas. (Gemma Rodríguez Villanueva, «Estamos quedando fatal», Carlos Rodríguez (coord.), Premio $M^{a}$ Teresa León, 2002, CORPES XXI) 
Además, no exactamente incide sobre nombres propios e indica una matización:

(199) Ese mismo chiste, contado por Anita, así haciéndose la entendida, con el cigarrillo de medio lado, iqué sentido tan distinto hubiera tenido! Quizás Ana no fuera exactamente Serena, pero hubiera sido la única persona del mundo capaz de hacer sonreír, de hacer entender a Serena la historieta, o algo a partir de historieta semejante, y otro tanto con san Jorge y el Vaticano. (Agustín Cerezales, Mi viajera. Ciervos errantes y tigres invisibles, 2001)

En este ejemplo, Ana no tiene las mismas cualidades que Serena. En alguna escala mental (el ejemplo no indica de qué tipo), el hablante sitúa a Ana en una posición ligeramente inferior a Serena, pero lo compensa por otra cualidad, el ser graciosa. En cambio, exactamente nunca aparece como focalizador enfático de identidad de una persona (véase apartado 5.3.5): la oración \#fue exactamente Serena es imposible, porque la identidad de una persona no se puede cuantificar y medir. En cambio, sí es aceptable fue precisamente Serena ('de todas las posibles alternativas, tuvo que ser ella').

Por último, el alcance de no exactamente recae también sobre oraciones subordinadas causales. En el siguiente ejemplo, se coordinan dos oraciones subordinadas causales (ambas introducidas por el nexo porque) mediante la conjunción adversativa sino. La alternativa aparece, por lo tanto, explícita:

(200) Cuando mama, el niño succiona el pezón con esta doble finalidad: nutrirse y satisfacerse. Por eso, a veces llora y mama no exactamente porque tiene hambre, sino porque se siente tenso y necesita succionar para calmarse. Busca lo mismo cuando succiona el chupete o su propio pulgar. (Mirta Videla; María Tereza Maldonado; Jorge Wasserman, Quiero dar de mamar a mi bebé. Vivencias, técnicas y mitos de la lactancia materna, 1983)

Por el contrario, tal y como observamos en el apartado 5.3.6, el adverbio de foco exactamente no introduce oraciones subordinadas causales. La correspondiente oración con exactamente es agramatical, o al menos muy cuestionable, mientras que precisamente sí incide sobre oraciones subordinadas causales:

El niño llora y mama precisamente porque tiene hambre.

\#El niño llora y mama exactamente porque tiene hambre.

En conclusión, exactamente extiende su alcance sintáctico cuando se combina con la negación no y aparece en contextos en los que el focalizador de exactitud exactamente no sería aceptable. Posiblemente, este aumento de polifuncionalidad sintáctica se debe a que el operador de negación no puede aparecer en todos estos contextos -incide sobre cualquier elemento oracional- y 
exactamente se asocia al operador de negación, adoptando las posibilidades sintácticas de no. En este sentido, el elemento primario o principal de esta construcción sería el adverbio de negación no y los adverbios de foco precisamente y exactamente se añadirían como elementos secundarios para desambiguar la negación. Por otro lado, también es posible que no exactamente adopte los contextos sintácticos de no precisamente por analogía. Dicho de otro modo, el «efecto paradigmático» abre nuevos huecos sintácticos a exactamente y aumenta su alcance.

\subsubsection{El «efecto paradigmático», datos cuantitativos y cambio de microparadigma}

La inferencia pragmática 'todo lo contrario' se ha convertido en la interpretación más frecuente de no precisamente. Este valor también aparece de manera esporádica en los demás adverbios del grupo. Ocasionalmente, la interpretación 'todo lo contrario', también con valor irónico, se da con no exactamente, cuando el contexto amplio aclara la recuperación de un elemento contrapuesto e inesperado:

(201) El comandante pensó que lo mejor era enviarla a un colegio en Estados Unidos, para limarle aquella libertad ganada en el desierto mexicano. El pobre parecía ignorar que Estados Unidos no es exactamente el sitio para enseñar una mujer a contener su libertad. La muchacha retornó más independiente que nunca y con avanzados conocimientos. (Rafael Nogales Méndez, Memorias, 1936)

López Samaniego $(2007,63)$ no encuentra ejemplos de no justamente en su corpus, por lo cual opina que se trata de un valor en el que se ha especializado precisamente. Efectivamente, son muy poco frecuentes. La búsqueda de las estructuras correspondientes en el CDH muestra que no justamente aparece fundamentalmente con el significado conceptual 'de manera injusta'. Solo hemos detectado unos pocos ejemplos recientes donde expresa una matización o inversión, es decir, adopta el valor de no exactamente o no precisamente:

(202) La casa, que además tenía paredes de papel, no era justamente un castillo. (Carlos Polimeni, Luca, 1991)

(203) Carlos está preocupado y yo comprendo su turbación porque los pesquisas siguen pisándole los talones. Saber que te siguen a todos lados no es justamente tranquilizador, ¿no crees? Peor aún si observas que están intentando concluir que has matado a alguien, [...]. (Leonardo Wild, El caso de los muertos de risa, 2001, CORPES XXI) 
Es llamativo que justamente no haya desarrollado ese uso en la misma medida que precisamente y exactamente, ya que, en todos los demás contextos observados en este capítulo, justamente aparece como sinónimo de precisamente. Probablemente, esta asimetría en el paradigma pragmático se debe a que justamente remite al significado base de justicia cuando se combina con la negación, de acuerdo con el adjetivo injusto y el adverbio injustamente, que solo se usan con el valor semántico de justicia.

Además, justamente y el adverbio corto justo suelen adoptar los usos pragmáticos y discursivos a la par, como variantes morfológicas. Sin embargo, el adverbio de foco justo no aparece en las construcciones de inversión. Por un lado, la combinación no + ser + justo remite al significado base justo ${ }_{1}$ 'según la justicia' (véase apartado 4.2.3.1). Por otro lado, no hemos encontrado ejemplos de [no + justo + sustantivo]. Curiosamente, en las siguientes oraciones, justo sería perfectamente posible sin el adverbio de negación:

Estados Unidos (?no) es justo el sitio para enseñar una mujer a contener su libertad. (compárese con ejemplo 201)

El niño llora y mama (\#no) justo porque tiene hambre. (compárese con ejemplo 200)

Sin embargo, con la negación, no son oraciones aceptables. Por algún motivo, no justo es cuestionable o incluso agramatical, en cuanto que el adverbio corto solo se combina perfectamente con la negación (El niño llora y mama no solo porque tiene hambre). En conclusión, mientras que exactamente aumenta sus posibilidades sintácticas en combinación con la negación (véase apartado anterior), la distribución sintáctica de justo, curiosamente, se reduce con la negación.

Por último, también hay algunas ocurrencias de no cabalmente, que parece tomar el valor de no exactamente, es decir, indica aproximación:

(204) Pero, a poco de navegar, Esteban, cuyo sentido de la orientación se había aguzado mucho en los últimos tiempos - habiendo adquirido por añadidura algunos conocimientos de navegación-creyó observar que el rumbo llevado por los barcos no era cabalmente el que podría conducirlos a la isla de Guadalupe. Barthelemy frunció el ceño ante la observación del escribano. «Guárdese el secreto - dijo-: Usted sabe muy bien que no podré cumplir la promesa que hice a esos forbantes. Sería un precedente funesto. El Comisario no lo toleraría. Vamos a una isla holandesa, donde venderemos el cargamento de negros». (Alejo Carpentier, El siglo de las luces, 1962)

En cuanto a la cuantificación de este uso, documentamos en nuestra muestra base 37 ocurrencias de precisamente y 14 de exactamente en combinación con la negación (tanto con valor modal como con valor de focalización). De nuevo, recurrimos al CDH para profundizar el análisis de esta función, para 
detectar las primeras documentaciones y para obtener datos más representativos. La Tabla 28 compara la frecuencia de los adverbios de exactitud en dos variantes de la construcción, [no + adverbio] y [no + ser (lema) + adverbio]. En el caso de precisamente y exactamente hay demasiados resultados como para cribarlos manualmente y verificar si todas estas ocurrencias corresponden a la función que nos interesa. Sin embargo, una ojeada a las primeras páginas de los resultados confirma que prácticamente todos los ejemplos son pertinentes. En el caso de justamente y cabalmente, descontamos los pocos ejemplos que no corresponden a la función que analizamos, sino que coinciden con otro uso (por ejemplo, modal).

Tabla 28: Frecuencia de las secuencias [no + adverbio] y [no + ser (lema) + adverbio] en el CDH.

\begin{tabular}{lrrrr}
\hline & precisamente & exactamente & justamente & cabalmente \\
\hline no + adverbio & 587 & 213 & 1 & 2 \\
no + ser + adverbio & 850 & 324 & 8 & 1 \\
\hline suma & 1437 & 537 & 9 & 3 \\
\hline
\end{tabular}

Como muestra este recuento, la focalización en combinación con la negación predomina, de nuevo, en precisamente. En este caso, es seguido por exactamente, mientras que justamente y cabalmente son muy marginales y justo no se usa. Aquí, la asimetría del paradigma se debe, por lo tanto, a razones semánticas $\mathrm{y}$, en concreto, a interferencias de la polisemia del lexema base justamente, que bloquea la construcción para este lexema en concreto. La escasez de cabalmente se debe probablemente a su baja frecuencia general en el español actual.

En resumen, el uso como focalizador en estructuras de negación se desarrolla antes en precisamente: aparece en el siglo XVIII como estrategia para corregir y matizar lo dicho al restar exactitud: no precisamente equivale a 'aproximadamente'. Esta estrategia sirve como mecanismo de atenuación ('no del todo', 'no completamente'). A partir de ahí, cuando se deja de expresar la alternativa en un segmento contrastivo (sino...), no precisamente evoluciona hasta inferir 'sino todo lo contrario', es decir, hasta la inversión irónica. Esta aparece en el siglo XIX y es la interpretación de no precisamente más frecuente en la actualidad. En cambio, los usos pragmáticos de no exactamente aparecen más tarde, en el siglo XX, y predomina la función atenuante de matizar o corregir lo dicho. En este sentido, no exactamente retoma la función originaria de no precisamente. Raras veces, no exactamente llega a inferir «todo lo contrario».

Este uso particular surge del juego con las alternativas implícitas, la propiedad central de todos los adverbios de foco. Los adverbios precisamente y exactamente 
indican cuál es la alternativa insinuada. Probablemente por influencia del valor más frecuente de precisamente como adverbio de focalización enfático de identidad, este adverbio infiere una inversión. En cambio, de acuerdo con los valores del adverbio de focalización de exactitud exactamente, la construcción no exactamente infiere la interpretación 'aproximadamente'. Además, gracias al «efecto paradigmático» este adverbio aumenta su alcance cuando se combina con la negación: no exactamente aparece en contextos en los que exactamente no puede aparecer como adverbio de foco de exactitud.

Si consideramos que se trata de una manera indirecta de expresarse, en la mayoría de los casos también hay una valoración subjetiva. Existe alguna razón por la que el hablante no dice explícitamente lo que quiere expresar, por lo tanto, la información afirmada implícitamente cobra relevancia. Si tenemos en cuenta que la ironía frecuentemente indica una actitud crítica, despreciativa o de burla, sirve, por un lado, para atenuar una crítica o, por el contrario, incluso para intensificarla (Andueza 2016, 655-656). Lo observamos en ejemplos como el silencio no es precisamente una de las virtudes de los caribeños o el rey Luis XII de Francia no era precisamente Billy el Rápido a la hora de pagar.

Creemos que el fenómeno analizado hay que considerarlo una construccionalización, es decir, una asociación esquemática entre una forma y un contenido semántico. La construcción formada por el adverbio de negación (no) y el adverbio de foco (precisamente o exactamente) no es del todo transparente y recuperable a partir de los significados conceptuales y procedimentales de cada uno: se combina el procedimiento de negación con el procedimiento de focalización, pero el significado particular que fija esta construcción no es directamente descriptible como suma de 'no' + 'precisamente'/'exactamente'. No es una simple colocación, ya que la mera suma de ambos daría como resultado el significado 'aproximadamente'. Sin embargo, los ejemplos muestran un abanico de valores pragmáticos nuevos. ${ }^{21}$

Si interpretamos no exactamente/no precisamente como simples adverbios de aproximación, esto significaría que saldrían de su microparadigma originario, el de los «adverbios pleonásticos enfatizadores de exactitud» (Kaul de Marlangeon 2002, véase el anexo) y entrarían - dentro del macroparadigma de la cuantificación - en otro microparadigma, el de los adverbios cuantificadores de aproximación. Este, según Kaul de Marlangeon (2002, véase el anexo), está formado por escasamente y aproximadamente. Sin embargo, no exactamente/no precisamente

21 Esta construcción también existe en inglés (not exactly), en alemán (nicht gerade), en portugués (não exatamente) y en francés (pas précisément). 
aportan matices pragmáticos nuevos y particulares. Aparecen en contextos en los que aproximadamente o escasamente no son aceptables:

\#el silencio es aproximadamente una de las virtudes de los caribeños (compárese con ejemplo 180)

\#el rey Luis XII de Francia era escasamente Billy el Rápido a la hora de pagar (compárese con ejemplo 196)

Por eso, es cuestionable que no precisamente/no exactamente se asocien a los adverbios de aproximación. Además, creemos que estas conmutaciones imposibles prueban que el alcance de ambas partes de la construcción, es decir, el foco de no y el foco de precisamente/exactamente, recae sobre el mismo segmento (una de las virtudes; Billy el Rápido...). El alcance del adverbio de negación no es el adverbio de exactitud; no hay un adverbio de exactitud negado, sino una combinación entre dos adverbios de foco. Esto prueba, quizás, que la construcción tiene un significado propio y no composicional.

Optamos, pues, por considerar que la construcción [negación + adverbio de foco] forma un microparadigma propio, en el que exactamente y precisamente se agrupan con otros adverbios. Por ejemplo, la combinación con la negación también se da con propiamente (Egea 1979, 216). En el caso de no propiamente -o también no estrictamente, no particularmente, no especialmente- parece ser obligatoria la resolución de la negación por la alternativa explícita, es decir, el segmento contrastivo introducido por sino. Además, consideramos que, por ejemplo, propiamente conserva su significado conceptual pleno; es un significado metalingüístico que indica que la denominación expresada no se aplica literalmente al referente extralingüístico. Matiza el segmento negado, pero no aporta matices irónicos de inversión:

(205) El punto de parranda también se puede considerar una variante del estilo de punto fijo; la décima se canta ininterrumpidamente, y el conjunto instrumental utiliza instrumentos de percusión y violín, este último en función no propiamente melódica, sino más bien contrapuntística. (Martha Esquenazi Pérez, Del areíto y otros sones, 2001, CORPES XXI)

\subsection{Conclusiones sobre la focalización}

A modo de conclusión, nos detendremos en una propiedad central que ayuda a definir los usos observados: el papel de las alternativas implícitas y sus escalas. Después, resumiremos la cronología de los diversos valores pragmáticos de la focalización para mostrar cómo cambia y evoluciona el paradigma. Además, 
analizaremos los cambios semánticos y sintácticos en relación con el marco teórico de la gramaticalización, la pragmaticalización y la subjetivización.

\subsubsection{Alternativas, escalas y una propuesta de definición}

La definición más general y abarcadora para precisamente, justamente, justo y cabalmente sería que ejercen una focalización enfática de identidad entre dos elementos coincidentes. Enfatizan y llaman la atención sobre una coincidencia (en el tiempo, en el espacio, de personas, de cosas, etc.) o indican la coincidencia de argumentos o temas del discurso. En cambio, exactamente funciona sobre todo como focalizador de exactitud y enfatiza tanto la exactitud minuciosa en datos temporales y espaciales como la correspondencia exacta en comparaciones (es decir, la coincidencia exacta entre dos cosas, sucesos, etc.). Tal y como advertimos al principio de este capítulo (apartado 5.3.1), la denominación adverbios de foco o de focalización no es del todo correcta, porque no se asocian siempre con el foco informativo de la oración sino que enfatizan cualquier segmento oracional. Sería, pues, más adecuado llamarlos adverbios enfatizadores.

El análisis ha mostrado que, efectivamente, los focalizadores excluyen alternativas implícitas. Es una propiedad constante, observada en todos los usos. En el caso de los focalizadores enfáticos de exactitud, las alternativas son menos exactas (aproximadas) y en el caso de la focalización enfática de coincidencia, las alternativas son menos significativas (menos sorprendentes, menos relevantes, menos oportunas, etc.) para la situación comunicativa. El carácter escalar y graduable ya está presente en el concepto base, la exactitud: es una propiedad inherentemente medible y cuantificable. Esta escalaridad se traspone a otros dominios más subjetivos, más abstractos y/o metafóricos.

Dado que los adverbios de foco precisamente, justamente, justo y cabalmente adquieren valores poco concretos, hay que inferirlos siempre del contexto. Por eso, resulta difícil establecer una categorización de los diversos efectos pragmáticos: López Samaniego $(2007,54)$ atribuye a precisamente y justamente una «riqueza de valores pragmáticos asociados». Para encontrar un «valor o significado básico que englobe la larga serie de valores contextuales y funciones discursivas» (López Samaniego 2007, 60), la autora propone definir el procedimiento general de estos adverbios como «focalización de coincidencia», que cubre un conjunto amplio de significados, desde una concurrencia de dos elementos en el tiempo o espacio, hasta la enfatización de identidad entre dos elementos semejantes o idénticos (López Samaniego 2007, 61). Además, la autora relaciona este uso con la Teoría de la Relevancia de Sperber y Wilson (1986): una determinada información se pone de relieve porque de alguna manera es significativa, porque 
tiene algún efecto contextual en la interpretación del resto del discurso. En este sentido, nuestro análisis ha mostrado que las variantes implícitamente excluidas son menos relevantes para la situación comunicativa.

Tal y como concluye López Samaniego (2007, 74), la inferencia concreta a la que conducen los focalizadores depende de dos factores: del tipo de elementos coincidentes y de la motivación que lleva al emisor a destacar o focalizar la coincidencia. En este sentido, proponemos que la interpretación de un ejemplo concreto surge de la combinación de dos factores determinantes:

a) Por un lado, depende de la naturaleza de los elementos coincidentes (sucesos, datos espaciotemporales, personas, argumentos, temas, relación lógica entre dos sucesos...). Siempre hay dos elementos coincidentes: el elemento focalizado, que se encuentra en el alcance sintáctico del adverbio, y otro elemento o mencionado explícitamente en el discurso o presente en la situación comunicativa.

b) Por otro lado, la interpretación depende de la valoración más subjetiva (sorpresa, oportunidad, suerte, desgracia, azar, crítica, justificación...) o menos subjetiva (exactitud minuciosa) que aporta el hablante. La valoración subjetiva no queda codificada explícitamente, sino que se infiere por el contexto amplio, gracias al conocimiento compartido entre los interlocutores o de acuerdo con estereotipos sociales como los topoi.

Esta complejidad y la dependencia contextual impiden definir un valor claro y concreto para los adverbios de foco precisamente, justamente, justo $\mathrm{y}$ cabalmente. ${ }^{22} \mathrm{Ni}$ siquiera indican si la coincidencia focalizada es oportuna o no, es decir, ni siquiera indican si la valoración subjetiva por parte del hablante es positiva o negativa. En todo caso, los adverbios de foco apuntan frecuentemente a las alternativas que se encuentran en los extremos de las escalas subyacentes, ya sea un extremo u otro. Estos extremos se presentan como los más relevantes por ser los más llamativos.

A veces, la coaparición de otros operadores como mira por dónde o de ciertos sustantivos (desgracia, suerte, etc.) indica cuál es la actitud subjetiva del hablante frente a su enunciado. Además, podemos hablar de cierta construccionalización en determinadas secuencias: precisamente por eso (mismo) y precisamente porque presentan cierta fijación no solo formal sino también interpretativa, ya

22 Consideramos que el valor atribuido al elemento focalizado es más concreto y claro en los adverbios de foco solo, incluso o ni siquiera. También en exactamente, el valor es más claro y concreto: exactitud minuciosa. 
que casi siempre aparecen con el valor de focalización paradójica, no esperada (inversión argumentativa).

Asimismo, hay cierta fijación y automatización en la construcción que combina un adverbio de foco con el operador de negación no. El adverbio de foco precisamente o exactamente ayuda a resolver la litotes porque indica cuál de las alternativas, ordenadas en una escala, es la que debe recuperar el interlocutor: o bien una alternativa cercana, aproximada (no he dicho exactamente eso) o bien la alternativa opuesta (no es precisamente católico). En este caso, la negación anula la coincidencia entre la palabra focalizada (por ejemplo, católico) y la realidad extralingüística. Es decir, lo expresado no se identifica con la realidad. En cambio, la identificación o coincidencia se da con una de las alternativas implícitas; en concreto, se da con la alternativa más relevante y significativa.

En el caso de la focalización informativa que sirve de mecanismo para crear un discurso coherente, el hablante focaliza un segmento que considera pertinente o que muestra semejanza temática con otro bloque de información. Así, la transición de un tema hacia otro es más relevante y pertinente, o se ejemplifica una observación general. Los adverbios precisamente, justamente y justo focalizan como oportuna una aportación concreta al tema. Es un mecanismo de digresión y construcción coherente del discurso que ayuda al procesamiento de la información, por lo tanto, en este caso no hay valores subjetivos. Este uso no cuenta con un perfil sintáctico propio o alguna construcción particular, sino que coincide formalmente con cualquiera de las demás funciones observadas.

Este abanico de valores pragmáticos encaja con el concepto de la multidimensionalidad, según el cual el funcionamiento de un operador o conector, por lo general, no se limita a un solo plano: solo a lo modal, solo a lo enunciativo, argumentativo o informativo (Fuentes Rodríguez 2013b; 2016; 2017). El valor básico de los adverbios de foco analizados en este capítulo corresponde a la focalización informativa. Consecuentemente, operan básicamente en el plano informativo: el hablante da mayor relevancia a una determinada información y la realza (Fuentes Rodríguez 2017, 11). Es el primer valor y el valor base de todos los adverbios analizados en este capítulo, y también aparece ocasionalmente en los adjetivos preciso, exacto y justo.

Además, en varias ocasiones, precisamente y, en menor medida, justamente, justo y cabalmente, entran en el plano de la modalidad, que «muestra la actitud subjetiva del hablante» (Fuentes Rodríguez 2017, 11): hemos analizado valores subjetivos como sorpresa, valoración negativa (coincidencia inoportuna) o positiva (casualidad favorable), etc. En este sentido, los adverbios de foco adquieren 
instrucciones relativas a la modalidad, una dimensión que, según Briz Gómez/ Pons Bordería/Portolés Lázaro (2008), también abarca estrategias como la intensificación o atenuación. Lo vemos en no precisamente y no exactamente. En concreto, Martí Sánchez $(2008,83)$ menciona precisamente como ejemplo de operador modal que expresa «contenidos subjetivos relativos a la resonancia en el hablante de determinadas informaciones».

Por último, también entra en juego ocasionalmente el plano argumentativo, que se ocupa de cómo busca el hablante convencer al oyente de sus tesis (Fuentes Rodríguez 2017, 11). Este valor aparece cuando precisamente (y, en menor medida, justamente, justo y cabalmente) focalizan la inversión de la argumentación, como en las estructuras de tipo precisamente por eso (mismo), es decir, cuando convierte una relación adversativa o concesiva entre dos proposiciones en una relación causal.

\subsubsection{Formación y evolución del paradigma}

El primer contexto en el que se desarrolla el valor de focalización de exactitud y de coincidencia es el de los datos espaciotemporales. Tanto los adjetivos como los adverbios de exactitud con significados conceptuales aparecen en el dominio del tiempo y espacio (apartado 4.2.2.1). Este también es el contexto en el que los adjetivos justo y preciso aparecen como focalizadores enfáticos. Consideramos, por lo tanto, que el tiempo y espacio constituyen el dominio prototípico de este grupo de focalizadores. Desde este ámbito central, los adverbios de foco (pero no los adjetivos), se expanden a contextos nuevos y se vuelven polifuncionales.

Tal y como observa Company Company $(2008,17)$, las innovaciones se inician en contextos sintáctica y semánticamente afines al significado original y avanzan gradualmente hacia contextos nuevos y diversos, a la vez que aumentan la frecuencia de empleo. ${ }^{23}$ Efectivamente, el proceso de desarrollo de los adverbios de foco analizados arranca en un contexto semántico afín a los adjetivos atributivos y adverbios modales base: la exactitud en datos temporales y espaciales (véase el apartado 4.2.2.1). Desde estos contextos más afines al concepto de exactitud, los adverbios de foco se extienden a contextos cada vez más alejados y cada vez más generales (personas, la relación lógica entre dos sucesos, argumentos, párrafos o citas, etc.).

23 Lo confirma, por ejemplo, el análisis diacrónico de verdaderamente de González Manzano (2010): la autora opta por llamar subjetivización al proceso mediante el cual este adverbio adquiere valores subjetivos y enfáticos. La innovación empieza en contextos más afines al valor original de verdaderamente y luego se extiende a contextos más alejados. 
Resumimos este desarrollo en cada uno de los adverbios:

Precisamente se usa desde el siglo XVI como focalizador de exactitud. El paso de focalización de exactitud a focalización que infiere coincidencia aparece durante la segunda mitad del siglo XVII y se consolida en la primera mitad del siglo XVIII. Al parecer, este cambio está plenamente consumado en precisamente, ya que - en el dominio del tiempo y espacio- prácticamente deja de usarse como focalizador de exactitud a principios del siglo XX y su función predominante hoy en día consiste en inferir una coincidencia significativa.

Justamente y justo se usan desde el siglo XVI como focalizadores de exactitud, igual que precisamente. No obstante, la evolución «focalización de exactitud > efecto de coincidencia» aparece dos siglos más tarde: en la segunda mitad del siglo XVIII, justamente aparece esporádicamente como focalizador de coincidencias y se consolida en el XIX. En la actualidad, justo y justamente son ambiguos entre una interpretación meramente focalizadora de exactitud (la información es rigurosamente exacta) y un posible efecto añadido de coincidencia significativa.

En el caso de justo, la escasa documentación en el corpus no permite datar con seguridad el valor de coincidencia significativa. Dado que justo como adverbio corto se marginaliza en la escritura entre los siglos XVII y XIX y solo se vuelve a admitir en el siglo XX, no queda documentado si desarrolla los diversos usos pragmáticos a la par que justamente. Llama la atención que, en el siglo XX, justo reaparece en todos los contextos y distribuciones de justamente y precisamente con los mismos valores pragmáticos. Es decir, justo no muestra el desarrollo sucesivo más tardío que se observa en exactamente, sino que justo se documenta «de golpe» en prácticamente todas las funciones. Por eso, es probable que hubiera una continuidad en la lengua hablada desde los siglos XVIII y XIX, en los que se usaría en los mismos contextos que justamente.

Frente a la tendencia de diferenciación semántica y funcional entre los adverbios en -mente y los adverbios cortos con la misma base léxica, justo y justamente son prácticamente sinónimos. En cambio, pares como claro/claramente, igual/ igualmente, firme/firmemente y otros no son sinónimos (Company Company 2017, 271). En esto, justo y justamente coinciden con los adverbios de focalización exclusiva solo y solamente, ya que estos dos son igual de polifuncionales: no se observan preferencias por uno $\mathrm{u}$ otro según el contexto sintáctico; solo y solamente son intercambiables y desempeñan la misma función discursiva (Medina Gómez/ Alarcón Neve 2017, 296). La única diferencia estadísticamente significativa entre solo y solamente es la subjetividad: el valor meramente exclusivo aparece más bien en solo, mientras que el valor de matización subjetiva (intensificación o atenuación), que supone un ligero semantic bleaching, aparece con mayor frecuencia en solamente (Medina Gómez/Alarcón Neve 2017, 292-294). 
En justo y justamente observamos una diferenciación según el medio, esto es, variación diamésica: en la lengua hablada, hay preferencia por justamente (véase apartado 4.1.3). Esto probablemente se debe a los usos subjetivo-enfáticos, ya que un mayor peso fónico permite una mayor expresividad. Efectivamente, el adverbio largo aparece en más contextos subjetivos. Por ejemplo, en el CORPES XXI, la combinación [justo + nombre propio] cuenta con 7 casos frente a 35 registros de [justamente + nombre propio]. En cambio, justo parece haberse especializado en colocaciones no subjetivas: justo antes, justo después, justo cuando... (véanse apartados 4.2.3.2 y 5.2.2.1).

En cuanto a cabalmente, se documenta ya esporádicamente como adverbio de foco de exactitud en textos alfonsíes y reaparece en los siglos XVIII y XIX en los mismos contextos sintácticos que precisamente y justamente con los mismos valores pragmáticos de focalización de coincidencia. Era, pues, igual de polifuncional y aportaba valores subjetivos, pero cae en desuso en el siglo XX.

Por último, exactamente difiere en su desarrollo pragmático de los demás adverbios: funciona, sobre todo, como focalizador de exactitud y apenas aparece como focalizador de coincidencias. Además, se especializa en otro contexto: exactamente surge en el siglo XVIII como focalizador de exactitud en comparaciones y es en este contexto donde aumenta su alcance: incide sobre oraciones subordinadas (como si). No hay valoraciones subjetivas en cuanto al incumplimiento de algún topos, ni sorpresa ante una coincidencia inesperada: los dos elementos simplemente se corresponden de manera exacta. Además, exactamente se especializa como enfatizador de exactitud en preguntas y desarrolla un uso puramente enfático (me da exactamente lo mismo, exactamente nada). Mientras que los demás adverbios avanzan, sobre todo, en contextos temporales, el desarrollo de exactamente avanza en el contexto de comparaciones. Dentro del paradigma de los focalizadores analizados, exactamente forma, pues, su propio subparadigma sintáctico (no siempre puede sustituir a los demás adverbios) y subparadigma pragmático (aporta valores pragmáticos distintos).

\subsubsection{Análisis cuantitativo}

El Gráfico 16 muestra el aumento del uso de precisamente, justamente y exactamente $^{24}$ como adverbios de foco en nuestra muestra base. Se ve claramente que el adverbio precisamente es el primero en el que arranca el desarrollo de los usos focalizadores, y el que supera a los demás en todos los cortes diacrónicos. En el

24 No incluimos el adverbio corto justo, ya que este, en nuestra muestra base, se incluye en el corpus de justo (adjetivo, adverbio, sustantivo), por lo cual no es comparable a los adverbios en -mente, que siguen el mismo criterio de representatividad (50 ocurrencias por medio siglo). 


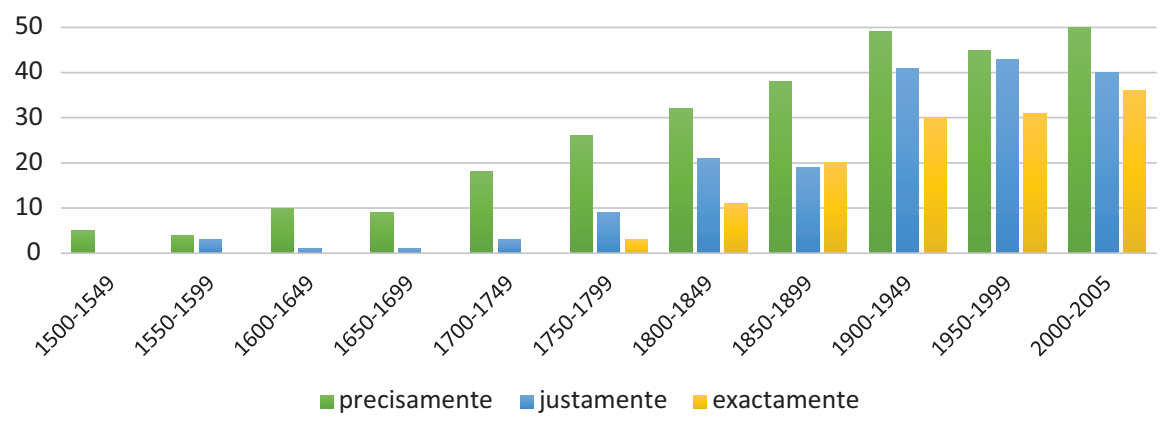

Gráfico 16: Frecuencia absoluta de los adverbios de foco en la muestra base de 50 ocurrencias por medio siglo.

último período observado (2000-2005), el 100\% de las 50 ocurrencias recogidas de precisamente corresponden a su uso como adverbio de foco. Lo sigue justamente $e^{25} \mathrm{y}$ el último y menos frecuente es exactamente.

No obstante, este gráfico precisa de una matización: nuestra muestra base es del mismo tamaño para los tres adverbios (50 ocurrencias por medio siglo para cada adverbio), por lo cual no tiene en cuenta que, en cuanto a la frecuencia de uso normalizada, precisamente es notablemente más frecuente que justamente y exactamente en el CDH (véase apartado 4.1).

Además, no incluimos el adverbio cabalmente, ya que su baja frecuencia no permite sacar una muestra base comparable a los demás adverbios (es decir, de 50 ocurrencias por medio siglo, en el $\mathrm{CDH}$ nuclear). Tal y como especificamos en el apartado 3.2.3, nos limitamos a un recuento en todo el CDH (incluyendo las extensiones) en períodos más generales. Dejando de lado la única documentación de cabalmientre en el siglo XIII, analizamos 100 ocurrencias por siglo en cuatro franjas: siglo XVIII, siglo XIX y siglo XX dividido en la etapa anterior a 1975 y la etapa posterior. Nuestro recuento manual muestra la siguiente evolución del adverbio de foco cabalmente (frente a su uso como adverbio de modo y como marcador de afirmación): durante el siglo XVIII, el 74\% de los registros de cabalmente corresponden a su uso como adverbio de foco, este porcentaje se eleva en el siglo XIX al 90\%. En siglo XX, hasta el año 1975, vuelve a bajar al 76\% y a partir del año 1975 solo se documenta en el 10\% de los casos recontados. El Gráfico 17 muestra el cruce de este recuento con la frecuencia normalizada de cabalmente en cada franja en todo el CDH.

25 En el caso de justamente corregimos los datos del último período (2000-2005), ya que el CDH recoge solamente 25 ocurrencias en este período; no llega a los 50 que establecimos como tamaño base representativo. Por eso, duplicamos los resultados de este período: las 20 ocurrencias de justamente se representan por el valor de 40, para que la comparación se base en muestras de igual tamaño. 


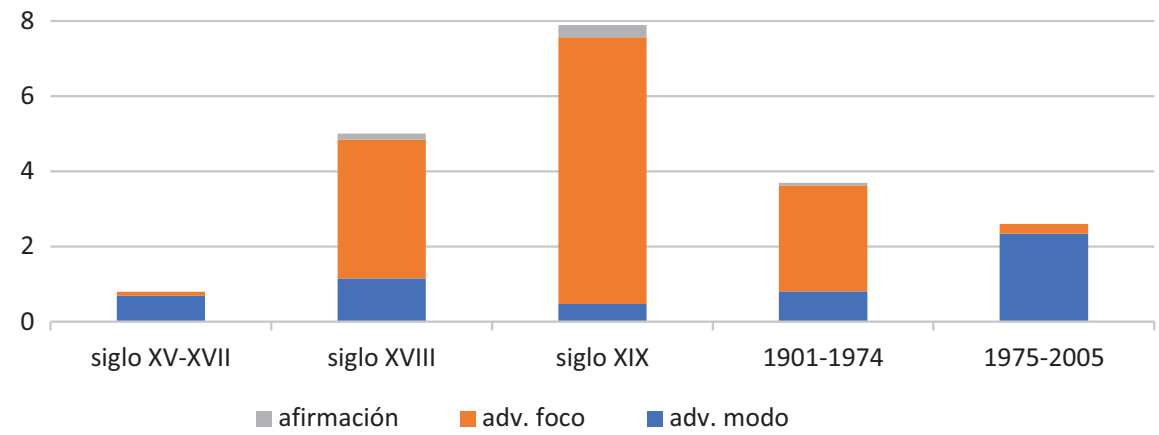

Gráfico 17: Frecuencia normalizada (por millón de palabras) de cabalmente en el CDH (nuclear y extensión), cálculo manual del porcentaje de uso de cada función.

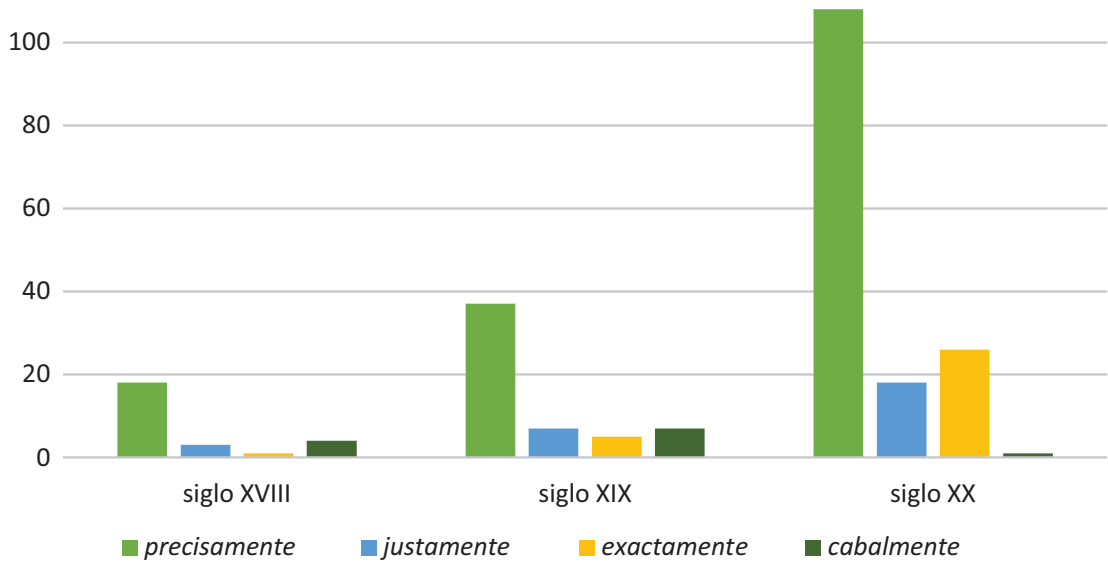

Gráfico 18: Frecuencia normalizada (por millón de palabras) de los adverbios de foco en el $\mathrm{CDH}$ (proporción basada en el porcentaje del uso focalizador en la muestra base).

Del mismo modo, cruzamos en los demás adverbios los valores de la frecuencia relativa normalizada en el CDH (expuestos en el apartado 4.1.2) con la proporción de su uso como adverbio de foco en nuestra muestra base. Teniendo en cuenta la frecuencia de uso normalizada, la diferencia entre los adverbios es notablemente mayor de lo que muestra el Gráfico 16. El Gráfico 18 refleja la frecuencia token real -es decir, la frecuencia normalizada- de cada adverbio de 
foco en el CDH, simplificado en tres cortes diacrónicos; el siglo XVIII, el siglo XIX y el siglo XX (1900-2005). ${ }^{26}$

Este gráfico revela claramente que precisamente es el adverbio de focalización por excelencia, con una frecuencia muy por encima de los demás. Es sin duda el miembro central de este paradigma y el elemento innovador. Además, según el análisis de la muestra base, la focalización es el valor predominante, casi exclusivo de este adverbio: el $96 \%$ de las ocurrencias de precisamente en el siglo XX (1900-2005) corresponde a su uso como adverbio de foco. El llamativo aumento de frecuencia de este adverbio en el CDH se debe, por lo tanto, casi exclusivamente a la expansión de los usos del adverbio de foco precisamente.

Resulta sorprendente que cabalmente no se quede atrás durante los siglos XVIII y XIX. En el siglo XVIII, cabalmente se usaba incluso con mayor frecuencia como adverbio de foco que justamente y aparece ya como focalizador de oraciones. Durante el siglo XIX, también se mantiene al mismo nivel con justamente y exactamente, pero es en el siglo XX cuando estos adverbios divergen: justamente y exactamente aumentan su uso como adverbios de foco, mientras que cabalmente decae (compárese también con el Gráfico 10 en el apartado 4.1.2).

\subsubsection{Analogía y «efecto paradigmático»}

El «efecto paradigmático», según el cual los demás adverbios imitan por analogía los usos de precisamente y toman sus valores pragmáticos, es esencial en el caso de cabalmente: habría sido quizás imposible que un adverbio tan poco frecuente - recordemos que durante los siglos XVIII y XIX, su uso modal era marginal- hubiera desarrollado tantos usos pragmáticos por sí mismo. Solo puede explicarse por analogía a precisamente y por la adherencia a un grupo de adverbios con un significado conceptual común, la exactitud. De hecho, desde el siglo XVIII hasta mediados del XX, el uso predominante de cabalmente es el

26 Calculamos los valores para este gráfico de la siguiente manera: nos basamos en la frecuencia normalizada (por millón de palabras) de los tres adverbios en el CDH en los tres siglos. De esta frecuencia normalizada calculamos el porcentaje que correspondería en cada siglo al uso de adverbio de foco, de acuerdo con nuestra muestra base y de acuerdo con el recuento manual de cabalmente. Los valores concretos son los siguientes (mostramos tres porcentajes, correspondientes al siglo XVIII, XIX y XX): precisamente $44 \%>70 \%>96 \%$, justamente $11 \%>$ $40 \%>82 \%$, exactamente $3 \%>31 \%>64 \%$ y cabalmente: $74 \%>90 \%>43 \%$. El gráfico representa la frecuencia normalizada (por millón de palabras) de cada adverbio de foco en el CDH: precisamente $18>37>108$; justamente $3>7>18$; exactamente $1>5>26$; cabalmente $4>7>1$. Por ejemplo, en un millón de palabras del siglo XIX, se encontrarán aproximadamente 37 ejemplos de precisamente como adverbio de foco frente a 7 de justamente focalizador, 5 de exactamente focalizador y 7 de cabalmente focalizador. 
de adverbio de foco (hasta el 90\% en el siglo XIX), y no el de adverbio de modo. Al contrario de cabalmente, los adverbios justamente y exactamente cuentan con una frecuencia de uso mucho mayor gracias a su difundido empleo como adverbios de modo, por lo cual son lexemas más usados y más presentes en el léxico mental de los hablantes. Probablemente por cuestiones de economía lingüística, estos dos adverbios van desplazando a cabalmente y este va desapareciendo. Se desecha del paradigma el elemento menos frecuente y el menos arraigado en el léxico.

Asimismo, solo el «efecto paradigmático» o la asociación con el adverbio de negación explican por qué exactamente aumenta su alcance sintáctico en la construcción no exactamente (no exactamente Serena, no exactamente porque tiene hambre), ya que estas posiciones sintácticas no se desarrollan en exactamente. En este sentido, no exactamente tiene un perfil sintáctico más flexible que su adverbio base gracias a la analogía con la construcción no precisamente.

Que precisamente sea el miembro central de este paradigma también se confirma en las diversas búsquedas específicas de determinados patrones en el $\mathrm{CDH}$, que expusimos a lo largo de este capítulo: los adverbios antepuestos a cuando, donde, porque, por eso, acabar de, estar y a nombres propios, así como en las construcciones [ser + adverbio + lo que] y [negación + adverbio]. En todas ellas, precisamente es, con diferencia, el más usado. En la mayoría de los contextos, precisamente fue probablemente el primer adverbio de foco en adoptar un valor pragmático nuevo o un contexto sintáctico nuevo, aunque en el corpus, justamente y cabalmente o bien lo siguen inmediatamente o bien son simultáneos.

El paradigma completo de los focalizadores analizados (incorporando también los adjetivos) no se forma simultáneamente, ya que los miembros se incorporan sucesivamente, como muestra el siguiente esquema, que diferencia entre las dos categorías básicas de focalización:

1) focalización enfática de datos espaciotemporales

a) exactitud

(siglo XIII cabalmente)

siglo XVI precisamente, justamente, justo (adv.)

siglo XVIII cabalmente, preciso (adj.)

siglo XIX exactamente

siglo XX justo (adv. y adj.), exacto (adj.)

b) coincidencia (valoración subjetiva)

siglo XVII precisamente

siglo XVIII justamente, cabalmente

siglo XX justo (adv. y adj.), preciso (adj.) 
2) focalización enfática de identidad en los demás contextos

a) exactitud (coincidencia o correspondencia exacta) siglo XVIII: exactamente en comparaciones siglo XIX: exactamente en otros contextos

b) coincidencia (valoración subjetiva) siglo XVIII: precisamente, justamente, cabalmente siglo XX: justo

Además de una serie de incorporaciones sucesivas de nuevos miembros al paradigma y de nuevos valores pragmáticos, aumenta el alcance sintáctico entre los siglos XVIII y XIX: los adverbios pasan a modificar oraciones subordinadas (causales, temporales y, en el caso de exactamente, comparativas) y precisamente, justamente, justo y cabalmente aumentan su alcance hasta modificar toda la oración (véanse apartados 5.2.2.1 y 5.4.2).

En contrapartida, también hay reducciones y pérdidas en este paradigma: en el siglo XX, precisamente prácticamente deja de usarse como focalizador de exactitud (valor 1.a.) porque se especializa como adverbio de foco de coincidencia (valor 1.b./2.b.). Por último, el adverbio cabalmente desaparece casi por completo: el uso de cabalmente como adverbio de foco se limita a los siglos XVIII y XIX y se va perdiendo a mediados del siglo XX.

Hay dos excepciones concretas en las que precisamente no es el elemento central ni el innovador o el más frecuente:

i. Por un lado, exactamente es -y fue en todos los cortes temporales- el adverbio focalizador de exactitud por excelencia en estructuras comparativas y en preguntas (¿dónde exactamente?).

ii. Por otro, justo y justamente son los únicos en presentar el valor semántico 'inmediatamente' (justo antes, justamente después, justo a tiempo...), probablemente porque retienen rasgos semánticos de su confusión homonímica con IUXTA (véase apartado 4.3.2.3).

En este sentido, observamos un cierto reparto interno en el paradigma: exactamente y justo/justamente siguen ocupando «parcelas» propias que heredan de su origen léxico. En cambio, precisamente prácticamente pierde la transparencia semántica y generaliza el nuevo valor subjetivo. También hay una cierta divergencia en cuanto a las inferencias pragmáticas: mientras que exactamente aporta énfasis en la rigurosidad exacta de la información focalizada, precisamente aporta principalmente una valoración subjetiva negativa (sorpresa, incoherencia, contradicción...).

Según König (1991, 23), los adverbios de foco del alemán se especializan o en la focalización de exactitud (genau) o en la focalización de coincidencia (gerade). 
Respecto a esta observación, López Samaniego $(2007,54)$ menciona la posibilidad de que el español esté experimentando una especialización parecida: la autora equipara el español justamente y exactamente con el alemán genau -como refuerzo de exactitud-y precisamente y justamente con el alemán gerade - para la coincidencia-.

Efectivamente, los datos históricos muestran que tal especialización entre, por un lado, exactamente como focalizador de exactitud y, por otro, precisamente como focalizador de coincidencia surge como producto de un desplazamiento sucesivo desde el valor de focalización de exactitud hacia el valor de focalización de coincidencia: el paso de la focalización de exactitud a la focalización de coincidencia está más avanzado y prácticamente generalizado en precisamente, dado que este adverbio actualmente ya no se suele usar como focalizador de exactitud. En cambio, justamente mantiene ambas etapas (la focalización de exactitud y la focalización de coincidencia). La situación peculiar de justamente, que participa en ambas categorías (exactitud y coincidencia), se debe a que está en una etapa intermedia y no ha generalizado el uso como adverbio de foco de coincidencia en la misma medida que precisamente. Por último, exactamente-el más tardío-se usa principalmente como focalizador de exactitud y casi nunca adopta valores de coincidencia. En este caso, la transparencia semántico-léxica de exactamente impide que aparezca en los mismos contextos que precisamente.

La asimetría de este paradigma - esto es, el reparto o la especialización interna - refleja, por lo tanto, la evolución más tardía o más temprana de las unidades. Por eso, algunas se encuentran en estados pragmáticos más avanzados que otras. No solo es decisiva la cronología, sino también la frecuencia: a pesar de aparecer simultáneamente con precisamente, los adverbios de foco justamente y cabalmente son menos frecuentes, por lo que su desarrollo está menos acelerado.

El análisis ha mostrado la posible influencia que tiene el elemento central de un paradigma en los demás elementos. Precisamente, justamente, justo, cabalmente y exactamente son elementos muy próximos tanto semánticamente (comparten el significado conceptual 'exacto') como funcionalmente (son adverbios). Por eso, es fácil y probable que de alguna manera se «contagien» entre sí. Dicho de otro modo, justamente, justo, cabalmente $\mathrm{y}$, en menor medida, exactamente adoptan o imitan usos de precisamente.

El «efecto paradigmático» también es responsable de que la focalización de casualidades significativas o la inversión argumentativa incluso se documenten de manera ocasional en exactamente. Asimismo, en el caso de la focalización de negaciones, no justamente y no exactamente pueden aparecer esporádicamente con el efecto de inversión, probablemente como imitación al modelo de precisamente. Por lo tanto, la existencia de un paradigma pragmático podría explicar la aparición esporádica de usos no consolidados. Hipotéticamente, todos los 
adverbios de este paradigma tienen el potencial de aparecer en todas las funciones analizadas, pero este no es el caso: hay un reparto interno de los diversos valores.

\subsubsection{Rasgos de pragmaticalización y subjetivización}

Los valores pragmáticos de focalización analizados en este capítulo surgen a través de inferencias pragmáticas contextuales. Primero, las inferencias se sobreentienden en el contexto. Por ejemplo, la coincidencia intencionada o (in)oportuna surge en algunos contextos donde, además de una focalización de exactitud en el tiempo cabe interpretar «algo más»: que esa coincidencia temporal es intencionada o (in)oportuna. Estas inferencias empiezan siendo ocasionales y progresivamente se van generalizando hasta convencionalizarse. En el español actual, precisamente provoca casi siempre una inferencia más allá de la simple exactitud: el oyente busca automáticamente interpretar la focalización como coincidencia significativa. Asimismo, en las estructuras con negación, la inversión hacia lo opuesto ('sino todo lo contrario') se ha generalizado en no precisamente, mientras que, en no exactamente la interpretación suele ser de atenuación o matización: ‘aproximadamente'.

Al tratarse de una evolución diacrónica gradual que abarca tanto cambios sintácticos como semánticos y que se relaciona con inferencias pragmáticas, analizaremos en el presente apartado si es posible describir el caso de los adverbios de foco precisamente, justamente, exactamente, etc., en términos de gramaticalización (pragmaticalización) o subjetivización.

\subsubsection{Cambio semántico I: semantic bleaching}

Según König $(1991,29)$, las partículas de foco tienen generalmente un significado léxico, pero este sufre un proceso de semantic bleaching (desgaste semántico) hacia un significado menos concreto (König 1991, 171). En primer lugar, analizaremos los cambios semánticos, ya que la pérdida de transparencia semántica es crucial para considerar la evolución de los adverbios de foco un proceso de gramaticalización (König 1991, 171) o un proceso de subjetivización (Traugott/Dasher 2002; Traugott 2010).

A partir de su significado conceptual de exactitud, los adverbios (y en menor medida los adjetivos) que nos ocupan en este estudio han desarrollado significados procedimentales: al focalizar un segmento del enunciado, guían las inferencias pragmáticas y dan instrucciones al interlocutor sobre cómo interpretar lo dicho:

a) El significado procedimental de los focalizadores de coincidencia precisamente, justo, justamente y cabalmente consiste en llamar la atención sobre un 
elemento del enunciado señalando su relevancia para la interpretación adecuada de la información. Estas instrucciones procedimentales desencadenan la inferencia pragmática, obligando al receptor a buscar una explicación de por qué se destaca cierta información: hay una coincidencia afortunada, (in)oportuna o intencionada, o cualquier circunstancia relevante y pertinente para la situación comunicativa. En otros casos, se trata de un hecho paradójico o el hablante subraya la inversión de la argumentación. Además, a nivel del discurso, podrían indicar coherencia temática.

b) En cambio, el significado procedimental de exactamente consiste en indicar que la información es rigurosamente exacta y correcta, que el dato ofrecido hay que interpretarlo literalmente.

Originariamente, el significado conceptual de exactitud fue la base de los valores pragmáticos y propició el desarrollo de los usos procedimentales de focalización. Hay diferentes grados de debilitamiento semántico (semantic bleaching): en algunos usos como, por ejemplo, en el dominio temporal, el significado léxico básico de exactitud es más transparente que en otros. En el caso del adverbio de foco exactamente, el significado conceptual o léxico se mantiene plenamente transparente, no hay semantic bleaching. Solo se pierde en un caso puramente enfático: en la expresión idiomática me da exactamente igual/lo mismo.

En precisamente, justamente, justo y cabalmente, el significado conceptual base de exactitud se va oscureciendo gradualmente a medida que se va generalizando el valor de coincidencia significativa. Así pues, llegan a aparecer en contextos que no permiten una lectura de 'exacto, no aproximado', como cuando focalizan la identidad de una persona. El significado conceptual original de exactitud se vuelve más opaco y solo hay persistencia en algunos contextos.

Esto nos permite diferenciar el contexto puente del contexto de cambio -es decir, el bridging context y el switch context, según Heine (2002)-. El contexto puente entre la focalización de exactitud y la focalización de coincidencia corresponde a aquellos en los que ambas interpretaciones son posibles. En estos contextos ambiguos surgen las inferencias pragmáticas contextuales. Consideramos que los contextos puente son los contextos comunes a todos los adverbios del grupo, incluyendo exactamente. El principal bridging context en el que surgen las inferencias a través de una doble lectura es el dominio del tiempo y espacio, o sea, la focalización de datos espaciotemporales exactos (valor 1a de la lista de arriba). El cambio se origina en este contexto ambiguo: un hecho ocurre exactamente en un momento significativo y coincidente (valor 1b).

Los contextos en los que el nuevo uso se independiza y en los que ya no es posible una lectura de 'exactamente, no aproximadamente, ni más ni menos' son los switch contexts. En ellos, se pierde el significado conceptual original. Hemos 
identificado principalmente dos switch contexts: cuando el alcance de los adverbios de foco es una persona (precisamente mi mujer, justamente Mauricio) o una oración principal (justo estábamos hablando de ti). Son los contextos de debilitamiento semántico (semantic bleaching), ya que en ellos no hay exactitud de algo gradual, medible o cuantificable.

En estos contextos de cambio o switch contexts, no puede aparecer el adverbio exactamente. Creemos que las limitaciones de exactamente son de naturaleza semántica y no sintáctica: no es que exactamente no pueda incidir sobre la categoría sintáctica «nombre propio», sino que no puede focalizar la referencia a una persona, porque semánticamente es imposible focalizar una persona como alternativa más exacta en una escala (\#exactamente Mauricio). Tampoco incide sobre oraciones principales porque una proposición o una acción entera difícilmente se puede calificar de exacta. Solo pueden ser cuantificados aspectos parciales de una acción, como la referencia espaciotemporal o la coincidencia en la apariencia física entre dos objetos. Además, en combinación con no, exactamente sí puede incidir sobre oraciones subordinadas causales y sobre nombres propios (Ana no era exactamente Serena). Esto prueba, por lo tanto, que las restricciones de exactamente (a secas, sin no) no son de naturaleza sintáctica, sino semántica.

Los cambios semánticos generalmente van de más concreto a más abstracto. Dependiendo del dominio al que se aplica, la exactitud ya es un concepto más o menos abstracto, pero es medible en términos matemáticos y se puede expresar en números, es decir, es cuantificable. En determinados usos (localizaciones, indicaciones temporales exactas, copias de un original), creemos que la exactitud es bastante concreta y hasta visible. En cambio, las valoraciones subjetivas que indican una coincidencia significativa, una casualidad inoportuna o una paradoja son conceptos más abstractos porque se basan en escalas subjetivas. Además, los nuevos usos remiten a un significado más general: precisamente se aplica a más referentes que exactamente, no se limita a entidades medibles o cuantificables.

\subsubsection{Cambio semántico II: enriquecimiento interpretativo}

Como acabamos de indicar, la pérdida del rasgo semántico de exactitud corre paralela a la adquisición de nuevos valores pragmáticos. El proceso llamado pragmaticalización por Claridge/Arnovick $(2010,179)$ conlleva, aparte de semantic bleaching, otro cambio paralelo: pragmatic strengthening 'enriquecimiento pragmático' y convencionalización de nuevos significados pragmáticos. Por ejemplo, como observa König (1991, 172-173), algunas partículas de foco muestran un proceso opuesto al semantic bleaching: experimentan un aumento o enriquecimiento interpretativo, mediante la convencionalización de implicaturas conversa- 
cionales. Lo que empezó como un aspecto del significado del enunciado inferido a través de las máximas conversacionales de Grice (1975), se convierte en un aspecto del significado convencionalizado de la partícula. Por ejemplo, hay un aumento interpretativo en el inglés even y el alemán eben, gerade (König 1991, 172-173).

En el caso de los adverbios de foco precisamente, justamente, justo y cabalmente, efectivamente, podemos suponer que la pérdida del valor semántico de exactitud (semantic bleaching) es compensada por otros valores nuevos. En este sentido, podemos hablar de «enriquecimiento interpretativo» a través de diversos valores subjetivos.

Creemos que el cambio semántico desde la focalización enfática de exactitud a la focalización de coincidencia es una metonimia, lo cual encaja con los conceptos de gramaticalización, pragmaticalización (Elvira 2015, 191) y subjetivización (Martí Sánchez 2008, 86): los cambios surgen por inferencias contextuales que van desplazando y oscureciendo la interpretación original. Los valores subjetivos inferidos del contexto se proyectan en el adverbio de exactitud, que los va absorbiendo como valor propio. Dicho de otro modo: los valores de trasfondo pasan al primer plano. Así, la metonimia se rutiniza y la nueva interpretación se convencionaliza. La pérdida o el oscurecimiento del concepto de exactitud es, por lo tanto, consecuencia de una generalización o abstracción del significado que se debe a la subjetivización y convencionalización de los efectos contextuales.

En contextos como precisamente por eso, el adverbio no solo focaliza enfáticamente una información como significativa, sino que prácticamente ha generalizado la valoración subjetiva inoportuna (sorpresa, contradicción, casualidad inesperada, etc.). Indica una inversión argumentativa y, en este sentido, se enriquece por un valor pragmático particular.

Otro contexto de enriquecimiento interpretativo sería el de no precisamente, que funciona como inversor: infiere siempre lo contrario. En estos usos, hay debilitamiento semántico del significado conceptual base de exactitud, pero, al mismo tiempo, esta «pérdida» es compensada por la convencionalización y casi automatización del matiz de contradicción e inversión.

Distinto es el caso de precisamente, justamente, cabalmente y justo cuando inciden sobre oraciones principales o sobre el predicado de una oración: justamente estábamos hablando de ti. En este caso, justamente equivale a "por casualidad exactamente en este mismo momento». Hay una acumulación de valores semántico-pragmáticos, ya que los adverbios de exactitud incorporan el valor de coincidencia temporal exacta ('en ese mismo momento'), y, además, la valoración subjetiva significativa ('por casualidad'). En este caso, hay enriquecimiento interpretativo, pero no hay semantic bleaching. El significado original sigue siendo transparente ('exactamente en ese mismo momento'), porque no se abandona el dominio fuente (el dato temporal). Es decir, puede haber enriquecimiento prag- 
mático (pragmatic strengtening) en un contexto puente sin pérdida del significado conceptual base.

\subsubsection{Subjetivización de precisamente, justamente, justo y cabalmente}

Las unidades léxicas subjetivas codifican explícitamente el punto de vista del hablante (Traugott/Dasher 2002, 21-23), por lo que suponen un mayor involucramiento del hablante y un mayor grado de expresividad (Company Company 2004). Su significado procedimental consiste en expresar la actitud del hablante hacia el contenido de su enunciado (Traugott 2010, 31). En este sentido, creemos que el desarrollo de los adverbios de foco de coincidencia puede clasificarse como un proceso de subjetivización. Ocurre en precisamente, justamente, justo y cabalmente, cuando expresan alguna valoración emocional-subjetiva, es decir, cuando entran en el dominio de la modalidad.

Traugott $(2010,33)$ considera a focus particles como even 'incluso' ejemplos de unidades subjetivas. Según la autora, las partículas focales como las analizadas por König (1991) siempre engloban subjetivización, dado que las inferencias asociadas de evaluación subjetiva en una escala se semantizan como parte del significado del focalizador (Traugott 2010, 51). Sin embargo, creemos que hay que matizar la noción de «subjetivo» en el caso de los adverbios en cuestión.

A nuestro modo de ver, los adverbios de foco son subjetivos siempre y cuando la escala que aplican sea una escala de valoración subjetiva, que depende del hablante individual. En este sentido, adverbios de foco más prototípicos como solo, incluso o ni siquiera son subjetivos, ya que expresan una valoración personal desde la perspectiva del hablante; la aplicación de la escala es subjetiva. Recordemos el ejemplo de Juan solo compró una camisa. El situar el elemento focalizado (por ejemplo, una camisa) en una posición baja de la escala es un acto subjetivo: para el hablante de este enunciado, una camisa es poco. Otro hablante quizás diría en la misma situación comunicativa: incluso una camisa y lo situaría en una posición alta en la escala. La escala de valoración es, por lo tanto, subjetiva y personal.

Sin embargo, en los focalizadores de exactitud como exactamente, la escala que se aplica no es subjetiva, ya que este adverbio de foco presenta una información como rigurosamente exacta, medible y cuantificable matemáticamente en números. No creemos que aporte subjetividad:

Porque sí, pequeña mía, hoy es el aniversario de nuestro primer encuentro, que sucedió exactamente a las veintitrés y diez (las once y diez minutos) de esta noche. (véase ejemplo 10)

El adverbio exactamente aporta información proposicional ('el dato temporal es exacto y no aproximado'). Como ya mencionamos anteriormente, la exclusión 
de alternativas y la propiedad escalar de exactamente no surge como inferencia pragmática contextual, sino que se encuentra ya en su propio significado conceptual: exacto se opone a aproximado y la exactitud en sí es graduable y cuantificable, por ejemplo, en números. Es el propio significado conceptual de exactamente el que excluye alternativas y las ordena en una escala de más a menos exacto.

En el ejemplo exactamente a las veintitrés y diez horas, la escala subyacente es el reloj, algo externo al hablante y a sus creencias, actitudes o valoraciones. La escala está fijada por leyes físicas que están fuera de la manipulación del hablante. En este sentido, exactamente se refiere a una característica perteneciente al mundo real del evento aludido. Consiguientemente, no creemos que todos los adverbios de foco sean a priori subjetivos, ya que no es el caso de exactamente. Asimismo, Kaul de Marlangeon $(2002,120)$ opina que los adverbios de exactitud se oponen a los adverbios restrictivos en cuanto a la expectativa del oyente: en exactamente dos horas, la expectativa es neutra, pero en solo dos horas, el hablante expresa que podría haber durado más. En cambio, precisamente dos horas no evalúa la cantidad, o sea, la duración en sí, sino la coincidencia de este dato con otro evento.

Ahora bien, cuando exactamente se usa como adverbio de foco de exactitud, como en el ejemplo citado, sí aporta énfasis, expresividad y un mayor involucramiento del hablante, que probablemente intenta impresionar a su interlocutora («insisto en que el dato es exacto, porque me acuerdo perfectamente»). Este involucramiento del hablante viene dado por todo el contexto, es algo que se nota en toda la oración y en el mismo hecho de especificar tan rigurosamente la hora de un recuerdo. Consiguientemente, no creemos que sea exactamente el elemento que aporte subjetividad a este ejemplo, sino que el adverbio de foco simplemente aporta énfasis y es un síntoma del involucramiento personal del hablante.

También hay cierto involucramiento del hablante y cierto énfasis en las comparaciones, ya que estas se presentan siempre desde una perspectiva subjetiva. Sin embargo, exactamente subraya que la comparación no es aproximada sino muy cierta y adecuada. Es decir, exactamente enfatiza la aparente credibilidad y casi objetividad de una comparación:

con cuyo nombre me sucede exactamente lo mismo que a Cervantes con el lugar de Argamasilla, [...]. (véase ejemplo 69)

El valor semántico original de los adverbios (y adjetivos) analizados no es, por lo tanto, en absoluto subjetivo, sino que aspira a una exactitud comprobable y medible de manera objetiva. De hecho, es el uso originario de los adverbios analizados, que surgen en el discurso científico (XLIX años cabalmientre; precisamente a las nueve de la mañana; a la semana justa, etc.). 
En el caso de precisamente, justamente, justo y cabalmente, surgen valores más subjetivos mediante los cuales el hablante expresa su punto de vista y su valoración personal y emocional sobre lo dicho (insinúa sorpresa, casualidades inesperadas, contradicciones, etc.). Los adverbios de focalización de coincidencia ya no aportan nada al contenido estrictamente proposicional del enunciado:

se da la paradoja que la persona más visible es precisamente la persona de quien menos se sabe. (véase ejemplo 113)

¡El hermano Macario hablando mal de Dios..., cometiendo sacrilegio, justo aquí, bajo el techo de la iglesia! (véase ejemplo 23)

A través de la focalización enfática, los adverbios precisamente, justamente, justo y cabalmente expresan la actitud del hablante ante la proposición. Esa valoración subjetiva consiste en ordenar una serie de alternativas en una escala subjetiva: es el hablante -y no un calendario o un reloj- el que decide cuál es la escala y cuál es la alternativa más significativa (sorprendente, oportuna, escandalosa, etc.) para él. No es una escala del mundo real, sino del mundo subjetivo personal. Aun siendo sumamente personal, la inferencia contextual suele ser recuperable para el oyente gracias a su conocimiento del mundo real y a que, en la mayoría de los casos, la escala valorativa sigue a algún topos generalizado.

En signos discursivos como solo o cierto, Hummel $(2012,158)$ opina que el efecto básico es la subjetivización y que el énfasis es secundario. En cambio, en los focalizadores justo, exactamente, precisamente, etc., opinamos que el efecto básico es la focalización referencial enfática (originariamente, de exactitud), a la cual se puede añadir la expresión indirecta de subjetividad.

Tal y como mostramos en el análisis, los valores subjetivos surgen como inferencia pragmática de todo el contexto, son cada vez más frecuentes y se automatizan. El proceso de subjetivización empieza como inferencia ocasional que se va generalizando y convencionalizando (Traugott/Dasher 2002; Martí Sánchez 2008, 83). Así, los adverbios en cuestión adquieren valores adicionales que codifican perspectivas y actitudes del hablante (emociones y perspectivas subjetivas). Sin embargo, para que sea un caso de subjetivización en sentido estricto, este significado subjetivo se tiene que incorporar en la gramática y codificarse como significado nuevo (Traugott/Dasher 2002, 30; Traugott 2010, 30). En tal caso, habría una gramaticalización del significado pragmático (Company Company 2004, 1) y un reanálisis del significado pragmático como significado semántico codificado, es decir, como un significado conceptual (Traugott/Dasher 2002, 35).

Consideramos que los adverbios de foco precisamente, justamente, justo $\mathrm{y}$ cabalmente adquieren valores subjetivos solo en determinados contextos y no 
están subjetivizados en el sentido de que no hay un cambio semántico acabado ni un nuevo significado lexicalizado. El valor subjetivo inferido del contexto es un valor pragmático, pero no se reanaliza, codifica y lexicaliza como nuevo significado semántico. Precisamente, justamente, justo y cabalmente son adverbios de foco que desencadenan una amplia serie de inferencias pragmáticas contextuales, siendo la inferencia de valoración subjetiva una de ellas. ${ }^{27}$

Por ejemplo, Hummel $(2012,157)$ clasifica justo como polisémico, ya que significa tanto ‘exactamente' como 'a propósito, intencionadamente'. Sin embargo, opinamos que este segundo uso es solo una inferencia pragmática contextual habitual, pero no un nuevo significado lexicalizado. Justo y los demás adverbios del grupo no pueden sustituir al adverbio intencionadamente y no han extendido el significado ‘intencionadamente' a nuevos contextos.

Además, los focalizadores de coincidencia no siempre expresan subjetividad - ni siquiera precisamente-. Es el caso de la focalización informativa que da coherencia temática a un texto o introduce una digresión. Este uso aparece en los mismos patrones sintácticos que la focalización subjetiva (por ejemplo, en construcciones copulativas de relieve o en enfatizaciones de datos). En este caso, no podemos hablar de subjetivización, sino más propiamente de discursivización o pragmaticalización: el adverbio de foco adquiere un valor procedimental textual. Por lo tanto, creemos que el significado base de los adverbios de foco de este grupo no es un significado conceptual subjetivo, sino que sigue siendo un significado procedimental: la focalización enfática. La subjetividad no es más que un efecto contextual.

Según Traugott (2010, 29, 60-61), hay que distinguir entre la subjetividad que pueda aportar un determinado lexema en contextos relevantes como inferencias pragmáticas asociadas y la subjetivización como proceso de codificación léxica de un significado nuevo. El pragmatic strengthening es un prerrequisito para la subjetivización, pero la subjetivización en sí no es pragmaticalización, sino semantización (Traugott 2010, 35), esto es, lexicalización de un nuevo significado subjetivo. Visto así, hay pragmaticalización en precisamente, justo, etc., y este proceso está especialmente avanzado en precisamente, pero la valoración subjetiva de una coincidencia no se ha convertido en un sig-

27 En cambio, parece que sí hay convencionalización y codificación como significado semántico en el adverbio alemán ausgerechnet (que comparamos como equivalente a precisamente en contextos de valoración subjetiva negativa). En ausgerechnet, es un significado lexicalizado: su definición en los diccionarios es «expresa emocionalmente desagrado, sorpresa, ira, etc.» o «expresa que el hablante cree muy improbable algo» (Duden en línea: s.v. ausgerechnet) [traducción nuestra]. 
nificado semántico codificado. Además, la interpretación concreta de la coincidencia (favorable, desagradable, intencionada...) hay que inferirla siempre del contexto. ${ }^{28}$

De acuerdo con la propuesta de Heine (2002), la lexicalización o convencionalización sería el siguiente paso al switch context, cuando el nuevo significado se extiende a contextos nuevos. La interpretación ya no depende del contexto porque el significado nuevo se ha incorporado como significado codificado, «normal» e inherente: es un significado «semántico» de la palabra, no un significado contextual «pragmático» (Heine 2002, 85-86). Es decir, una vez que se haya lexicalizado una implicatura conversacional en un marcador discursivo dado, como parte de su significado conceptual, el contexto pasa a un segundo plano y ya no es determinante (Hummel 2013c, 80-81). No es el caso de las unidades analizadas.

Únicamente podemos hablar de convencionalización y codificación de un nuevo valor concreto en la construcción no precisamente, que ha convencionalizado y fijado el valor de inversión hacia lo contrario: no precisamente automáticamente indica ‘sino todo lo contrario'. Hay fijación y convencionalización vinculadas a una construccionalización.

Según Traugott $(2010,55)$, la subjetivización es un cambio lingüístico que se sitúa y se motiva en el hablante o emisor (en la producción) y no en el oyente (en la recepción), con lo cual contradice a la mayoría de los modelos de cambio lingüístico, que adscriben el reanálisis a la adquisición del lenguaje por niños. Creemos que, efectivamente, los valores subjetivos en los adverbios de foco de coincidencia surgen porque el emisor quiere expresar su valoración subjetiva, y no porque el receptor capte una interpretación nueva, no intencionada por el emisor. Asimismo, Hummel (2013c, 79) opina que hay que distinguir las inferencias que surgen por ambigüedad no intencionada de las inferencias intencionadas y «creativas» por parte del hablante, quien invita al oyente a inferir una interpretación determinada. Este último parece ser claramente el caso de los focalizadores analizados. En algunos ejemplos, hemos observado que como receptores indirectos sin conocimiento del contexto amplio- no conseguimos captar la inferencia intencionada por el emisor, pero sabemos claramente que hay alguna.

28 Por ejemplo, según Garcés Gómez (2013, 310-311), el adverbio aparentemente ha codificado e incorporado un valor subjetivo a su significado convencional (las apariencias engañan, hay una oposición entre lo aparente y la realidad). En cambio, otros adverbios que más recientemente se incorporaron a su mismo paradigma únicamente manifiestan este valor en contextos en los cuales este contraste se explicita. 


\subsubsection{Cambios sintácticos}

En general, una consecuencia sintáctica de la subjetivización es la ampliación del alcance sintáctico (Company Company 2004, 6). Efectivamente, los adverbios precisamente, justamente, cabalmente y justo han aumentado su ámbito y tienen un alcance variable. El desarrollo sintáctico de las unidades analizadas va desde las posiciones sintácticas centrales, dentro de la oración, hacia posiciones cada vez más periféricas, siendo la oración completa el alcance máximo de los adverbios de foco. Es un proceso gradual y sucesivo, que se presenta en tres etapas en precisamente, justamente y cabalmente:

sintagmas (s. XVI) $\rightarrow$ oración subordinada (s. XVIII) $\rightarrow$ oración principal (s. XVIII/XIX)

Esta evolución parece ser más acelerada en cabalmente, que ya a finales del siglo XVIII aparece como adverbio con alcance sobre toda la oración (véanse ejemplos 47 y 129 del año 1786).

Este desarrollo sucesivo se documenta solo en los adverbios en -mente. El adverbio corto justo se documenta en la primera etapa del siglo XVI (modificación de sintagmas), pero luego solo reaparece en la escritura del siglo $\mathrm{XX}$, con una altísima frecuencia y de manera simultánea tanto como modificador de oraciones subordinadas como de oraciones principales. Creemos que, en la lengua hablada, justo seguía el desarrollo de justamente durante los siglos XVIII y XIX y que simplemente no se documenta en el corpus escrito de estos siglos.

Al mismo tiempo, los adverbios de foco aumentan su flexibilidad y movilidad sintáctica: pueden aparecer antepuestos o pospuestos e incluso desligados del elemento focalizado (es decir, en posición no contigua) o en posición destacada. En ciertas ocasiones, aparecen incluso en posición interior, insertos en el segmento que focalizan (véase apartado 5.4). En este sentido, observamos en los adverbios una «liberación» sintáctica: pierden restricciones. Sobre todo, precisamente, cabalmente y justamente pueden aparecer prácticamente en cualquier posición oracional e incidir sobre cualquier elemento oracional o sobre la oración entera.

Hay «menos sintaxis» 0 «prescindibilidad de la sintaxis» (Company Company 2004) en el sentido de que ya no hay restricciones sintácticas, sino casi absoluta libertad. Efectivamente, como sostiene la autora, esta «cancelación de la sintaxis» es fruto de un significado más subjetivo y abstracto que permite a los adverbios asociarse con cualquier segmento oracional.

En exactamente, no hay subjetivización, pero, aun así, aumenta su alcance sintáctico en un contexto particular: el de las comparaciones entre dos cosas exactamente iguales. En este contexto, exactamente alcanza a oraciones subordinadas (exactamente como si...). 
Como consecuencia de «menos sintaxis», las unidades también suelen sufrir restricciones sintácticas, o sea, pierden capacidades sintácticas. No obstante, los adverbios de foco analizados no parecen cumplir estas características descritas como «empobrecimiento», aislamiento y rigidización sintáctica (Company Company 2004, 7). Al contrario de los marcadores discursivos, los adverbios de foco mantienen una función sintáctica en la oración y siguen teniendo alcance sintáctico (scope). No son unidades autónomas, es decir, no son theticals. Ni siquiera lo son cuando aparecen entre pausas, ya que siguen teniendo alcance sintáctico. Los adverbios de foco no cambian de categoría, sino que siguen siendo adverbios que modifican algún constituyente oracional.

En cuanto a la pérdida de capacidades sintácticas, hemos observado que -al contrario de los adverbios de modo - los adverbios de foco no suelen aparecer modificados por otro modificador (como muy o tan), aunque hemos documentado una excepción (muy precisamente allí). Es raro pero posible que aparezcan coordinados entre sí. Además, precisamente y exactamente pueden combinarse con el operador de negación no. Todas estas observaciones contradicen la tendencia a la "pérdida de capacidades sintácticas».

En el caso de los adjetivos preciso y justo, observamos una cierta fijación sintáctica como resultado de un proceso de subjetivización (Martínez 2009, 1314), ya que solo como adjetivos atributivos y antepuestos al sustantivo adquieren el énfasis y expresan una valoración subjetiva (en este preciso momento...). No hay énfasis ni subjetivización cuando aparecen pospuestos o como adjetivos predicativos. Consecuentemente, la pérdida de capacidades sintácticas se confirma en los adjetivos, pero no en los adverbios.

De acuerdo con las características de la «gramaticalización por subjetivización» analizadas por Company Company (2004), resumimos los cambios semánticos y sintácticos que observamos en el caso de los adverbios de foco precisamente, justamente, cabalmente y justo:

a) Semántica: debilitamiento y desgaste del significado referencial originario. El significado conceptual base de exactitud se va oscureciendo gradualmente a medida que los adverbios de foco van explorando nuevos valores subjetivo-emocionales contextuales.

b) Sintaxis: los adverbios de foco analizados aumentan su alcance sintáctico hasta modificar oraciones enteras; pérdida de restricciones sintácticas: se combinan con cualquier elemento de la oración (palabras, sintagmas, oraciones); y mayor autonomía sintáctica (aparecen en posición destacada y en posición no contigua al elemento focalizado).

En este sentido, nos parece más acertado hablar de «liberación» sintáctica (y no de «empobrecimiento»), ya que las posibilidades sintácticas de los adverbios de 
foco aumentan. La libertad sintáctica es una propiedad característica de adverbios de foco como solo, que se relacionan con cualquier elemento oracional (Medina Gómez/Alarcón Neve 2017). Por lo tanto, al convertirse en adverbios de foco, los adverbios precisamente, justo, exactamente, etc., adquieren esta libertad sintáctica.

En este sentido, los adverbios de foco analizados no cumplen las siguientes características sintácticas enumeradas por Company Company $(2004,22)$ como pertinentes a la subjetivización:

a) distribución rígida y posición fija: los adverbios de foco son extremadamente flexibles.

b) aistamiento: los adverbios de foco se integran en la oración, incluso se pueden combinar con la negación y coordinarse.

c) atcance predicativo extraoracionat: los adverbios de foco tienen alcance oracional, ya que modifican palabras, sintagmas u oraciones.

d) imposibilidad de modificación: es rara, pero posible.

Estas son las características sintácticas que nos permiten distinguir los adverbios de foco (operadores pragmáticos de focalización) de los marcadores discursivos, es decir de las unidades theticals (véase apartado 6.5.3 para una comparación con los marcadores de afirmación, que sí cumplen estas características).

\subsubsection{Rutas y características de la gramaticalización/pragmaticalización}

De acuerdo con Claridge/Arnovick $(2010,167)$, los signos discursivos o pragmáticos que retienen demasiado de su significado conceptual primario no se pueden clasificar de «pragmaticalizados», como sería el caso, por ejemplo, de fortunately 'afortunadamente' como adverbio oracional o como adverbio de modo. No hay tanta diferencia entre ambos usos como para postular un proceso de pragmaticalización. En esta misma línea, consideramos que la focalización de exactitud en los adverbios analizados todavía no es pragmaticalización. Es en el surgimiento de otros valores contextuales independientes del concepto de la exactitud (como la focalización de coincidencias) donde observamos procesos de pragmaticalización y, en concreto, de subjetivización.

La ruta (cline) de gramaticalización o pragmaticalización de los adverbios como marcadores discursivos propuesta por Traugott (1995) tiene como etapa intermedia la fase de adverbios disjuntos (o adverbios con función periférica):

«Clause-internal Adverbial > Sentence Adverbial > Discourse Marker» (Traugott 1995, 1).

«adverbio con función oracional $\rightarrow$ adverbio con función periférica $\rightarrow$ marcador discursivo». (Martí Sánchez 2008, 88) 
Sin embargo, los adverbios de foco no son adverbios oracionales; siguen siendo adverbios internos a la oración (clause-internal adverbials), pero con un mayor alcance sintáctico que los adverbios de modo. No consideramos que los adverbios de foco sean adverbios con función periférica, ya que no actúan desde fuera de la oración, sino que siguen siendo adverbios con función oracional, dentro de la oración. En ocasiones aumentan su alcance hasta incidir sobre toda la oración. Se encuentran, por lo tanto, en una etapa intermedia entre la primera y la segunda, pero siguen claramente una ruta que va hacia una mayor libertad sintáctica y un mayor alcance sintáctico.

En los adverbios de foco analizados, a nuestro modo de ver, la ruta sería la siguiente:

adverbios de modo 'de manera exacta, precisa' > adverbios de focalización de exactitud > adverbios de focalización de coincidencia significativa

En cualquier ruta o camino (cline) de cambio lingüístico gradual, hay layering, es decir, coexistencia de usos anteriores y nuevos (Traugott 2010, 38). Mientras que justamente y justo (y en siglos anteriores también cabalmente) mantienen las tres etapas, precisamente está más avanzado y solo conserva marginalmente la primera y la segunda porque se ha especializado en la tercera. En cambio, exactamente no llega a la tercera etapa, y en la segunda etapa se desvía hacia contextos propios que divergen del resto del paradigma.

Considerando la subjetivización y la gramaticalización o pragmaticalización procesos graduales, o un «continuum evolutivo dinámico» (Company Company 2004, 23), hemos llegado a la conclusión de que los adverbios de foco analizados muestran un grado más bien intermedio de subjetivización: no llegan a convencionalizar y codificar como significado léxico las valoraciones subjetivas. Tampoco llegan a gramaticalizarse como marcadores discursivos extraoracionales. Por tanto, las unidades analizadas no siguen toda la ruta (cline) de gramaticalización o pragmaticalización de los marcadores discursivos, sino que se quedan en un estadio más bien intermedio o incipiente, lo cual es perfectamente compatible con la concepción gradual de la gramaticalización o pragmaticalización.

Según König (1991, 171-173), el desarrollo de las partículas de foco hasta cierto punto puede considerarse gramaticalización, por estas cuatro razones:

a) El origen de la focalización está en nociones más concretas (hay semantic bleaching) y en clases de palabras centrales (adverbios, por ejemplo), que se convierten en focus particles.

b) Posiblemente, hay formación de paradigmas.

c) Aumento de cohesión sintáctica: tendencia a posicionar las partículas de foco en posición adyacente. 
d) No obstante, no suele haber atrición fonológica, ya que las partículas de foco pueden llevar énfasis.

Al elegir la denominación partículas de foco (focus particles), König (1991) asume que estas unidades (provenientes en su mayoría de adverbios) experimentan un cambio de categoría. Sin embargo, optamos por seguir considerando precisamente, justamente, etc., adverbios. No abandonan su categoría original, sino que siguen siendo adverbios (esto es, modificadores), pero con nuevas distribuciones y funciones sintácticas, que encajan en el concepto de la polifuncionalidad adverbial. Si consideramos la diferenciación entre microsintaxis y macrosintaxis (Fuentes Rodríguez 2013b; 2017), podemos afirmar que, en el nivel de la microestructura, precisamente, justamente, etc., son adverbios. En el nivel de la macroestructura adoptan valores nuevos: la focalización enfática y la expresión de modalidad subjetiva.

En cuanto al semantic bleaching (factor a), hemos observado que, efectivamente, el concepto de exactitud se vuelve opaco en algunos usos de precisamente, justamente, justo y cabalmente.

Respecto a la formación de paradigmas (factor b), observamos que todo el grupo de los adverbios de exactitud -precisamente, justamente, justo, cabalmente, exactamente- pasa a funcionar como adverbios de foco. 0 sea, los elementos de este paradigma pragmático provienen de un mismo campo semántico. La formación de un paradigma no es nueva en este subgrupo de adverbios de foco, sino que ya existía antes un paradigma semántico de los adverbios de modo correspondientes (véase apartado 4.2). Es justamente la cercanía semántica entre los adverbios de exactitud la que explica por qué todos ellos acaban apareciendo como adverbios de foco. El «efecto paradigmático» impulsa el aumento de usos pragmáticos y discursivos. En conclusión, en este caso concreto, el paradigma no es tanto consecuencia de una gramaticalización o pragmaticalización, sino que es, sobre todo, un factor pujante que impulsa el cambio. Más que resultado, es causa.

En cuanto al aumento de cohesión sintáctica (factor c) observamos más bien lo contrario: la posición adyacente es la posición originaria de estos adverbios de foco, que con el tiempo pueden aparecer también en posiciones no adyacentes, es decir, no contiguas al elemento focalizado. Es lo que calificamos de «liberación sintáctica».

Respecto a la atrición fonológica (factor d), es cierto que no hay cambios en la sustancia fónica. Más bien al contrario, la pronunciación enfática, destacada de los adverbios de foco se traduce ocasionalmente en una posición destacada por comas en la escritura. 
En conclusión, las unidades analizadas - a pesar de desarrollar valores fuertemente subjetivos- no cumplen todas las características de la pragmaticalización o gramaticalización. Un criterio crucial de estos procesos es la decategorización (Traugott 1995, 14; Martí Sánchez 2008, 88). No es el caso de los focalizadores analizados, ya que consideramos que siguen siendo adverbios altamente polifuncionales. En cambio, sí cumplen los criterios de la generalización del significado (Martí Sánchez 2008, 88): precisamente, justamente, cabalmente y justo se extienden a más contextos al desarrollar un significado más abstracto y generalizado. En cuanto al crecimiento de las funciones pragmáticas en detrimento de las semánticas (Martí Sánchez 2008, 88), observamos que, efectivamente, el uso como adverbios de foco ha ido creciendo a medida que el uso como adverbios de modo ha ido decayendo. Este desplazamiento no ocurre con la misma velocidad en todos los adverbios del grupo. Sobre todo, precisamente casi ha generalizado su uso como adverbio de foco (de coincidencia), apenas se usa ya como adverbio de modo.

Según Martí Sánchez (2008, 89), no todos los operadores pragmáticos llegan a gramaticalizarse; la gramaticalización sería un paso final en su desarrollo, cuando la forma sola y exclusivamente se usa como operador, como es el caso de de hecho o desde luego. Sin embargo, gran parte de los operadores pragmáticos no se consideran gramaticalizados porque no cumplen plenamente estas cuatro características que son «síntomas de la plena constitución de un OP [operador pragmático]» (Martí Sánchez 2008, 89):

1. Su reconocimiento como unidad independiente por especialistas y hablantes.

2. Menor dependencia contextual y de la entonación.

3. Menor motivación.

4. Entrada lexicográfica independiente.

De acuerdo con estas cuatro características, no podemos considerar los adverbios de foco analizados como plenamente gramaticalizados o pragmaticalizados. En todos los diccionarios consultados, aparecen en una misma entrada conjunta con su adverbio de modo base, dado que sigue habiendo cierta motivación semántica (la transparencia del concepto de exactitud) entre el adverbio de modo base y el adverbio de foco. Sin embargo, a pesar de que el DLE (2014, s.v. precisamente) define este adverbio como ‘de manera precisa' (es decir, como adverbio de modo), en realidad no es este su significado más habitual. No creemos que se haya gramaticalizado (o pragmaticalizado) del todo, ya que las obras lexicográficas siguen agrupando el uso de precisamente ‘de manera precisa' como adverbio de modo y su uso como adverbio de foco bajo una misma entrada.

En cuanto a la dependencia contextual, hemos observado que el contexto es crucial para la interpretación de los adverbios de foco y para obtener las infe- 
rencias intencionadas, por lo cual no hay «menor dependencia contextual», sino todo lo contrario. La interpretación de las inferencias intencionadas depende claramente del contexto, esto es, tanto de la situación comunicativa como del co-texto. Además, la dependencia contextual va aumentando diacrónicamente.

\subsubsection{Otros factores: frecuencia de uso, profundidad histórica, sociedad y tipología textual}

Algunos de los seis factores analizados por Company Company (2008), que aceleran o impulsan el cambio semántico-pragmático, resultan ser decisivos para la creación de este paradigma de adverbios de foco.

Uno de los factores cruciales para la creación de nuevos valores pragmáticodiscursivos es la frecuencia de empleo (Company Company 2008, 30-32): «la alta frecuencia lleva, por lo regular, a la gramaticalización de la forma o construcción que experimenta el cambio, la poca frecuencia aminora, por lo regular, la difusión del cambio». Resulta difícil determinar si la frecuencia es más bien una causa o una consecuencia de un cambio. Para Bybee (2003, 602), una frecuencia alta no solo es el resultado de una gramaticalización, sino que también es un factor que contribuye al proceso; es una fuerza activa que fomenta los cambios. La repetición contribuye a la automatización (Bybee 2003, 603). En cambio, Traugott $(2010,55)$ puntualiza que, a pesar de que la frecuencia es un factor que contribuye a los cambios asociados a la gramaticalización, no es propiamente una causa.

La frecuencia también puede ser vista como un indicio, una consecuencia: un aumento significativo de frecuencia suele ser un indicio de que ha ocurrido un cambio, ya que el aumento suele estar vinculado a la difusión de los nuevos usos, la cual es posterior a los procesos de gramaticalización (Mair 2004). Es decir, el aumento de frecuencia refleja el aumento de tipos de contextos de uso (Bybee 2003, 602). Dicho de otro modo: si aumenta la frecuencia type de un lexema en vías de gramaticalización, consecuentemente también aumenta su frecuencia token, en total. Para que una innovación (un nuevo type) se consolide, tiene que aumentar su frecuencia token.

Eso es lo que observamos en precisamente, la forma innovadora y el miembro central del paradigma. Aparece en contextos nuevos y va aumentando la diversidad de usos pragmáticos, o sea, se vuelve polifuncional. Además, estas funciones pragmáticas muestran una frecuencia de uso muy elevada en el CDH (cada type tiene una frecuencia token elevada), como comprobamos en la búsqueda de diversos patrones. 
La mayoría de los usos pragmáticos y de los nuevos contextos de precisamente aparecen entre los siglos XVII y XIX. No hemos encontrado un contexto nuevo en el siglo XX que no se haya documentado anteriormente. Es decir, la frecuencia type de precisamente aumenta antes del siglo XX y es acompañada por un aumento notable de frecuencia token. Sin embargo, el gran aumento de frecuencia token de precisamente ocurre en el siglo XX, hay una verdadera explosión (véase Gráfico 18). Por lo tanto, el aumento de frecuencia token es posterior y contribuye a la consolidación de los nuevos valores y contextos (types). También en exactamente, el notable aumento de frecuencia token ocurre en el siglo XX y es posterior a la aparición de contextos nuevos o types nuevos (siglos XVIII y XIX).

Los demás adverbios del grupo no aumentan tanto su frecuencia, sino que adoptan las innovaciones por analogía a precisamente. Los adverbios justamente y cabalmente desarrollan paralela y simultáneamente los mismos valores pragmáticos, por lo que su frecuencia type es casi igual a la de precisamente. Ahora bien, justamente y cabalmente consolidan los nuevos types incluso sin aumentar notablemente su frecuencia token. El «efecto paradigmático» hace que sea prescindible el aumento de frecuencia token en los miembros periféricos del paradigma.

Por último, la alta frecuencia de uso suele ser un factor que acelera la generalización de los nuevos valores: las etapas anteriores ya no se prolongan en precisamente. En cambio, a pesar de desarrollar las nuevas etapas al mismo tiempo - esto es, a pesar de que el aumento de frecuencia type es paralelo y simultáneo en casi todas las estructuras observadas- los adverbios justamente y cabalmente muestran una frecuencia token mucho menor $\mathrm{y}$, por eso, la generalización de los nuevos valores avanza más lento. Probablemente por eso, justamente mantiene etapas anteriores (layering) que precisamente ya ha dejado atrás.

Otro factor determinante es el «tipo de categoría que experimenta el cambio» (Company Company 2008, 32-33): no es de extrañar que los nuevos valores de focalización se desarrollaran en los adverbios (en -mente), y no en los adjetivos base ni en el adverbio corto justo. En general, la categoría de los adverbios en -mente es altamente polifuncional y propensa a desarrollar valores pragmático-discursivos, como observan por ejemplo Garcés Gómez (2013) y Hummel (2018b; 2018c, 7). El desarrollo de valores de focalización en los adjetivos preciso, justo y exacto es posterior y sigue claramente el modelo de los adverbios correspondientes: surge en el dominio del tiempo y espacio. El uso de los adjetivos como operadores de focalización se limita a este bridging context, pero no se expande a nuevos switch contexts.

El análisis diacrónico ha mostrado que, en este caso, el factor «profundidad histórica o antigüedad del cambio» (Company Company 2008, 22) no es relevante, ya que no son los miembros más antiguos del grupo -justamente y cabal- 
mente- los que propulsan el desarrollo de la focalización. El reemplazo casi total del uso original (adverbio de modo) por el uso innovador (adverbio de foco) ocurre en precisamente, un elemento más reciente del grupo. De acuerdo con lo expuesto anteriormente, la alta frecuencia "gana» a la antigüedad. Además, quizás es también por la antigüedad del adverbio modal justamente 'con justicia' por lo que este adverbio no avanza en la misma medida que precisamente. Es decir, el uso más antiguo, más frecuente y mejor consolidado de justamente ${ }_{1}$ 'con justicia' frena la expansión de justamente 2 'exactamente' como adverbio de foco, de acuerdo con esta tendencia: «A mayor frecuencia de empleo de la forma conservadora, mayor dificultad de la innovadora para avanzar en el canal de gramaticalización» (Company Company 2008, 30).

En cuanto al aspecto fónico (Company Company 2008, 25-30), no hay grandes diferencias entre los adverbios del grupo (son adverbios en -mente de cuatro o cinco sílabas); no parece ser un factor relevante ni se observan cambios en la sustancia fónica. Sí se observa una preferencia por la forma más larga (justamente frente a justo) en la lengua hablada, probablemente porque permite transmitir más énfasis.

Por último, nuestro estudio de corpus no nos permite pronunciarnos en cuanto al «tipo de sociedad usuaria de la lengua» (Company Company 2008, 33-38). Sí podemos mencionar algunas diferencias diatópicas: tal y como observamos en el apartado 4.1.3, mientras que en España predomina el adverbio de foco precisamente, en el Cono Sur aumenta la frecuencia de uso de justamente (en detrimento de precisamente). En cambio, cabalmente se ha conservado algo más en México y Centroamérica.

En cuanto al factor «género textual o tradición discursiva de manifestación del cambio» (Company Company 2008, 37-38), no lo hemos analizado sistemáticamente, aunque sí podemos observar dos tendencias: el uso de los adverbios de exactitud con el significado 'rigurosamente exacto, no aproximado' se documenta principalmente en textos científicos, tales como tratados matemáticos o de navegación (véase apartado 4.2). En cambio, los valores subjetivos de los adverbios de foco de coincidencia se detectan frecuentemente en textos más propensos a la inclusión de la perspectiva subjetivo-emocional del emisor: los ejemplos citados pertenecen en su mayoría a novelas, cartas o diarios. Frecuentemente, los adverbios de foco de coincidencia se ponen en boca de algún personaje o del narrador. El enunciador entra en primer plano en los usos más subjetivos.

Además, en cuanto a sociedad y tradiciones discursivas, creemos que sí tiene importancia la llamada «dimensión intercultural» (Hummel 2013b) de cultismos como son los adverbios cultos «internacionales»: en francés y en inglés, los adverbios correlatos de precisamente, exactamente y justamente también desarrollan usos como adverbios de foco. En especial, hay que tener en cuenta la gran 
influencia del francés sobre el español durante el siglo XVIII (es decir, durante la extensión de uso de precisamente). Recordemos que, durante los siglos XVIII y XIX, précisément era el más frecuente de los tres adverbios en francés (véase Tabla 8 en el apartado 4.1.1) y desarrolla también usos como focalizador de exactitud y coincidencia en francés. Sin embargo, no experimenta un aumento de frecuencia posterior y desde el siglo XX es menos frecuente que justement y exactement.

Parece haber una tendencia divergente entre ambos idiomas: mientras que en español triunfa precisamente, con una amplia gama de usos pragmáticos (mientas que marginaliza su valor original 'de manera precisa'), en francés es el adverbio justement el que desarrolla usos como la inversión argumentativa (Bruxelles et al. 1982; Serça 1996; Gómez-Jordana 2010b).

Esa «competición» entre justamente y precisamente también se ve en el cuadro diatópico del español: recordemos que, en el CORPES XXI, la frecuencia de precisamente es diametralmente opuesta a la de justamente. Las zonas de mayor frecuencia de precisamente son a la vez las de menor frecuencia de justamente (España), mientras que las zonas de mayor frecuencia de justamente son las de menor frecuencia de precisamente (Cono Sur). En este sentido, el español del Cono Sur se asemeja a la tendencia del francés, que también prefiere el adverbio de foco justement.

Por último, la dimensión intercultural también explicaría por qué cabalmente acaba siendo desechado del paradigma: no cuenta con correlatos en francés, inglés, etc., ya que es una formación propia del iberorromance. 